\title{
Median raphe controls acquisition of negative experience in the mouse
}

András Szőnyi ‡, Krisztián Zichó ‡, Albert M. Barth, Roland T. Gönczi, Dániel Schlingloff, Bibiána Török, Eszter Sipos, Abel Major, Zsuzsanna Bardóczi, Katalin E. Sos, Attila I. Gulyás, Viktor Varga, Dóra Zelena, Tamás F. Freund and Gábor Nyiri*

$\ddagger$ These authors contributed equally.*Corresponding author. E-mail: nyiri.gabor@koki.mta.hu

INTRODUCTION: Coping with negative experience is essential for survival. Animals must quickly recognize a harmful situation, produce an adequate response, and learn its context, so that they can predict the reoccurrences of similar experiences. This process requires the lateral habenula ( $\mathrm{LHb})$ and the medial ventral tegmental area $(\mathrm{mVTA})$ for evaluating and predicting aversive stimuli. LHb neurons promote encoding of aversive behavior, learn to respond to cues that predict aversive stimuli and activate negative experience-processing mVTA dopaminergic neurons (DA). Over-excitation of LHb neurons lead to depression-like symptoms, whereas their inactivation has an anti-depressant effect. Coping with negative experience also requires the septo-hippocampal system to record and recall contextual memories of events. This process necessitates increased firing of pacemaker parvalbumin (PV)-positive neurons in the medial septum and the vertical limbs of the diagonal bands of Broca (MS/VDB) and subsequent theta-oscillations in the hippocampus. However, how all these brain centers coordinate their activity during adverse events is poorly understood.

RATIONALE: Because LHb does not project directly to the septo-hippocampal system, the brainstem median raphe region (MRR) has been proposed to coordinate their activity. Although MRR plays an important role in regulating mood, fear and anxiety and neuronal projections from it have been extensively studied for decades, yet it is still unclear how MRR neurons process these negative experiences. Using cell typespecific neuronal tract-tracing, monosynaptic rabies-tracing, block-face scanning immuno-electron microscopy, in vivo and in vitro electrophysiological methods, we investigated the neurons of mouse MRR that are responsible for these functions. We used in vivo optogenetics combined with behavioral experiments or electrophysiological recordings to explore the role of MRR neurons responsible for the acquisition of negative experience.

RESULTS: We discovered that the MRR harbors a vesicular glutamate transporter 2 (vGluT2)-positive cell population that gave rise to the largest ascending output of the MRR. These neurons received extensive inputs from negative sensory experience-related brain centers, whereas their excitatory fibers projected to LHb, mVTA and MS/VDB (Fig. A). MRR vGluT2-neurons mainly innervated MRR- or mVTA-projecting cells in medial ("limbic") LHb, creating a direct feedback in the MRR-LHb-mVTA axis. MRR vGluT2-neurons were selectively activated by aversive but not rewarding stimuli in vivo. Stimulation of MRR vGluT2-neurons induced strong aversion (Fig. B-D), agitation and aggression and suppressed reward-seeking behavior, whereas their chronic activation induced depression-related anhedonia. The latter can at least partly be explained by our 3D electron microscopy data showing highly effective synaptic targeting of LHb neurons and by our in vitro data showing that MRR vGluT2-terminals can trigger depressive behavior-related bursting activity of LHb neurons. MRR vGluT2-neurons seem to be involved in active responses to negative experience, therefore they induced aggression or avoidance, classical fight or flight responses. Suppression of MRR vGluT2-neurons precisely at the moment of the aversive stimulus presentation strongly distupted the expression of both contextual and cued fear memories and prevented fear generalization. MRR vGluT2-neurons could facilitate the learning of negative experience, because their LHb-projecting axons bifurcated and selectively innervated pacemaker MS/VDB PV-positive neurons that projected to the hippocampus. Consequently, in vivo stimulation of MRR vGluT2-neurons instantly evoked memory acquisition-promoting hippocampal theta-oscillations in mice, in vivo.

CONCLUSION: Our results revealed that the MRR harbors a previously unrecognized brainstem center that serves as a key hub for the acquisition of negative experience. MRR vGluT2-neurons could activate the aversion- and negative prediction-related LHb-mVTA axis and could swiftly transform the state of the septo-hippocampal system for immediate acquisition of episodic memories of the negative experience. Maladaptations in processing negative experience is the basis of several types of mood disorders, which have a huge social and economic impact on individuals and society. Selective targeting of this neural hub may form the basis of new therapies.

MRR vGluT2-neurons serve as a key hub for aversive behavior. MRR vGluT2 (VG2)-neurons process aversive events by activating neurons of LHb and mVTA, and hippocampus (HIPP)-projecting memory acquisitionpromoting parvalbumin (PV)-positive cells in MS/VDB (A). After viruses made MRR vGluT2-neurons lightsensitive (B), mice were lightstimulated in a specific area (C) that caused significant avoidance of that area, compared to control mice (D). (PFC: prefrontal cortex)
A

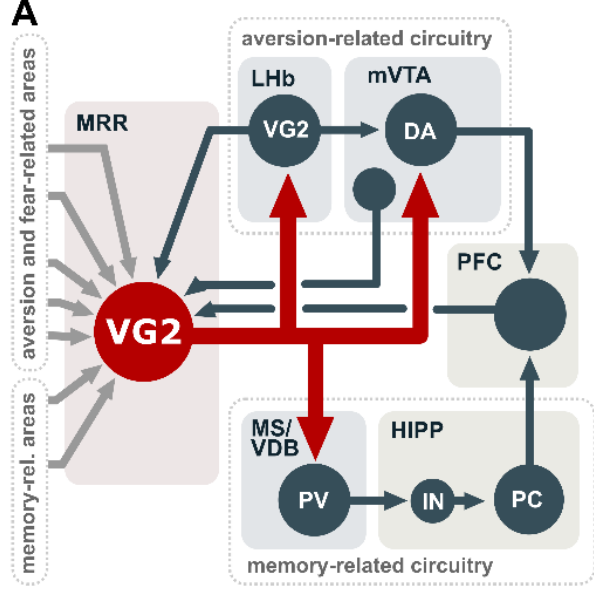

B

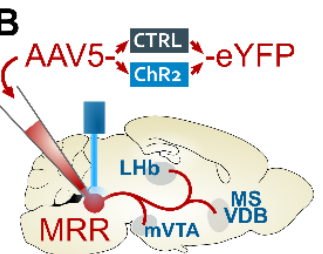

vGluT2-Cre mouse

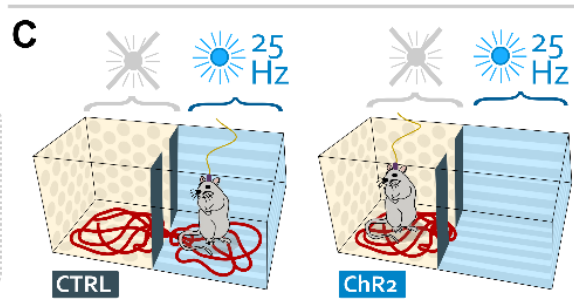

"This manuscript has been accepted for publication in Science. This version has not undergone final editing. Please refer to the complete version of record at http://www.sciencemag.org/. The manuscript may not be reproduced or used in any manner that does not fall within the fair use provisions of the Copyright Act without the prior, written permission of AAAS." 


\title{
Median raphe controls acquisition of negative experience in the mouse
}

András Szőnyi ${ }^{1} \ddagger$, Krisztián Zichó ${ }^{1} \ddagger$, Albert M. Barth ${ }^{1}$, Roland T. Gönczi ${ }^{1}$, Dániel Schlingloff ${ }^{1,3}$, Bibiána Török $^{2,3}$, Eszter Sipos ${ }^{2}$, Abel Major ${ }^{1}$, Zsuzsanna Bardóczi ${ }^{1}$, Katalin E. Sos ${ }^{1,3}$, Attila I. Gulyás ${ }^{1}$, Viktor Varga ${ }^{1}$, Dóra Zelena ${ }^{2}$, Tamás F. Freund ${ }^{1}$ and Gábor Nyiri ${ }^{1 *}$

1: Laboratory of Cerebral Cortex Research, Department of Cellular and Network Neurobiology, Institute of Experimental Medicine, Hungarian Academy of Sciences, Budapest, Hungary

2: Laboratory of Behavioral and Stress Studies, Department of Behavioral Neurobiology, Institute of Experimental Medicine, Hungarian Academy of Sciences, Budapest, Hungary

3: János Szentágothai Doctoral School of Neurosciences, Semmelweis University, Budapest, Hungary

$\ddagger$ These authors contributed equally to this work.

*Corresponding author, E-mail: nyiri.gabor@koki.mta.hu

\begin{abstract}
Adverse events need to be quickly evaluated and memorized, yet how these processes are coordinated is poorly understood. We discovered a large population of excitatory neurons in median raphe region (MRR) expressing vesicular glutamate transporter 2 (vGluT2) that received inputs from several negative experiencerelated brain centers, projected to the main aversion centers and activated septo-hippocampal system pivotal for learning of adverse events. They were selectively activated by aversive but not rewarding stimuli. Their stimulation induced place aversion, aggression, depression-related anhedonia, suppression of reward-seeking behavior and memory acquisition-promoting hippocampal theta-oscillations. By contrast, their suppression impaired both contextual and cued fear memory-formation. These results suggest that MRR vGluT2-neurons are crucial for the acquisition of negative experiences and may play a central role in depression-related mood disorders.
\end{abstract}

\section{Introduction}

To survive, animals must quickly recognize a harmful situation, produce an adequate response, and learn its context to help predict the occurrence of similar negative experiences in the future (1-6). This process requires the lateral habenula (LHb) and medial ventral tegmental area (mVTA) for evaluating and predicting aversive stimuli, and requires the septo-hippocampal system to record and recall memories of these adverse events. Yet, how these brain centers coordinate their activity during adverse events is poorly understood. Because LHb does not project directly to the septo-hippocampal system, the brainstem median raphe region (MRR) has been proposed to coordinate their activity (7-14). Although the MRR plays an important role in regulating mood, fear and anxiety, its role in processing negative experience remains elusive $(13,15,16)$. It contains projection neurons expressing serotonin (5HT) and/or type 3 vesicular glutamate transporter (vGluT3), yet after decades of studies, it is still unclear how MRR neurons can support these functions (17-19). Although projections from the MRR to LHb, mVTA, medial septum and the vertical limbs of the diagonal bands of Broca (MS/VDB) must be crucial to understand negative experience-related behavior, the identity of key MRR neurons responsible for these connections remains unknown $(20,21)$. 


\section{Results}

\section{Most MRR projection neurons are vGluT2-positive}

In mice the transmitter phenotypes and targets of almost 25\% of MRR neurons are unknown (22). Here, injections of the Cre-dependent tracer virus AAV5-eYFP (Supplementary Materials) into the MRR of vGluT2-Cre mice, together with complete stereological measurements revealed that at least $20 \%$ of the MRR neurons are vGluT2-positive (Fig. 1A-C, Table S5, see Supplementary Materials). MRR vGluT2-positive neurons were evenly distributed both in the median and the para-median part of the MRR. Fluorescent immunohistochemistry demonstrated that this group of cells was distinct from 5HT-and/or vGluT3-positive neurons in the MRR (Fig. 1B). Terminals of eYFP-expressing MRR neurons of vGluT2-Cre mice were positive for vGluT2 (Fig. S1A-B), but they do not express the plasma membrane serotonin transporter (SERT), vesicular GABA transporter (vGAT) or vGluT3 (Fig. S1C).

\section{MRR vGluT2-neurons are linked to negative experience-related brain regions}

Viral labeling of vGluT2-neurons with Cre-dependent AAV5-eYFP in vGluT2-Cre mice revealed that they strongly innervate the LHb and the mVTA (Fig. 1E-F), as well as other neurons locally (Fig. S1D). We never observed similar innervation patterns after injecting surrounding brain areas in vGluT2-Cre mice, nor after injecting AAV5-eYFP into the MRR of TpH-Cre, vGluT3-Cre or vGAT-Cre mice (labeling serotonergic, vGluT3positive and GABAergic MRR neurons respectively, Fig. S3A-I).

Injections of Cre-dependent AAV5-eYFP into the MRR of vGluT2-Cre mice showed that MRR vGluT2neuronal projections avoided positive reinforcement-related lateral VTA DA cells (Fig. 1G). Instead, they innervated mVTA DA neurons (Fig. 1G-H). Glutamatergic LHb neurons also innervate mVTA DA cells to regulate negative reward predictions and aversive behavior $(1-3,23)$. Indeed, when we simultaneously injected AAV5mCherry into the LHb and AAV5-eYFP into the MRR of the same vGluT2-Cre mice, we detected that both LHb and MRR vGluT2-neurons targeted the mVTA specifically (Fig. 1G-H).

Aversion-related mVTA DA cells target the medial prefrontal cortex (mPFC) $(23,24)$. We injected the retrograde tracer Choleratoxin B subunit (CTB) into the MPFC and Cre-dependent AAV5-eYFP into the MRR of vGluT2-Cre mice (Fig. S1E). vGluT2-positive MRR terminals established synaptic contacts with those mVTA DA neurons that project to the mPFC (Fig. S1F-G), showing that vGluT2-positive MRR neurons target DA cells related to negative reward predictions.

Glutamatergic LHb neurons (primarily in the medial part of LHb) also innervate the MRR (25), but the identity of their target cells is unknown. We injected Cre-dependent AAV5-eYFP into the MRR and AAV5mCherry into the LHb of vGluT2-Cre mice and found that MRR vGluT2 neurons primarily targeted the medial part of LHb (Fig. 1E), whereas at least 39\% of LHb terminals innervated VGluT2-positive neurons in the MRR (Fig. 1I-L). Serotonergic and vGluT3-positive MRR neurons were also targeted by LHb vGluT2 neurons (for the exact ratios see Fig. S2F-G). Using combined anterograde and retrograde tracing, we also found that there is a direct reciprocal connection between the LHb-projecting vGluT2-positive MRR neurons and the MRRprojecting vGluT2-positive LHb neurons (Fig. 11, for measured ratios see Fig. S1H-J, Fig. S2A-E, Supplementary Materials). vGluT2-positive MRR neurons also innervate LHb neurons that project to the mVTA (Fig. S1H-J). These results indicate an excitatory positive feed-back loop between the VGluT2-neurons of MRR and LHb. Both of these neuronal populations project to the aversion-encoding mVTA as well.

To identify upstream brain areas that synaptically target the MRR vGluT2-positive neurons, we used mono-trans-synaptic rabies tracing (26). We used a Cre-dependent helper virus encoding both an avian tumor virus receptor A (TVA) and an optimized rabies glycoprotein, and we used a TVA-receptor-dependent and glycoprotein-deleted rabies virus in vGluT2-Cre mice (Supplementary Materials, Fig. $1 \mathrm{~N}-\mathrm{O}$ ), the specificity of which virus combination has already been validated in our previous study (27). Brain areas that play an 
essential role in negative experience-related behavior showed a strong convergence onto vGluT2-positive MRR cells, including the dorsal raphe, lateral hypothalamus, periaqueductal grey or zona incerta (Fig. 1P-T, for details see Table S6). LHb accounts for most of the monosynaptically labelled input cells (Fig. 1R). Areas related to the encoding of aversive memories (like the mammillary areas, the pontine reticular nucleus or nucleus incertus) also sent strong projections onto vGluT2-positive MRR neurons (Table S6).

\section{MRR vGluT2-neurons establish multiple burst-promoting synapses on LHb neurons}

Negative experience-related behavior and subsequent depression-like symptoms are strongly promoted by the excitatory inputs of LHb neurons (28-30). Using block-face scanning electron microscopy, we revealed that MRR vGluT2-neurons provide an extensive synaptic coverage on LHb neurons (Fig. 2A-B, E-F) and most of its axon terminals established more than one synapse on different or the same target cells (Fig. 2D). $\mathrm{N}$-methyl-D-aspartate (NMDA)-receptor-dependent burst-firing in LHb neurons play a key role in the development of depression $(28,30)$. We found that MRR vGluT2-neurons established NMDA receptorcontaining excitatory glutamatergic synapses on LHb neurons (Fig. $2 \mathrm{C}$ ). In LHb, astroglia cooperate with excitation to regulate neuronal bursting and depression-like symptoms (28). These glial processes enwrapped most synapses of MRR vGluT2-terminals in LHb (Fig. 2B, E, F).

To test this physiologically, we selectively activated MRR vGluT2-fibers in the LHb in vitro, using channelrhodopsin 2 (ChR2)-containing Cre-dependent AAV5-ChR2-eYFP in optogenetic experiments (Fig. 3A). Light stimulation of ChR2-containing MRR vGluT2-positive fibers reliably evoked glutamatergic excitatory postsynaptic currents (EPSCS) in voltage-clamped neurons of LHb (Fig. 3B, Fig.S4A-B), which received MRR vGluT2-terminals (Fig. 3G). These EPSCs showed strong short-term depression and they were abolished by the simultaneous blockade of $\alpha$-amino-3-hydroxy-5-methyl-4-isoxazolepropionic acid (AMPA)- and NMDA-type glutamate receptors (Fig. 3B-D). After activating ChR2-expressing vGluT2-positive MRR terminals in the LHb, we frequently observed the induction of burst-firing in LHb neurons (Fig. 3E-F), whereas some spontaneous burst-firing was also present in these neurons. Bursting disappeared after the combined blockade of AMPAand NMDA-type glutamate receptors (Fig. 3E).

\section{MRR vGluT2-neurons are selectively activated by aversive stimuli in vivo}

We explored the in vivo response of identified MRR vGluT2-neurons to aversive and rewarding stimuli. We used a combination of multichannel recording and optogenetic tagging in the MRR of Cre-dependent, AAVChR2-eYFP injected vGluT2-Cre mice. Awake mice were head-fixed on top of an air-supported spherical treadmill, while multiple single units were simultaneously recorded from the MRR using a multichannel silicone probe. Light pulses that were used to tag vGluT2-neurons, were delivered through an optic fiber positioned above the MRR (Fig. 4A-B). Tagged neurons reliably responded to brief blue laser light pulses with short latency and small jitter (Fig. 4C). A large set of optogenetically identified vGluT2-positive MRR neurons were robustly activated by strongly aversive air puffs (Fig. 4D-F). By contrast, MRR vGluT2-neurons were practically never affected by rewarding stimuli (water drops, Fig. 4D-F). Mildly aversive LED flashes triggered a slight, transient elevation of activity in a small subgroup of vGluT2-positive MRR neurons, partially overlapping with the airpuff activated group (Fig. S4G-H), but this effect was significantly lower compared to air-puff (Fig. 4D-F).

\section{Optogenetic activation of MRR vGluT2-neurons causes strongly aversive behavior}

The rapid, adverse experience-specific in vivo activity of MRR vGluT2-neurons suggest that they specifically process negative experience. To light-activate MRR vGluT2-neurons selectively in vivo, we injected ChR2-containing Cre-dependent AAV5-ChR2-eYFP into the MRR of vGluT2-Cre mice ("ChR2-mice"). Control mice were injected with a control virus that expressed no ChR2 ("CTRL-mice"). Then, we implanted an optic fiber over the MRR (Supplementary Materials, Fig. 5A, Fig. S5). After handling, mice were placed into a chamber 
containing two different areas with different visual cues (Fig. 5A). In the habituation session, mice did not prefer any of the two areas (Fig. S6A-B). 24 hours later, mice were placed into the same chamber and received optogenetic stimulation $(25 \mathrm{~Hz})$ only in one area of the chamber (area selection was systematically random). ChR2-mice, but not CTRL-mice, showed a powerful and immediate real-time place aversion of the stimulationlinked area (Fig. 5A-B, Fig. S6A-B). On the next day, previously stimulated ChR2-mice, but not CTRL-mice, showed a strong conditioned aversion of the area that was previously linked to stimulation (Fig. 5A-B, Fig. S6AB).

We investigated whether the activity of MRR vGluT2-neurons is powerful enough to counteract the strongly positive expectation of a motivated, food-seeking animal. Here, the above mentioned ChR2- and CTRLmice were food-restricted, and were trained for 10 days in an operant conditioning task to nose-poke for food rewards (Fig. 5C, Supplementary Materials). On the last day of their training, both groups of mice reached a plateau in the total number of nose-pokes during the 30 minutes-long operant conditioning session (Fig. 5C). 24 hours later, mice received blue laser stimulation that started after each rewarded nose-poke during the whole, 30 minutes-long session. ChR2-mice, but not CTRL-mice, poked significantly less for reward pellets, compared to the last day of their training (Fig. 5D-E).

We also tested whether the activation of these cells can induce passive coping. We performed an optogenetic contextual fear conditioning experiment with the same cohort of mice that participated in the operant conditioning task (Fig. S6C). Mice were allowed 3 days to rest and regain their original weight, and on the 25th day, they were put into a new environment, where they received 15 seconds-long laser stimulation ten times. 24 hours later, mice were tested in the same environment. Neither ChR2-mice, nor CTRL-mice showed any sign of freezing behavior, neither during light stimulation nor 24 hours later in the same environment (Fig. S6C).

\section{Activation of MRR vGluT2-neurons induces aggression and depressive symptoms}

Neuronal activity in LHb is related to aggressive behavior (31). Therefore, we investigated whether activation of MRR vGluT2-neurons induces the prediction of negative experience in a social context and whether it promotes an aggressive behavior in mice during these social interactions. We used a DREADD (Designer Receptors Exclusively Activated by Designer Drugs)-containing AAV based chemogenetic tool that expresses mutant receptors that activates cells upon binding to clozapine-N-oxide (CNO). We injected either Cre-dependent excitatory DREADD virus AAV8-h3MDq-mCherry ("hM3Dq-mice") or Cre-dependent AAV8mCherry virus ("CTRL-mice") into the MRR of vGluT2-Cre mice. Then, both hM3Dq- and CTRL-mice received intraperitoneal injections of CNO (Fig. 6A, see Supplementary Materials) and performed two behavioral tests. In the social interaction test, mice were placed into a new environment 30 minutes after CNO injections, together with an unfamiliar mouse. CTRL-mice showed mostly prosocial behavior towards the conspecific (Fig. 6B). In contrast, hM3Dq-mice became highly aggressive (Fig. 6B, Fig. S4C-F). Five days later, we carried out a resident-intruder test. Thirty minutes after $\mathrm{CNO}$ injections, a subordinate intruder mouse was placed into the home cage of the CTRL- or hM3Dq-mice. Again, hM3Dq-mice became highly aggressive towards the intruder (Fig. 6C, Fig. S4C-F). In a separate experiment, chemogenetic activation of AAV8-h3MDq-expressing MRR vGluT2-neurons by CNO injections also induced significantly higher motor activities in a Y-maze compared to CTRL-mice (Fig. S4I).

Aggressive behavior frequently accompanies depressive state (32-34), which is also promoted by chronic over-activation and burst-firing of LHb neurons (28-31,35). Using the above mentioned types of CTRLand hM3Dq-mice, we tested whether chronic activation of MRR vGluT2-neurons promoted depression-like symptoms. Mice received intraperitoneal injections of the DREADD-agonist CNO three times a week, for three weeks (Fig. 6A, Supplementary Materials). On day 19, mice were tested in a sucrose preference test, which can detect anhedonia, a classic symptom of depression (36). CTRL-mice preferred the $1 \%$ sucrose solution over 
water significantly more than hM3Dq-mice (Fig. 6D). The postmortem weight of the adrenal glands of hM3Dqmice was significantly higher than that for CTRL-mice (Fig. S4J).

\section{MRR vGluT2-neurons activate memory acquisition-promoting MS/VDB neurons}

Fast and effective processing of negative experience requires the immediate induction of memory acquisition, which necessitates a rapid change in the state of the MS/VDB-hippocampal system (37). Indeed, after AAV5-eYFP labeling of MRR vGluT2-neurons, we observed an abundant axonal labeling in the MS/VDB (Fig. 7A-B). MRR vGluT2-neurons established NMDA receptor-containing excitatory synapses selectively with PV-positive GABAergic cells in the MS/VDB (Fig. 7A-E, Supplementary Data for Figure 7, Fig. S1K). Using hippocampal injections of the retrograde tracer FluoroGold, in combination with AAV5-mCherry into the MRR of vGluT2-Cre mice we found that MRR vGluT2-neurons directly innervate hippocampus-projecting PV-neurons in MS/VDB (Fig 7F-H). These PV-neurons are the pacemakers of memory acquisition-promoting hippocampal theta-rhythm $(38,39)$.

The theta-rhythmic activity of LHb neurons and the hippocampal network are phase-locked and their concerted activity is necessary for proper memory formation $(8,14)$. Therefore, we investigated whether individual axons of MRR vGluT2-neurons bifurcate and target both areas. We performed double retrograde tracing by injecting CTB into the LHb and FluoroGold into the MS/VDB of vGluT2-Cre mice, and we labelled vGluT2-positive MRR cells with AAV5-mCherry (Fig. 7I-J).

At least $61 \%$ of vGluT2 MRR neurons retrogradely labeled from MS/VDB were retrogradely labeled from LHb as well (Fig. 7K).

We also investigated the effect of activation of MRR vGluT2-neurons on hippocampal network activity in vivo. Using AAV5-ChR2-eYFP, we expressed ChR2 in MRR vGluT2-neurons and implanted an optic fiber over the MRR and a Buzsaki-probe into the dorsal CA1 (Fig. 8A). Ten-second-long stimulation of MRR vGluT2neurons by a $25 \mathrm{~Hz}$ light-train triggered some movement (possibly related to the above-mentioned active avoidance of the stimuli) and they triggered hippocampal theta-oscillations (Fig. 8B-D) known to facilitate the formation of memories.

\section{MRR vGluT2-neurons are necessary for fear memory acquisition}

MRR vGluT2-neurons are specifically excited by negative experience, which they relay to aversion centers and to the septo-hippocampal system, likely promoting memory encoding. We injected Cre-dependent Archaerhodopsin T-3 (ArchT 3.0)-containing AAV5-ArchT-GFP (ArchT-mice) or control Cre-dependent AAV5eYFP (CTRL-mice) into the MRR of vGluT2-Cre mice, and implanted an optic fiber over the MRR (Fig. 8E, Fig. S5). After handling, mice were tested in a delay cued fear conditioning paradigm. First, we placed mice into a new environment " $A$ ", where they received three auditory tones, at the end of which they received foot-shocks and light illuminations. Light delivery was precisely aligned to foot-shocks (Fig. 8E). All mice displayed equally strong immediate reactions to foot-shocks. In the following tests, mice received no more light illumination. 24 hours later, mice were placed into the same environment " $\mathrm{A}$ " to test their contextual memories. CTRL-mice expressed strong contextual freezing behavior, whereas ArchT-mice showed almost no freezing behavior (Fig. $8 \mathrm{E})$. On the next day, we placed mice into a different, neutral environment (environment " $\mathrm{B}$ "), where ArchTmice showed significantly lower generalized fear compared to CTRL-mice (Fig. 8E). Then, in the same neutral environment, we presented the mice with the auditory cue. CTRL-mice showed very high levels of freezing. In contrast, light inhibited ArchT-mice showed significantly diminished freezing, indicating impaired fear memory formation (Fig. 8E). Even after cue presentation was over, the difference between the fear levels of ArchT-and CTRL-mice remained significant (Fig. S6D). 


\section{Discussion}

Animals must recognize adverse events quickly, decide whether to fight or flight and in parallel they must efficiently learn the context of that event so that they can predict it in the future. The LHb and mVTA are activated during the acquisition of negative experience $(7,23,24,40)$, which initiates the encoding of "negative reward prediction errors" and aversion in these nuclei $(5,41)$. Activation of mVTA dopaminergic neurons is also aversive $(23,42)$, whereas the activity of lateral VTA neurons play a role in positive reinforcement. LHb contains nearly exclusively glutamatergic neurons, which encode aversive behavior and activate dopaminergic (DA) neurons of mVTA $(23-25,43)$. LHb activity also indirectly inhibits encoding of positive reinforcement in the lateral VTA $(23,44)$. These processes fine-tune future strategies in similar situations $(5,41,45-48)$. LHb and $\mathrm{mVTA}$ conveys information related to negative predictions and learns to respond to cues that predict aversive stimuli $(3,42,49-53)$.

Meanwhile, the MS/VDB-hippocampal system must also be switched into the state optimal for memory acquisition to record the context of such events $(8,14)$. These processes are also necessary for the prediction and prevention of negative experience in the future. Yet, it was not clear which neuronal pathway orchestrates the coordinated activation of these networks. Although the MRR was known to play a central role in processing negative experience $(15,54)$, its known cell types did not project to the LHb, and the transmitter phenotypes and targets of almost $25 \%$ of the MRR neurons were not even known (22).

We discovered that these previously unrecognized vGluT2-positive MRR neurons project heavily into the LHb, mVTA and MS/VDB (Fig. S7). They are the largest population of projection neurons from the MRR, they are glutamatergic and do not express 5HT, vGluT3 or vGAT. We detected an extensive convergence of monosynaptic inputs to MRR vGluT2-neurons from several environmental experience-related brain centers [Fig. S7, $(7,40,55)$ ]. MRR vGluT2-neurons predominantly innervate the medial ("limbic") division of LHb that projects to the MRR and $\mathrm{mVTA}$, but they mostly avoid lateral ("pallidal") division of LHb that receives a different set of inputs $(25,51,56,57)$. MRR vGluT2-neurons directly innervate MRR- or mVTA-projecting LHb cells, creating a direct feedback in the MRR-LHb-mVTA axis.

Our in vivo physiological measurements confirmed the central and specific role of MRR vGluT2neurons in the formation of negative experience. MRR vGluT2-neurons were strongly and specifically activated by strong aversive stimuli, they were mildly activated by weak aversive stimuli, whereas rewarding stimuli did not affect their activity. This suggests that these neurons are primarily responsible and necessary for relaying negative experience in the brainstem. Indeed, specific optogenetic inhibition of these neurons precisely during the presentation of adverse stimuli eliminated or significantly decreased hippocampus-dependent contextual or hippocampus-independent cued fear memories, respectively. These data showed that this neural hub is essential for processing negative experience.

The elevation of excitatory transmission in the LHb or the stimulation of mVTA has similar effects (23, $46,58,59)$. MRR vGluT2-neurons heavily project to LHb and also selectively innervate mVTA DA neurons (but do not innervate neurons in lateral VTA that are mostly reward-related), suggesting that they can effectively activate negative prediction centers. Indeed, their optogenetic activation triggered immediate behavioral changes by inducing acute place aversion. The adverse event was effectively memorized, because it induced conditioned place aversion. Furthermore, the selective activation of MRR vGluT2-neurons could negate an otherwise strongly rewarding behavior in an operant conditioning task. The activation of MRR vGluT2-neurons did not induce passive freezing behavior directly, instead MRR vGluT2-neurons seem to be involved in active responses to negative experience, and therefore they induce avoidance, flight or fight behavior.

Depression is thought to be a result of a learning mechanism based on chronically sustained negative experiences $(60,61)$. Glutamatergic synapses on LHb neurons show long-term plasticity mechanisms, and LHb neurons can learn to respond to cues preceding aversive events $(28,29,50,62)$. The chronic elevation of glutamatergic transmission in $\mathrm{LHb}$ causes depressive disorder through the promotion of burst-firing of $\mathrm{LHb}$ 
neurons, which is also regulated by adjacent glial cell coverage (28-30, 50, 63, 64). MRR vGluT2-neurons massively innervate $\mathrm{LHb}$ neurons with different types of NMDA receptor-containing excitatory contacts that are mostly covered by glial processes on LHb neurons. They can also evoke burst-firing of LHb neurons. We also revealed an abundant reciprocal excitatory connection between vGluT2-positive glutamatergic neurons of LHb and MRR that may result in a reverberation and may support pathological learning and excessive activation of LHb neurons, if the loop is not controlled effectively. To mimic a chronically maladapted circuitry, we chemogenetically induced chronic over-activation of vGluT2-positive MRR neurons and it caused anhedonia in the sucrose-preference test that is a typical sign of depressive disorder in mice.

Aggression is a well-known symptom of depression in both mice and humans (32-34) and both LHb and MS/VDB plays a role in the emotional processing of aggressive behavior (31). Indeed, the activation of MRR vGluT2-neurons also promoted aggressive behavior. Aggression is commonly associated with agitation, the most distinguishing features of which include restlessness, pacing and motor activities. Indeed, we observed elevated locomotor activity and exploration in chemogenetically stimulated mice, which together suggests that activation of vGluT2-positive MRR neurons promotes agitation and active aversive behaviors (flight and/or fight responses) in neutral or social situations.

MRR has a complex effect on the MS/VDB-hippocampal activity and the formation of contextual fear memories, although its mechanism is not well understood $(9,11)$. In vivo optogenetic activation of MRR promoted memory acquisition-related theta rhythm through a mechanism conveyed by a non-serotonergic and non-GABAergic MRR cell population (13). Activation of pacemaker PV-positive MS/VDB neurons are essential for the generation of hippocampal theta rhythm and proper episodic memory formation $(38,39,65)$. PV-positive MS/VDB neurons are innervated by glutamatergic cells of the MRR $(18,66,67)$, but the identity of those neurons were unknown. We discovered that MRR vGluT2-neurons not only project to the LHb/mVTA aversion axis, but the axons of most of these MRR vGluT2-positive excitatory neurons bifurcate and simultaneously innervate PV-positive neurons in the MS/VDB and can instantly and reliably promote hippocampal theta rhythm generation necessary for memory acquisition. MRR vGluT2-neurons increased theta rhythm-related exploratory behavior, while animals exhibited conditioned place aversion on the day following stimulation, suggesting the facilitation of strong memory formation. MRR vGluT2-neurons may also facilitate the phase-locking of theta rhythm in the LHb and the hippocampus.

Our data revealed that the MRR vGluT2-positive neuronal population is a previously unrecognized neural hub of the brain that is both necessary and sufficient for the acquisition of negative experience, but which is not activated by positive rewarding experience. MRR vGluT2-neurons receive extensive convergence of inputs from sensory experience-related brain areas, its inhibition disrupts aversive memory formation, its activation promotes agitated and aversive behavior and flight, and it quickly negates motivated behavior. If flight is not an option during social interaction, it provokes fight and aggression. It also facilitates long-term memory formation related to negative experience and its chronic activation produces a depression-like phenotype, likely through inducing long-term bursting activity in LHb neurons $(28,30)$, which we showed in our vitro experiments. Therefore, vGluT2-positive MRR neurons control the acquisition of negative experience by simultaneously triggering the activity of brain aversion centers and hippocampal episodic memory encoding. Maladaptations in processing negative experience is the basis of several types of mood disorders, which have a huge social and economic impact on individuals and society. Selective targeting of this neural hub may form the basis of new therapies. 


\section{Acknowledgements}

We thank S. Arthaud (INSERM, Lyon, France) for his help with vGluT2-Cre mice. Viruses used in this study are subject to a material transfer agreement. We thank L. Barna, the Nikon Microscopy Center at IEM, Nikon Austria GmbH and Auro-Science Consulting Ltd. for technical support for fluorescent imaging. We thank K. Demeter, C. Fazekas, D. Várkonyi and the Behavior Studies Unit of the IEM-HAS for the support for behavioral experiments. We thank É. Mikics, M. Aliczki and Z. Balogh for their help in planning and evaluating the operant conditioning experiments. We thank Z. Erdélyi and F. Erdélyi and the staff of the Animal Facility and the Medical Gene Technology Unit of the IEM-HAS for expert technical help with the breeding and genotyping of the several mouse strains used in this study. We thank Z. Hajós, E. Szépné Simon, M. Mayer, N. Kriczky for their help with experiments and A. Kriczky, K. Iványi and G. Goda for other assistance. We thank J. Budd, L. Acsady for their comments on an earlier version of this manuscript. A.S. is currently affiliated to the Laboratory for Cellular Mechanisms of Learning and Memory, Friedrich Miescher Institute for Biomedical Research, Basel, Switzerland and the Laboratory of Cellular Neurophysiology, Department of Cellular and Network Neurobiology, Institute of Experimental Medicine, Hungarian Academy of Sciences, Budapest, Hungary; no work - related to this manuscript - was performed in any of these laboratories.

\section{Funding}

This work was supported by the European Research Council (ERC-2011-ADG-294313, SERRACO), the National Research, Development and Innovation Office, Hungary (OTKA K119521, OTKA K115441, OTKA K109790, OTKA KH124345, OTKA NN125643, FK129019, PD121248, EFOP-3.6.3-VEKOP-16-2017-00009, NKFIH K120311 and VKSZ_14-1-2015-0155); the U.S. National Institutes of Health (NS030549); the Human Brain Project of EU (EU H2O20 720270) and the Hungarian Brain Research Program (2017-1.2.1-NKP-2017-00002). The New National Excellence Program of the Ministry of Human Capacities, Hungary supported D.S. (UNKP-163-IV), A.S. (UNKP-17-3-III-SE-9), A.M. (UNKP-18-02-I-SE-20), A.M.B. (UNKP-18-4-SE-126) and K.Z. (UNKP-18-2-ISE-22). A.M.B. was supported by the Bolyai János Research Fellowship of the Hungarian Academy of Sciences.

\section{Author contributions}

Conceptualization: A.S., K.Z., G.N.; Investigations: A.S., K.Z., R.T.G., Z.B. and K.E.S performed and analyzed fluorescent and transmission electron microscopy experiments, supervised by G.N.; A.M. and Z.B. performed and analyzed the scanning electron microscopy experiments, supervised by G.N.; A.S., K.Z. and R.T.G. performed and analyzed the optogenetic behavioral experiments, supervised by G.N.; A.M.B. performed and analyzed the in vivo optogenetic tagging in head-fixed EEG recording experiments, supervised by V.V.; D.S. planned the in vitro experiments, recorded and analyzed the data, supervised by A.I.G; B.T., E.S. and D.Z. performed and analyzed the chemogenetic behavioral experiments, supervised by D.Z.; Writing of the original draft: A.S., K.Z., T.F.F., G.N., which was edited by all authors; Funding acquisition: A.M.B., A.I.G., V.V., D.Z., G.N., T.F.F. 


\section{Competing interests}

Authors have no competing interests.

\section{Data and materials availability}

Viruses AAV2/5-EF1 $\alpha$-DIO-eYFP, AAV2/5-EF1 $\alpha$-DIO-mCherry and AAV2/5-CAG-FLEX-ArchT-GFP were obtained under an MTA with the UNC Vector Core. Virus AAV2/5-EF1 $\alpha$-DIO-hChR2(H134R)-eYFP was obtained under an MTA with the Penn Vector Core. Viruses AAV2/8-hSyn-DIO-mCherry and AAV2/8-hSyn-DIOhM3D(Gq)-mCherry were obtained under an MTA with Addgene. Viruses AAV2/8-hSyn-FLEX-TVA-p2A-eGFPp2A-oG and Rabies $(\Delta G)$-EnvA-mCherry were obtained under an MTA with the Salk GT3 Vector Core.

Data generated and analyzed during the current study are presented in the manuscript or in the Supplementary Materials file, while additional custom written codes for in vivo electrophysiological recordings are available from: https://doi.org/10.6084/m9.figshare.8924771.v1

\section{Supplementary materials contain}

Supplementary Methods,

Supplementary Data for Main Fig. 1-8,

Figs. S1 to S7,

Tables S1 to S6,

References (68-79) 

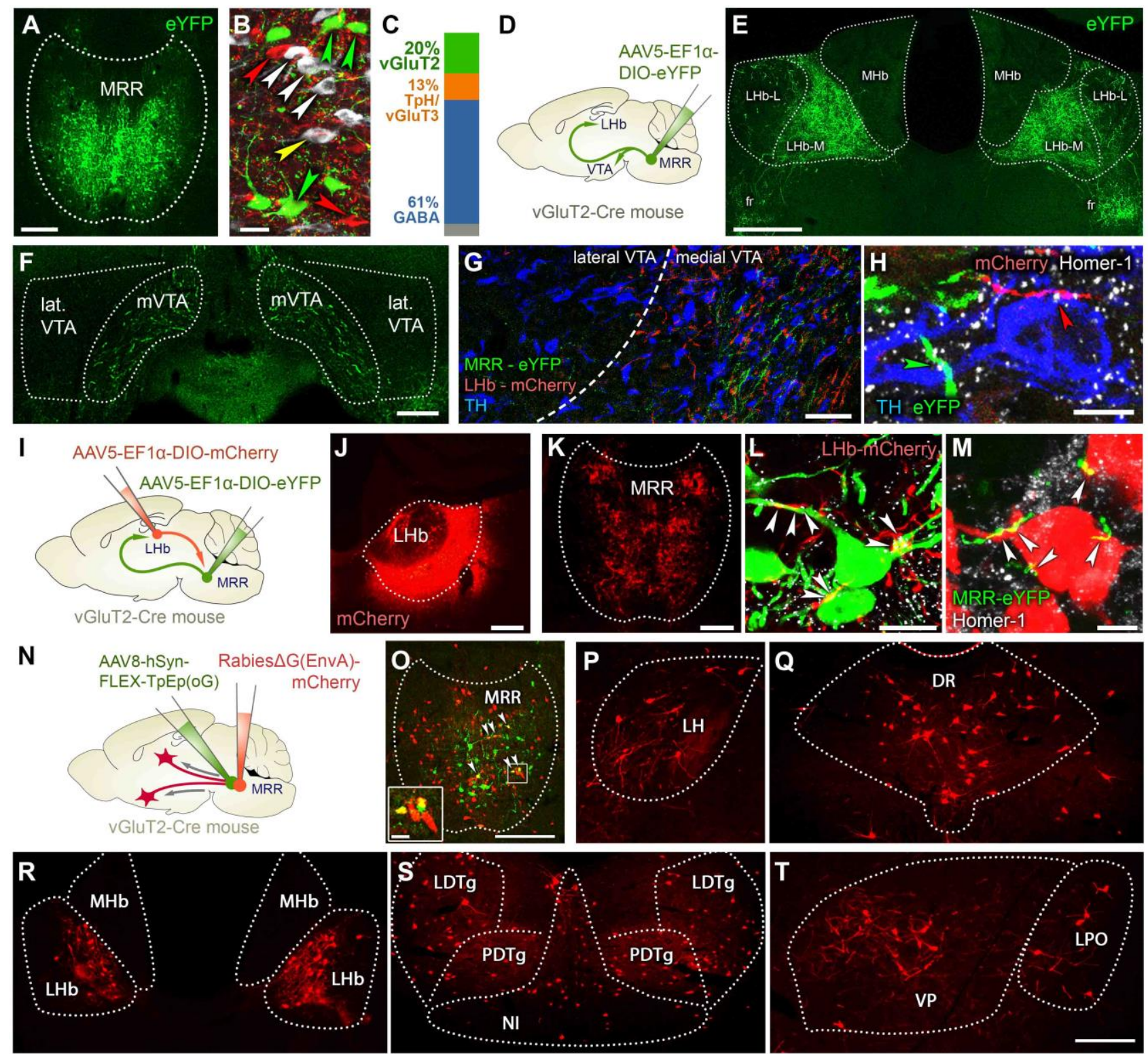

A: AAV5-eYFP labeling in MRR in vGluT2-Cre mice. Scale bar: $200 \mu \mathrm{m}$.

B: eYFP-labelled vGluT2-positive (green arrows), immunolabelled TpH (serotonin)-positive (white arrows), vGluT3-positive (red arrows) and TpH/vGluT3 double positive (yellow arrow) cells in MRR. Scale bar: $20 \mu \mathrm{m}$. C: At least $20 \%$ of the MRR neurons are vGluT2-positive. (For stereological statistical details see Table S5). D: AAV2/5-EF1 $\alpha$-DIO-eYFP was injected into the MRR of vGluT2-Cre mice $(n=3)$.

E-F: Virally labelled vGluT2-positive MRR fibers innervate the LHb (primarily the medial part) and mVTA. Abbreviations: fr: fasciculus retroflexus; LHb-L: lateral habenula, lateral division; LHb-M: lateral habenula, medial division; MHb: medial habenula; VTA: ventral tegmental area. Scale bars: $200 \mu \mathrm{m}$.

G: vGluT2-positive fibers from MRR (green) and LHb (red) innervate the same medial VTA, but not the lateral VTA. Dopaminergic cells were labelled with anti-tyrosine hydroxylase (TH, blue). Scale bar: $50 \mu \mathrm{m}$. (For statistical details see Suppl. Data for Fig. 1).

H: vGluT2-positive MRR axon terminal (green) and an LHb terminal (red) establish Homer-1 (white) positive synaptic contacts with the same dopaminergic cell (TH, blue) in mVTA. Scale bar: $5 \mu \mathrm{m}$

I: AAV2/5-EF1 $\alpha$-DIO-eYFP was injected into the MRR and AAV2/5-EF1 $\alpha$-DIO-mCherry was injected into the LHb of vGluT2-Cre mice, bilaterally $(n=2)$. 
J-K: Injection site in the LHb (J) and its vGluT2-positive fibers in the MRR (K). Scale bar: $200 \mu \mathrm{m}$.

L: vGluT2-positive LHb fibers (red) establish Homer-1 (white) positive synaptic contacts (white arrowheads) with vGluT2-positive MRR neurons (green). Scale bar: $10 \mu \mathrm{m}$. (For statistical details see Suppl. Data for Fig. 1). M: vGluT2-positive MRR fibers (green) establish Homer-1 (white) positive synaptic contacts (white arrowheads) with vGluT2-positive LHb neurons (red). Scale bar: $5 \mu \mathrm{m}$.

N: A helper AAV2/8-hSyn-FLEX-TpEp(oG) was injected into the MRR of vGluT2-Cre mice, followed by an injection of Rabies $\triangle G(E n v A)$-mCherry two weeks later ( $n=3$ mice).

O: Injection site of helper (green) and rabies (red) viruses into the MRR of vGluT2-Cre mice. Inset illustrates some starter neurons expressing both viruses. Scale bar for large image is $100 \mu \mathrm{m}$, for inset it is $10 \mu \mathrm{m}$.

P-T: Rabies labeled neurons in different brain areas establish synapses on vGluT2-positive MRR neurons. Scale bar for all images: $100 \mu \mathrm{m}$. (For abbreviations see Suppl. Data for Fig. 1, for detailed analysis see Table S6) 
A

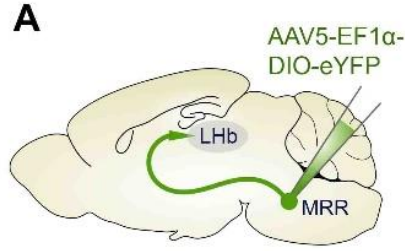

D
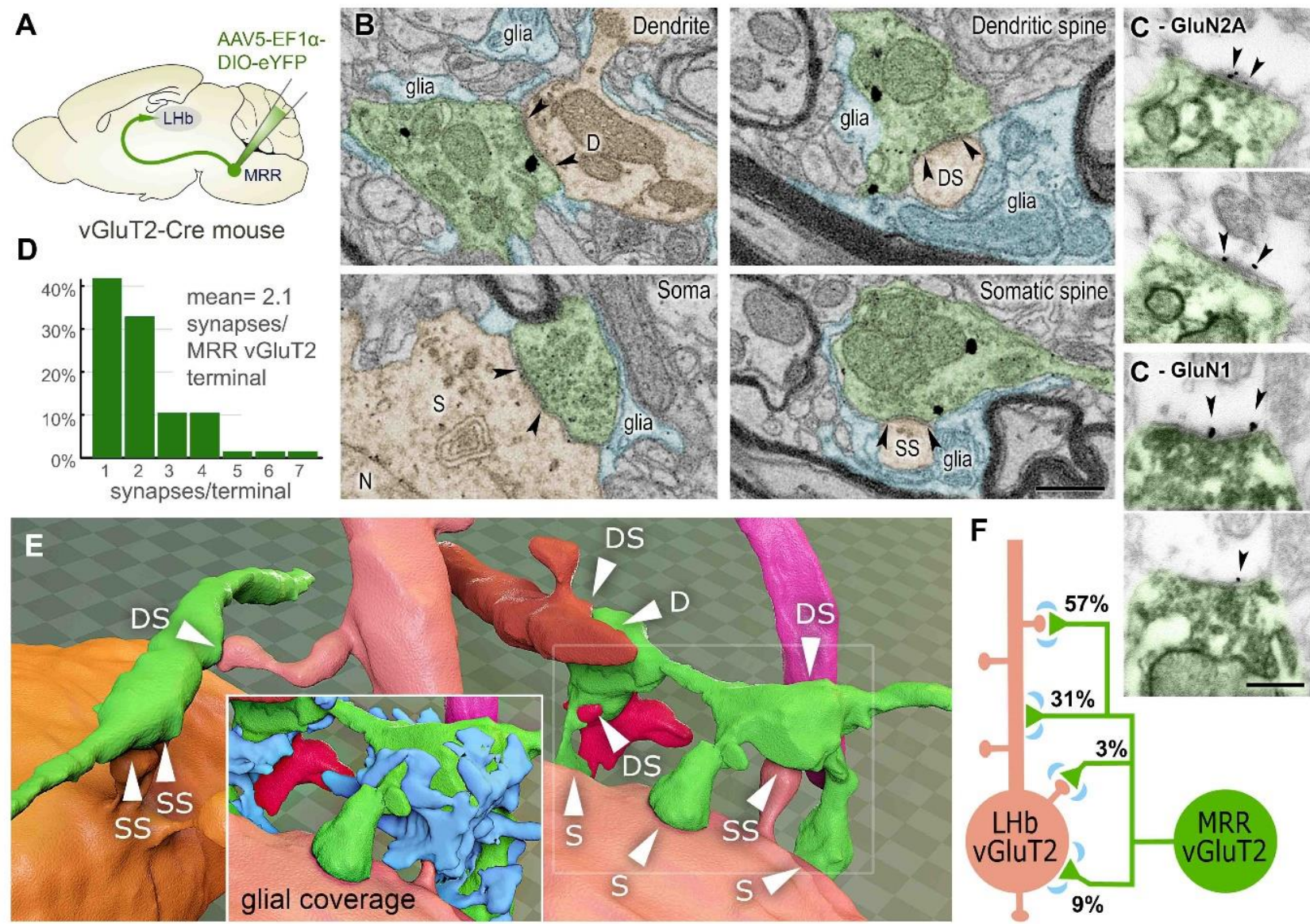

A: AAV2/5-EF1a-DIO-eYFP was injected into the MRR of vGluT2-Cre mice.

B: Scanning electron micrographs represent different types of synaptic contacts established by eYFP-positive MRR terminals (immunogold labeling, black spheres) on different subcellular compartments of LHb neurons. Arrows show synaptic edges. Abbreviations: D: dendrite, DS: dendritic spine, N: nucleus, S: soma, SS: somatic spine. Scale bar: $500 \mathrm{~nm}$.

C: AAV-eYFP positive terminals (serial sections of immunoperoxidase labeling, dark DAB precipitate) establish synapses on LHb neurons that contain the GluN2A (upper two images) or GluN1 (lower two images) NMDAreceptor subunits (immunogold particles indicated with arrowheads). For statistical details, see Supplementary Data for Figure 2C. Scale bar: $300 \mathrm{~nm}$.

D: MRR vGluT2-terminals establish more than one synapse on LHb neurons (from 2 mice).

E: 3D reconstruction of MRR vGluT2 fibers (green) shows their synapses with different membrane domains of LHb neurons. Inset shows the abundant glial coverage around MRR vGluT2 terminals (blue).

F: Schematic illustration of the proportion of MRR vGluT2 synapses on different membrane domains LHb neurons (from 2 mice). 


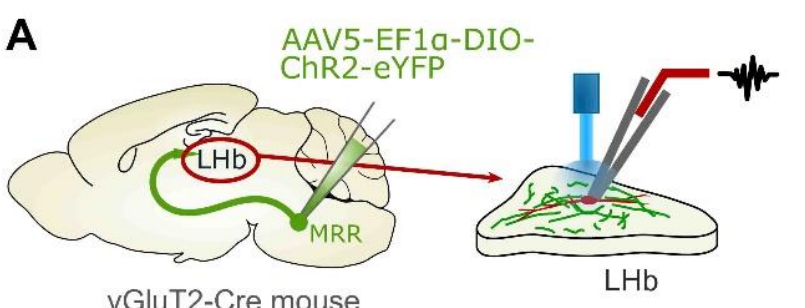

B

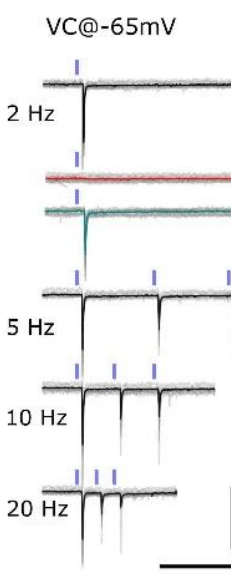

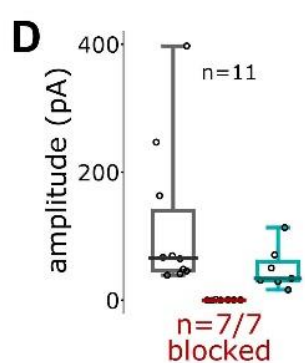

$E$
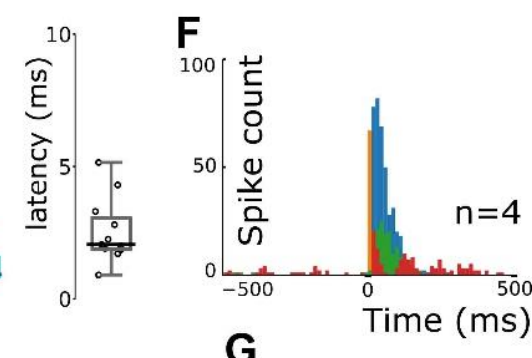

G
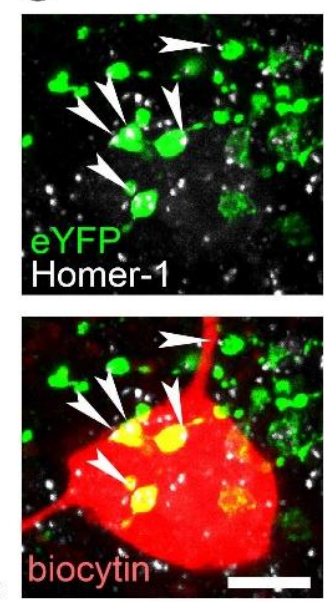

A: AAV2/5-EF1 $\alpha$-DIO-ChR2-eYFP was injected into the MRR of vGluT2-Cre mice ( $n=3)$. Six weeks later, 300- $\mu$ mthick horizontal in vitro slices were prepared from the LHb. Neurons in LHb were whole-cell patch clamped in voltage clamp mode. (Supplementary Methods and Suppl. Data for Fig. 3).

B: Light stimulations of MRR vGluT2-fibers evoked excitatory postsynaptic currents (EPSCs) in LHb neurons. The average responses to $2 \mathrm{~ms}$ light pulses are shown above individual grey traces. Responses are strong in control conditions (black), they were completely abolished (red trace) by $20 \mu \mathrm{M}$ NBQX (AMPA/kainite receptor antagonists) and $50 \mu \mathrm{M}$ AP5 (NMDA antagonist), and partially recovered after washout (teal). Scale bars: 200 $\mathrm{ms}, 200 \mathrm{pA}$.

C: Cells displayed short-term depression of EPSC amplitudes at all stimulation frequencies (averages from 10 cells, for statistical data see Suppl. Data for Fig. 3).

D: EPSC amplitude and latency distributions from all 11 recorded neurons (in grey). EPSPs were sensitive for glutamatergic antagonists in 7 out of 7 tested cells (red), and partially recovered after washout (teal). (For statistical data see Suppl. Data for Fig. 3).

E: Traces show representative current-clamped ( $\mathrm{I}=0) \mathrm{LHb}$ neurons displaying spontaneous (asterisks) and lightevoked (pale blue lines, 5 pulses at $20 \mathrm{~Hz}$ ) bursts. 10 consecutive stimulations are shown. Both spontaneous and light-evoked bursts were abolished by application of NBQX and AP5 (right panel). Scale bars: $1 \mathrm{sec}, 20 \mathrm{mV}$. F: Peri-stimulus time-histogram show action potential distributions upon light stimuli ( $n=4$ cells).

G: A representative, recorded LHb cell (biocytin labeling, red) receives Homer-1 positive (white) synaptic contacts (white arrowheads) from eYFP-positive MRR fibers (green). Scale bar: $5 \mu \mathrm{m}$. 

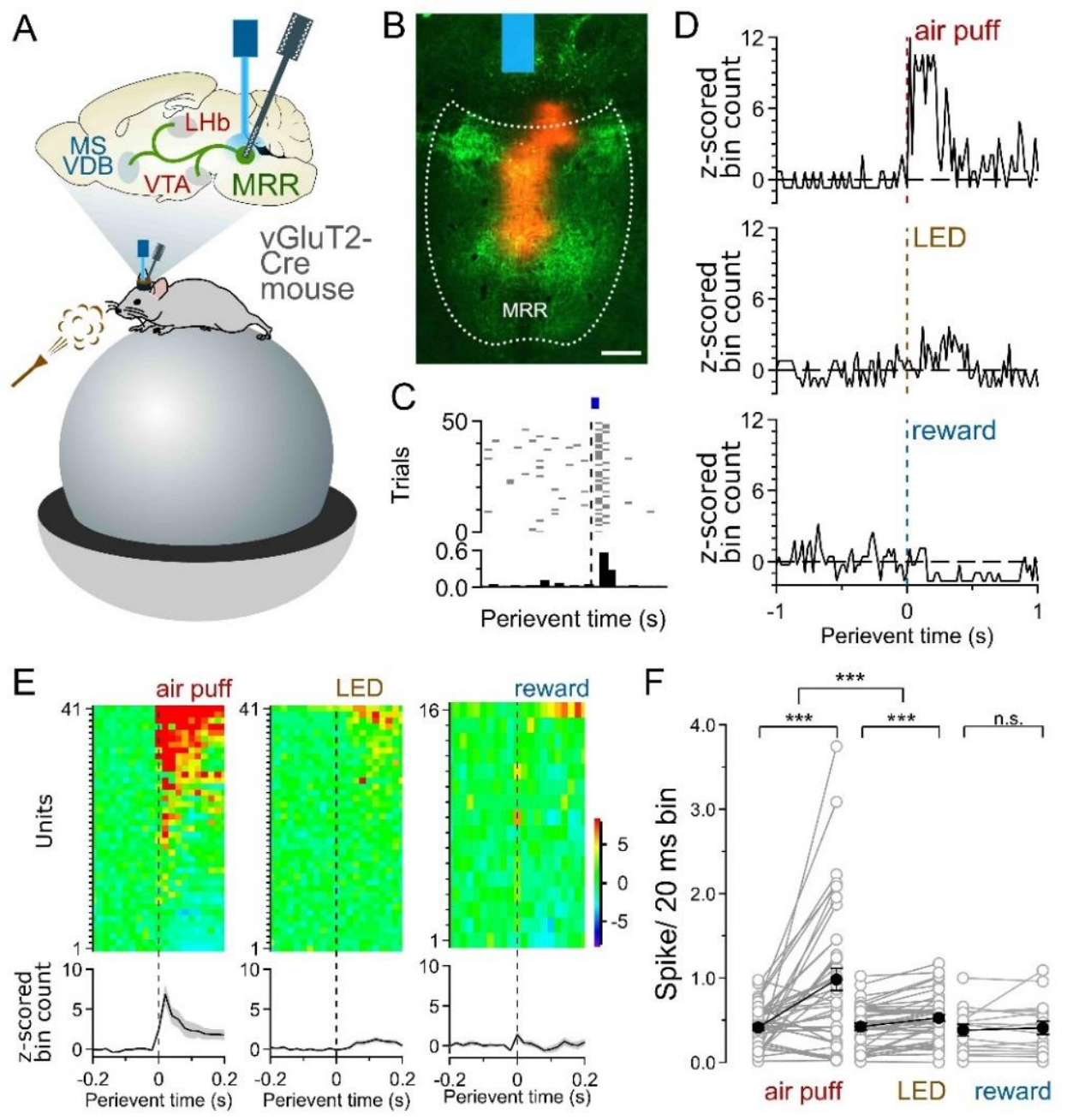

A: AAV2/5-EF1a-DIO-ChR2-eYFP was injected into the MRR of vGluT2-Cre mice. A silicone probe was inserted into and an optical fiber was placed above the MRR. Mice were head-fixed on top of an air supported spherical treadmill, and strongly aversive (air puff), mildly aversive (LED flash) and rewarding (water drops) stimuli were randomly presented to the awake animals (8 mice).

B: A representative image of virus expression (green) and the position of the implanted optic fiber (blue) and silicone probe (red Dil labeling) in the MRR of a vGluT2-Cre mouse. Scale bar: $200 \mu \mathrm{m}$.

C: A raster plot and a peri-stimulus time histogram, corresponding to an optogenetically tagged vGluT2 neuron in the MRR, shows short latency, high success rate and low jitter of the responses. The blue square indicates the light pulse.

D: A representative MRR vGluT2-neuron was robustly activated by an aversive air puff, was only weakly activated by a slightly aversive LED stimulus (LED) and showed no response to water reward.

E: Top matrices show the reaction of individual MRR vGluT2-neurons to different stimuli (each row is one neuron's z-scored peri-stimulus time histogram), sorted by descending response magnitudes. Bottom plots show average response across all tagged units (from 8 animals, mean +/- SEM).

F: Paired plots of cells (same as displayed in E) show the baseline vs. stimulus-evoked firing activity of MRR vGluT2-neurons (grey: individual tagged neurons, black: mean +/- SEM). Air puffs evoked significantly larger response than LED flashes. Reward induced no significant population response. (For statistical data see Suppl. Data for Fig. 4). 

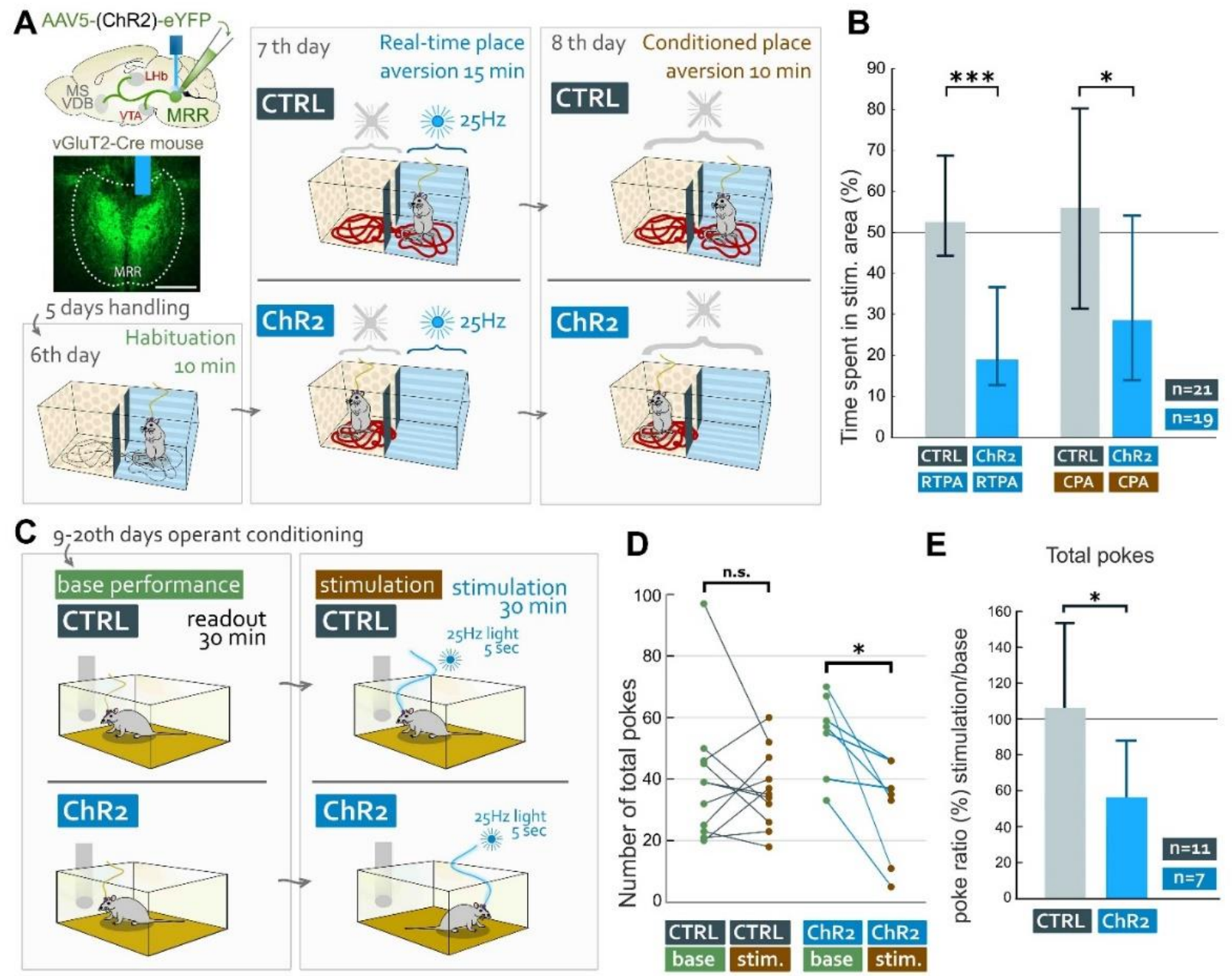

A: After injecting ChR2-containing AAV2/5-EF1a-DIO-ChR2-eYFP ("ChR2-mice") or control (only eYFP containing) Cre-dependent AAV5 ("CTRL-mice") into the MRR of vGluT2-Cre mice, we implanted an optic fiber over the MRR. Image represents an injection site in MRR and the position of the optic fiber (blue, scale bar: $500 \mu \mathrm{m}$ ). Four weeks later, mice were habituated to a chamber with two areas. On day 7 , mice received $25 \mathrm{~Hz}$ light illumination in one of the areas of the chamber. ChR2 expressing mice showed significant real-time place aversion (RTPA) of the stimulated area, immediately. On day 8, no light was presented, but ChR2-mice displayed a significant conditioned place aversion (CPA), suggesting that the activity of MRR vGluT2-neurons can directly induce real-time and learned active contextual avoidance. (Also see Suppl. Fig. 6A)

B: RTPA and CPA tests show significant effects (medians \& interquartile ranges, for statistical details see Suppl. Data for Fig. 5).

C: Between days 9-21 mice were food-restricted and learned to nose-poke for reward pellets (see Supplementary Methods for details). On day 22, mice received 5 second $25 \mathrm{~Hz}$ light starting with the nosepokes. Compared to base performance (on day 21), ChR2-mice performed significantly less nose-pokes when nose-pokes were paired with laser stimulation (on day 22).

D: The total number of nose-pokes for rewards during the base and stimulation performance in the operant conditioning task (For statistical details see Suppl. Data for Fig. 5).

E: Nose-poke ratios of stimulation/base performance in the operant conditioning task (mean \& SD, For statistical details see Suppl. Data for Fig. 5). 
Fig. 6: Chronic over-activation of MRR vGluT2-neurons induces aggression and anhedonia

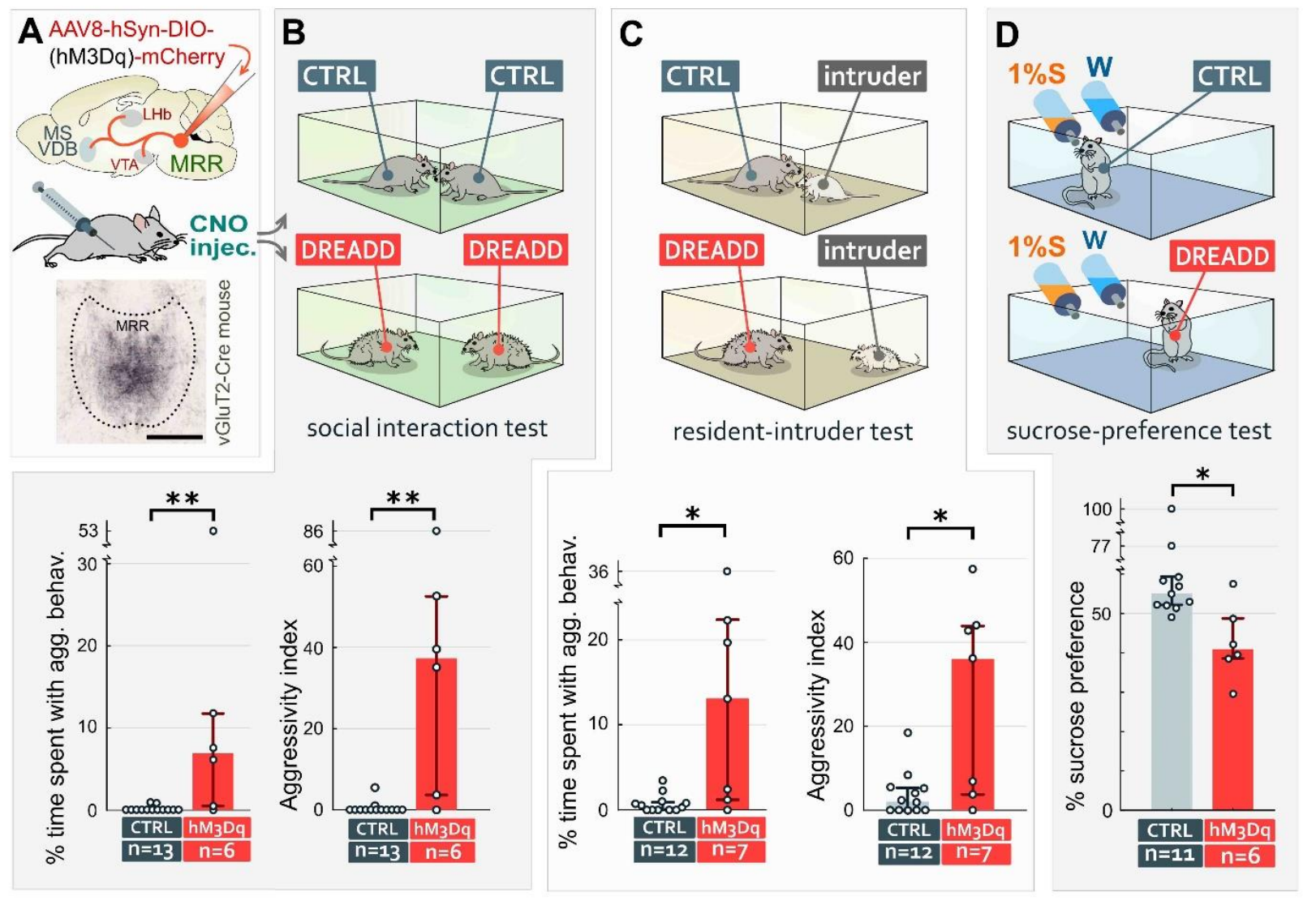

A: AAV2/8-hSyn-DIO-hM3D(Gq)-mCherry or control AAV2/8-hSyn-DIO-mCherry was injected into the MRR of vGluT2-Cre mice (14 CTRL-and $8 \mathrm{hM} 3 \mathrm{Dq}$-mice). All mice received hM3Dq-agonist clozapine $\mathrm{N}$-oxide (CNO, $1 \mathrm{mg} / 10 \mathrm{ml} / \mathrm{kg}$ intraperitoneally 30 min prior testing). Image represents a DAB labeled injection site in MRR (scale bar: $500 \mu \mathrm{m}$ ).

B-C: Social interaction (B) and resident-intruder (C) tests. Percentage of time spent with aggressive interactions and aggressivity index are shown at the bottom. Chemogenetic stimulation of MRR vGluT2-neurons lead to highly aggressive behavior, suggesting the induction of active coping with a perceived strongly negative experience.

D: Testing anhedonia in a sucrose preference test (see Suppl. Methods for details). Chronic stimulation of MRR vGluT2-neurons (in hM3Dq-mice) lead to a significant difference in sucrose preference compared to CTRLmice, suggesting the induction of depression-related anhedonia. Graphs show medians and $25 \%-75 \%$ quartiles. For statistical details see Suppl. Data for Fig. 6. 

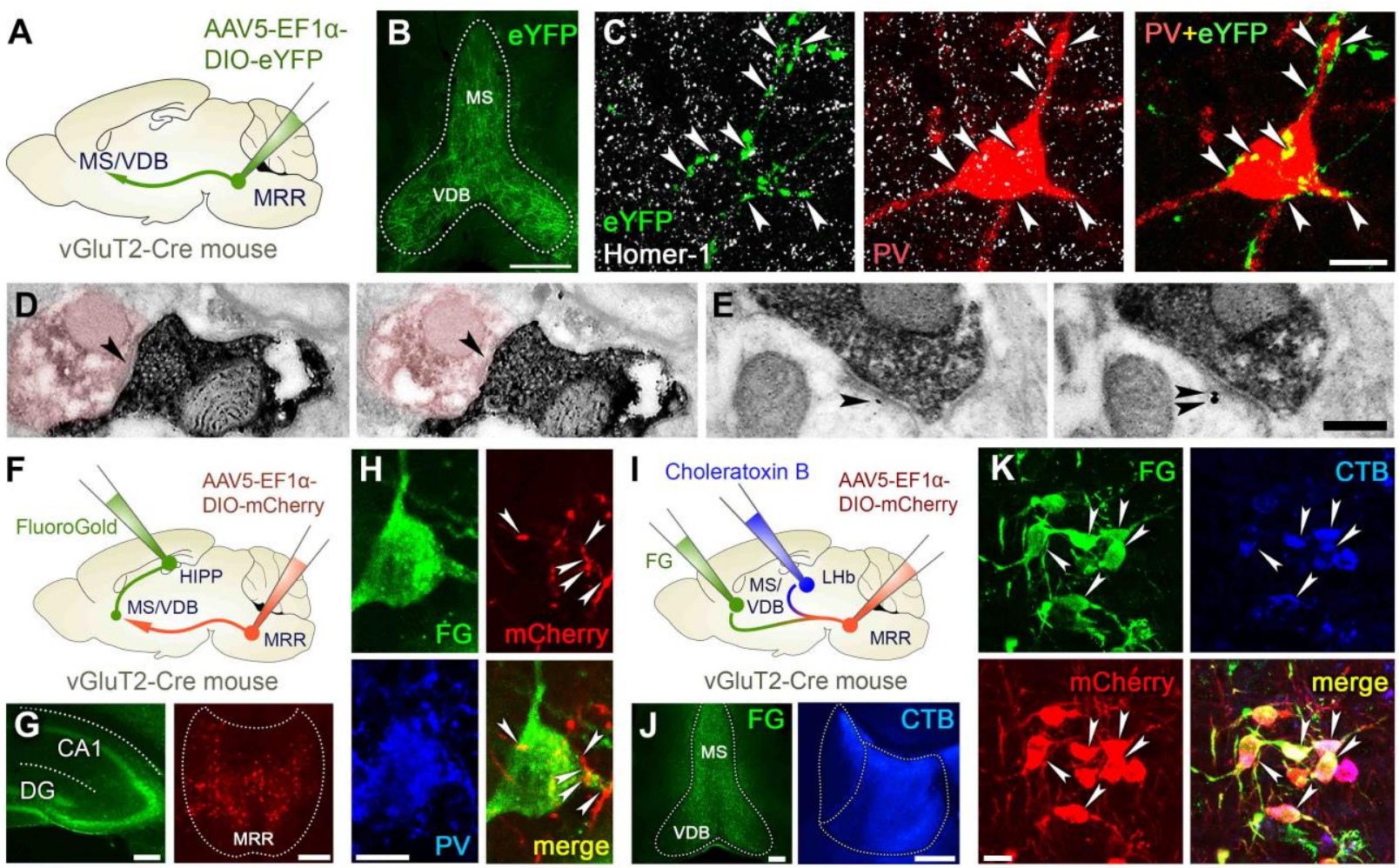

vGluT2-Cre mouse
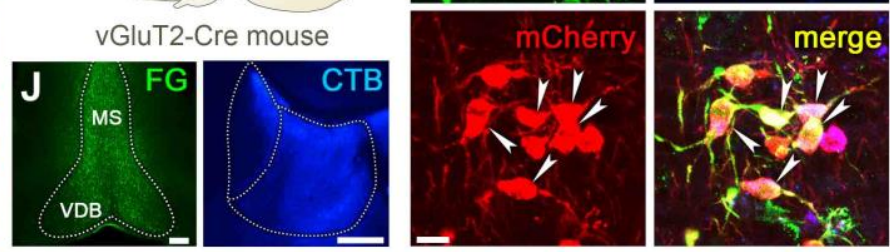

A: AAV2/5-EF1 $\alpha$-DIO-eYFP was injected into the MRR of vGluT2-Cre mice $(n=3)$.

B: MRR vGluT2-neuronal fibers innervate the MS/VDB. Scale bar: $200 \mu \mathrm{m}$.

C: A representative MS/VDB PV-positive neuron (red) is innervated by basket-like multiple synapses of vGluT2-positive MRR fibers (green), establishing Homer 1-positive (white) synaptic contacts (white arrowheads). Scale bar: $10 \mu \mathrm{m}$. (For statistical details see Supplementary Data for Fig. 7)

D-E: Electron microscopic images show serial sections of synapses of vGluT2-positive MRR terminals (dark SIDAB). D: PV-positive dendrite (false red colored, DAB-Ni precipitate) in the VDB received synaptic contacts (at least 12 synapses were reconstructed, black arrowheads) E: Synapses contained GluN2A subunit of the NMDA-receptors (immunogold labeling, black arrowheads) postsynaptically. Scale bar: $300 \mathrm{~nm}$. (For statistical details see Supplementary Data for Fig. 7)

F: AAV2/5-EF1 $\alpha$-DIO-mCherry was injected into the MRR and FluoroGold into the bilateral hippocampi of vGluT2-Cre mice $(n=2)$.

G: Representative injection sites in the hippocampus (green FluoroGold, FG labeling) and MRR (red AAVmCherry). Scale bars: $200 \mu \mathrm{m}$.

H: AAV-mCherry containing vGluT2-positive MRR terminals (red) establish several putative contacts (white arrowheads) with a FluoroGold (FG)-positive (green) septo-hippocampal PV-positive (blue) neuron. Scale bar: $10 \mu \mathrm{m}$.

I: Double retrograde tracing was performed by injecting FluoroGold into the MS/VDB and CTB into the LHb, bilaterally, and AAV2/5-EF1 $\alpha$-DIO-mCherry was injected into the MRR to virally label vGluT2-positive neurons in vGluT2-Cre mice $(n=2)$.

J: Representative injection sites in the MS/VDB (FluoroGold, FG, labeling) and in the LHb (CTB labeling). Scale bars: $200 \mu \mathrm{m}$.

K: MRR vGluT2-neurons (red) contain both FG (green) and CTB retrograde labeling (blue) shows that bifurcating axons of these neurons simultaneously target both MS/VDB and LHb. (For statistical details see Supplementary Data for Fig. 7) Scale bar: $20 \mu \mathrm{m}$. 
A

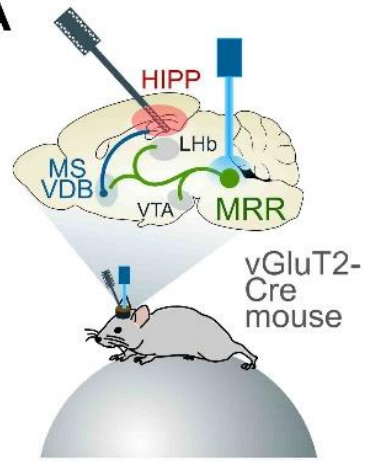

B

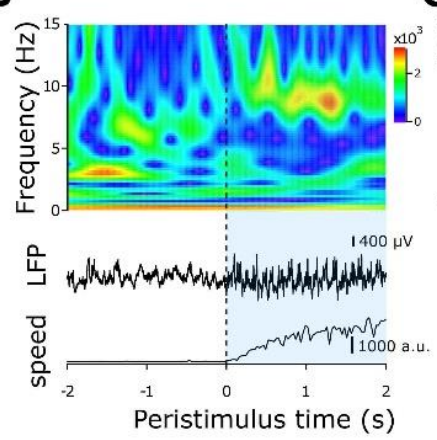

C

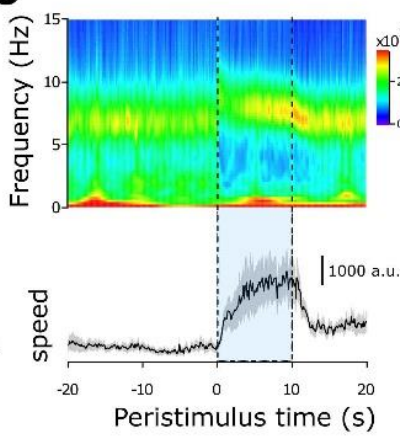

D

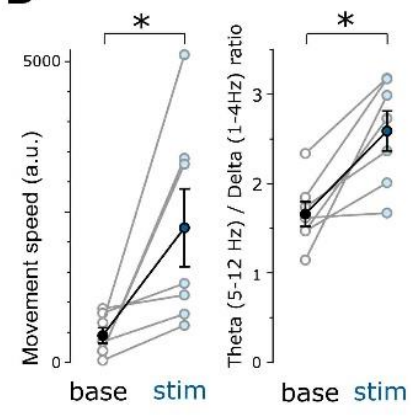

E
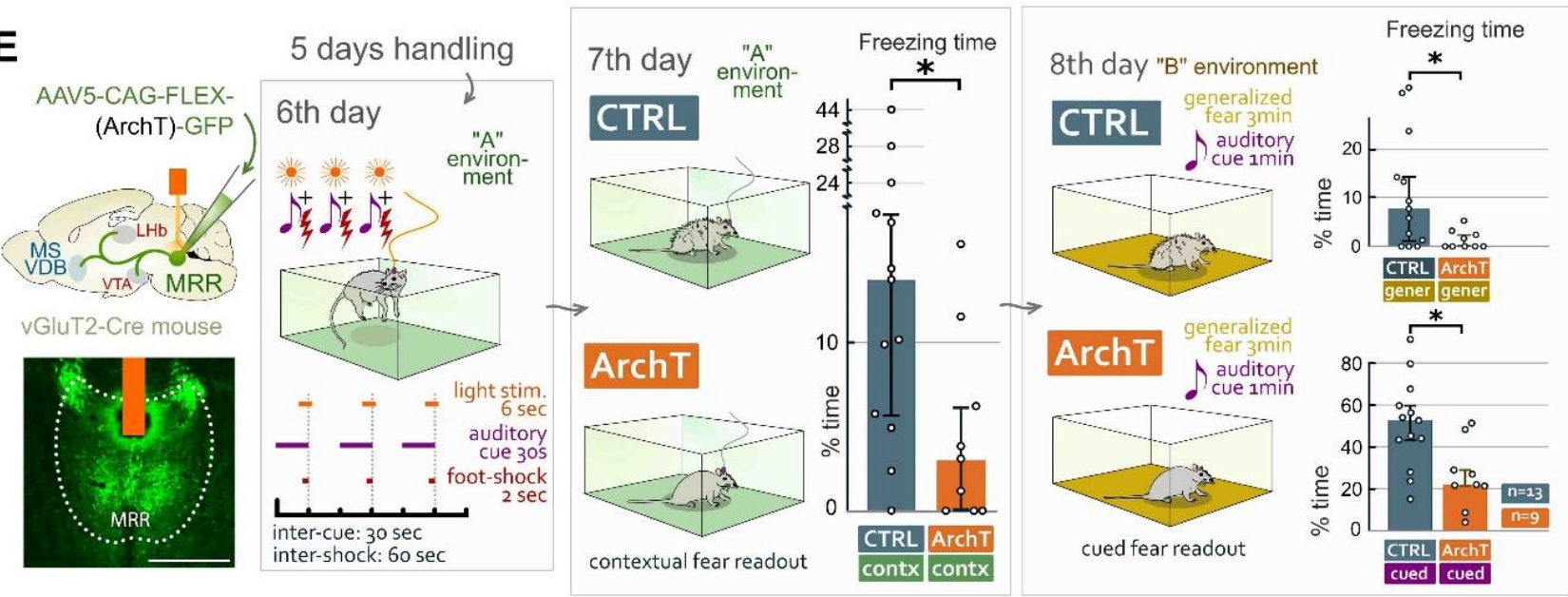

A: AAV2/5-EF1a-DIO-ChR2-eYFP was injected into the MRR of vGluT2-Cre mice. An optical fiber was inserted into the MRR and a silicone probe was implanted into the hippocampal CA1 region to measure concurrent hippocampal network activity ( $n=7$ mice). Mice were head-fixed on top of an air supported spherical treadmill and their behavior was monitored.

B: Bottom panel: running speed, middle panel: local field potential (LFP) recordings from the pyramidal layer of the dorsal hippocampal CA1 region, top panel: corresponding wavelet spectrogram. Vertical dashed line indicates the onset of laser stimulation, which rapidly induced a switch to theta oscillation.

C: Bottom panel: average running speed (mean +/- SEM), top panel: corresponding averaged wavelet spectrogram (7 mice). Vertical dashed lines highlight the MRR laser illumination period.

D: Paired plots indicating movement speed (left panel) and theta/delta ratios (right panel) during baseline (10 $\mathrm{s}$ long window before laser onset) vs stimulation (10 s long window after laser onset) periods (grey: individual animals, black: mean +/- SEM. For statistical data see Suppl. Data for Fig. 8).

E: Design of cued fear conditioning experiments with optogenetic inhibition of MRR vGluT2-neurons. Fluorescent image represents one of the injection sites to label MRR vGluT2-neurons and the orange area represents the position of the optic fiber (scale bar: $500 \mu \mathrm{m}$ ). After handling, light-illumination of MRR was switched on precisely during foot-shocks that mice received at the end of the auditory cue presentation on day 6 . On day 7 and 8 mice received no more light. On day 7, contextual freezing behavior in ArchT-mice in the same environment was almost completely diminished (below 5\% threshold) compared to CTRL-mice, which received virus without ArchT. On day 8, ArchT-mice showed significantly less generalized fear and cued fear in a novel environment compared to CTRL-mice (For statistical details see Suppl. Data for Fig. 8). Medians and interquartile ranges are shown on the graphs. 


\section{Supplementary Materials for}

\section{Median raphe controls acquisition of negative experience}

András Szőnyi, Krisztián Zichó, Albert M. Barth, Roland T. Gönczi, Dániel Schlingloff, Bibiána Török, Eszter Sipos, Abel Major, Zsuzsanna Bardóczi, Katalin E. Sos, Attila I. Gulyás, Viktor Varga, Dóra Zelena, Tamás F. Freund and Gábor Nyiri*

*Corresponding author, e-mail: nyiri.gabor@koki.mta.hu

This file includes:

Supplementary Methods

Supplementary Text for Main Figures 1 to 8

Figs. S1 to S7

Tables S1 to S6

References (68-79) 


\section{Supplementary Methods}

\section{Ethical considerations}

All experiments were performed in accordance with the Institutional Ethical Codex and the Hungarian Act of Animal Care and Experimentation guidelines (40/2013, II.14), which are in concert with the European Communities Council Directive of September 22, 2010 (2010/63/EU). The Animal Care and Experimentation Committee of the Institute of Experimental Medicine of Hungarian Academy of Sciences and the Animal Health and Food Control Station, Budapest, have also approved the experiments under the project numbers PEI/001/33-4/2013, PE/EA/2553-6/2016 and PE/EA/254-7/2019.

\section{Mice}

The following mice were used in the experiments: males and females of vGluT2-iRES-Cre, vGAT-iRESCre, BAC-vGluT3/iCre, TpH2/iCre-ERT2 (The Jackson Laboratory) and males of C57BI/ 6 wild type (Charles River). We used adult, at least 6 weeks-old mice. Mice had access to food and water ad libitum and were housed in a vivarium (3-5 mice/cage) until used in experiments, after which they were single-housed. Mice used for optogenetic behavioral experiments were maintained on a normal $12 \mathrm{~h}$ light-dark cycle, with experiments performed during the light phase of the cycle. Mice used for chemogenetic behavioral experiments were maintained on a reversed $12 \mathrm{~h}$ light-dark cycle, with experiments performed during the dark phase of the cycle.

\section{Stereotaxic surgeries for viral gene transfer, retrograde tracing and optic fiber implantations}

Mice were anesthetized with $2 \%$ isoflurane followed by an intraperitoneal injection of an anesthetic mixture (containing $8.3 \mathrm{mg} / \mathrm{ml}$ ketamine and $1.7 \mathrm{mg} / \mathrm{ml}$ xylazine-hydrochloride in $0.9 \%$ saline, $10 \mathrm{ml} / \mathrm{kg}$ body weight); and were then mounted in a small animal stereotaxic frame (David Kopf Instruments, CA, USA) and the skull surface was exposed. A Nanoject II precision microinjector pump (Drummond, Broomall, PA) was used for the microinjections. For anterograde tracing, optogenetic and chemogenetic experiments, we injected 10$100 \mathrm{nl}$ and for stereological measurements 1000-1200nl of one of the following viruses into the target brain areas: AAV2/5-EF1 $\alpha$-DIO-eYFP; AAV2/5-EF1 $\alpha$-DIO-mCherry; AAV2/5-EF1 $\alpha$-DIO-hChR2(H134R)-eYFP; AAV2/5CAG-FLEX-ArchT-GFP (UNC Vector Core for the viruses above), AAV2/8-hSyn-DIO-mCherry and AAV2/8-hSynDIO-hM3D(Gq)-mCherry (Addgene; $4.4-21 \times 10^{12}$ colony forming units/ml for all viruses). For retrograde tracing experiments we injected 20-40 $\mathrm{nl}$ of $2 \%$ FluoroGold (Fluorochrome, Denver, CO, USA) or $0.5 \%$ Choleratoxin B subunit (List Biologicals, Campbell, CA, USA) into the target areas. The coordinates for the injections were defined by a stereotaxic atlas (Paxinos \& Watson 2012); the null coronal plane of the anteroposterior (AP) axis was defined by the position of Bregma; the null sagittal plane of the mediolateral (ML) axis was defined by the sagittal suture; the null horizontal plane of the dorso-ventral (DV) axis was defined by the bregma and lambda. The median raphe region (MRR) was defined as the median raphe and the para-median raphe areas together. The injection coordinates were the following (always given in $\mathrm{mm}$ at the AP, ML and DV axes, respectively): median raphe region: $-4.5,0.0,-4.5$ or $-4.1,0.0,-4.6$; median raphe region for stereology (4 injections altogether): $-4.3,0.0,-4.3$ and -4.8 and $-4.7,0.0,-4.1$ and -4.6 ; lateral habenula: $-1.5 ;+/-0.5$; -2.8 ; hippocampus: (2-2 injections bilaterally) $-2.0,+/-1,5,-2$ and $-2.7,+/-2.5,-2.7$; VTA: $-3.4,+/-0.2,-4.5$; medial septum: +1.0, 0.0, -4.3; vertical limb of the diagonal bands of Broca (VDB): +1.0, 0.0, -5.2; medial prefrontal cortex (1-1 injection bilaterally): $+1.8,+/-0.3$ and -2.7 .

For behavioral experiments, during a second, similar surgical procedure 4-6 weeks after virus injections, optic fibers (105 $\mu \mathrm{m}$ core diameter, $0.22 \mathrm{NA}$, Thorlabs $\mathrm{GmbH}$, Dachau/Munich, Germany) were implanted into the MRR with the tip at the following coordinates: $-4.5,0.0,-4.4$. Positions of the optic fibers are illustrated in Suppl. Fig. 5. After the surgeries, mice received $0.3-0.5 \mathrm{ml}$ saline and $0.03-0.05 \mathrm{mg} / \mathrm{kg}$ meloxicam (Metacam, Boehringer Ingelheim, Germany) intraperitoneally or $0.1 \mathrm{ml}$ buprenorphine $(0.1 \mathrm{mg} / \mathrm{kg}$; 
Bupaq) subcutaneously and were placed into separate cages to rest, until further experiments or perfusions. Following two weeks of recovery, animals used in chemogenetic experiments were moved to the behavioral examination unit and adapted to reversed lighting cycle for another 2 weeks before behavioral experiments started.

\section{Mono-trans-synaptic rabies tracing}

A detailed description of the monosynaptic rabies tracing technique used has already been published by (26). Briefly, vGluT2-Cre mice were prepared for stereotaxic surgeries as described above, and $30 \mathrm{nl}$ of the virus AAV2/8-hSyn-FLEX-TVA-p2A-eGFP-p2A-oG (Salk GT3 Core, $4.5 \times 10^{12}$ colony forming units/ml) was injected into the MRR at the coordinates given above. These Cre-dependent viruses contain an avian tumor virus receptor A (TVA), which is necessary for them to be infected by the rabies viruses and they contain an upgraded version of the rabies glycoprotein (OG) that provides an increased trans-synaptic labeling potential for the rabies viruses (68). After 2-3 weeks of survival, mice were injected with the genetically modified Rabies $(\Delta G)$-EnvA-mCherry (Salk GT3 Core, $3.5 \times 10^{7}$ colony forming units $/ \mathrm{ml}$ ) at the same coordinates. After 10 days of survival, mice were prepared for perfusions.

\section{Perfusions}

Mice were anesthetized with $2 \%$ isoflurane followed by an intraperitoneal injection of an anesthetic mixture (containing $8.3 \mathrm{mg} / \mathrm{ml}$ ketamine, $1.7 \mathrm{mg} / \mathrm{ml}$ xylazine-hydrochloride, $0.8 \mathrm{mg} / \mathrm{ml}$ promethaziniumchloride) to achieve deep anesthesia. The mice were then perfused transcardially with $0.1 \mathrm{M}$ phosphatebuffered saline (PBS, pH 7.4) solution for $2 \mathrm{~min}$, followed by of $4 \%$ freshly depolymerized paraformaldehyde (PFA) solution for $40 \mathrm{~min}$, followed by PBS for $10 \mathrm{~min}$, then the brains were removed from the skull (protocol A). Animals used in chemogenetic behavioral experiments were perfused with $0.1 \mathrm{M}$ phosphate buffered saline (PBS) for 1 minutes, then with 4\% PFA in PBS for 20 minutes. Brains were taken out and post-fixed for $24 \mathrm{~h}$ in fixative at $4^{\circ} \mathrm{C}$ then cryoprotected by $20 \%$ glucose-PBS solution for 24 hours at $4^{\circ} \mathrm{C}$ (protocol B). For block-face scanning electron microscopy, mice were perfused with $0.1 \mathrm{M}$ phosphate-buffered saline (PBS, pH 7.4) solution for $30 \mathrm{sec}$, followed by a fixative solution containing 2\% PFA and 1\% glutaraldehyde (GA) and 15\% picric acid for 5 minutes (all salts were obtained from Sigma-Aldrich); the brains were then removed from the skull on ice, cut sagittally and coronally into 5 pieces and immersion fixed in 4\% PFA and 0,1\% GA in 0.1 M phosphatebuffer (PB, pH 7.4) for 4 hours at room temperature, then the fixative was washed out with $0.1 \mathrm{M} \mathrm{PB}$ (protocol C). After perfusions brains were cut into $30 \mu \mathrm{m}$-thick sections using a sliding microtome or to 50,60 or 100 $\mu \mathrm{m}$-thick sections using a vibrating microtome (Leica VT1200S or Vibratome 3000).

\section{Antibodies}

The list and specifications of the primary and secondary antibodies used can be found in Suppl. Table S1-S2. The specificities of the primary antibodies were extensively tested, using either knock-out mice or other reliable methods. Secondary antibodies were extensively tested for possible cross-reactivity with the other antibodies used, and possible tissue labeling without primary antibodies was also tested to exclude autofluorescence or specific background labeling. No specific-like staining was observed under these control conditions. Combinations of the used primary and secondary antibodies in the different experiments are listed in Supplementary Table S3-S4.

\section{Fluorescent immunohistochemistry and laser-scanning confocal microscopy}

Perfusion-fixed sections were washed in $0.1 \mathrm{M} \mathrm{PB}$ (pH 7.4), and incubated in $30 \%$ sucrose overnight for cryoprotection. Sections were then freeze-thawed over liquid nitrogen three times for antigen retrieval. Sections were subsequently washed in PB and Tris-buffered saline (TBS, pH 7.4) and blocked in 1\% human 
serum albumin in TBS (HSA; Sigma-Aldrich) and then incubated in a mixture of primary antibodies for 48-72 $\mathrm{h}$. This was followed by extensive washes in TBS, and incubation in the mixture of appropriate secondary antibodies overnight. We used DAPI staining (Sigma-Aldrich) to visualize cell nuclei. Then, sections were washed in TBS and PB, dried on slides and covered with Aquamount (BDH Chemicals Ltd) or with Fluoromount$G$ Mounting Medium (Invitrogen). For the viral anterograde and retrograde tracing experiments, each injection site was reconstructed from $50 \mu \mathrm{m}$ sections using a Zeiss Axioplan2 microscope. Every part of the injected tissue containing even low levels of tracer was considered as part of the injection site. Sections were evaluated using a Nikon A1R confocal laser-scanning microscope system built on a Ti-E inverted microscope with a 10x air objective or with a 0.45 NA CFI Super Plan Fluor ELWD 20XC or with a 1.4 NA CFI Plan Apo VC 60x oil objective or with a Nikon Ni-E C2+ confocal system equipped with a 0.75 NA Plan Apo VC DIC 20x objective, both operated by NIS-Elements AR 4.3 software. Regions of interests were reconstructed in z-stacks; distance between the focal planes was $0.5 \mu \mathrm{m}$ for examined synaptic contacts and $2 \mu \mathrm{m}$ for examined neuronal somata. In case of the monosynaptic rabies tracing experiments, coronal sections spaced at $300 \mu \mathrm{m}$ were prepared from the whole brain for confocal laser-scanning microscopy, and every trans-synaptically labeled cell was scanned using a Nikon Ni-E C2+ confocal system equipped with a 0.13 NA Plan Fluor $4 \times$ objective operated by NIS-Elements AR 4.3 software. The cell counting was performed using the Adobe Photoshop CS6 software.

\section{Immunoperoxidase labeling for virus injection localization in chemogenetic experiments}

Red fluorescent protein (RFP) was labeled with a rabbit polyclonal antibody (Rockland Immunochemicals, Inc., Pennsylvania, USA). The primary antibody was detected by biotinylated anti-rabbit goat serum (Rockland Immunochemicals, Inc., Pennsylvania, USA) and avidin-biotin complex diluted in TBS (1:1000, Vectastain ABC Kit, Vector Laboratories, USA). The peroxidase reaction was developed in the presence of diaminobenzidine tetrahydrochloride $(0.2 \mathrm{mg} / \mathrm{ml})$, nickel-ammonium sulphate $(0.1 \%)$ and hydrogen peroxide $(0.003 \%)$ dissolved in TBS. The sections were mounted on glass slides and covered by a DPX mounting medium.

For identification of virus location, microscopic images were digitized by an OLYMPUS CCD camera using a $4 x$ magnification lens. The extent and anatomical localization of viral gene expression was determined by the atlas of Paxinos and Franklin (2012).

\section{Immunogold-immunoperoxidase double labeling and electron microscopy}

Perfusion-fixed sections were washed in 0.1 M PB for 1 hour, then cryoprotected by incubation in 30\% sucrose overnight and freeze-thawed three times over liquid nitrogen. For synaptic detection of N-methyl-Daspartate (NMDA) receptor GluN1 or GluN2A subunit, sections were pretreated with $0.2 \mathrm{M} \mathrm{HCl}$ solution containing $2 \mathrm{mg} / \mathrm{ml}$ pepsin (Dako) at $37^{\circ} \mathrm{C}$ for $6 \mathrm{~min}$. Then sections were blocked in $1 \%$ HSA in TBS, followed by incubation in a mixture of primary antibodies. After repeated washes in TBS, sections were incubated in blocking solution (Gel-BS) containing $0.2 \%$ cold water fish skin gelatin (Aurion) and $0.5 \%$ HSA in TBS for $1 \mathrm{~h}$. Sections were then incubated in mixtures of secondary antibody solutions overnight. After intensive washes in TBS, the sections were treated with $2 \%$ glutaraldehyde in $0.1 \mathrm{M} \mathrm{PB}$ for $15 \mathrm{~min}$ to fix the gold particles in the tissue. To develop the labeling for MRR vGluT2 fibers, this was followed by incubation in avidin-biotinylated horseradish peroxidase complex (Elite ABC; 1:300; Vector Laboratories) diluted in TBS for $3 \mathrm{~h}$. The immunoperoxidase reaction was developed using 3-3'-diaminobenzidine (DAB; Sigma-Aldrich) as chromogen. To enlarge immunogold particles, this was followed by incubation in silver enhancement solution (SE-EM; Aurion) for 40-70 min at room temperature. The sections were treated with $0.5 \%$ osmium tetroxide in $0.1 \mathrm{M}$ PB on ice and they were dehydrated in ascending ethanol series and in acetonitrile and embedded in Durcupan (ACM; Fluka). During dehydration, the sections were treated with $1 \%$ uranyl-acetate in $70 \%$ ethanol for 20 min. After this, 70-100nm serial sections were prepared using an ultramicrotome (Leica EM UC6) and collected on 
single-slot copper grids. Sections were examined using a Hitachi H-7100 electron microscope and a Veleta CCD camera driven by the iTEM 5.0 software (Olympus). Randomly sampled terminals of the MRR establishing synaptic contacts in the LHb and MS/VDB were always fully reconstructed.

\section{Silver-gold intensified and nickel-intensified immunoperoxidase double labeling (SI-DAB/DAB-Ni)}

Perfusions, sectioning and incubations of sections in primary antibody solutions were performed as described above. In the SI-DAB reaction, it was followed by subsequent washes in the appropriate secondary antibody solutions for $24 \mathrm{~h}$ in TBS. After subsequent washes in TBS and incubation in avidin-biotin-peroxidase complex for $3 \mathrm{~h}$ (ABC Elite 1:300, Vector Laboratories), ammonium nickel sulphate-intensified 3-3'diaminobenzidine (DAB-Ni) was used for the development of immunoperoxidase reaction. This reaction was further intensified with silver-gold (SI-DAB) as described in detail in Dobó et al. 2011. This intensification step converts the labeling from homogenous to granular by loading fine gold particles onto the DAB-Ni deposit. After washes in TBS, sections were blocked in 1\% HSA for $1 \mathrm{~h}$ and incubated in primary antibody solutions for the second DAB-Ni reaction for 48-72 $\mathrm{h}$. This step was followed by incubation with an ImmPRESS secondary antibody solution overnight. The second immunoperoxidase reaction was developed by DAB-Ni, resulting in a homogenous deposit, which was clearly distinguishable from the silver-gold intensified SI-DAB at the electron microscopic level (69). Further dehydration, contrasting and processing of the sections for electron microscopy was performed as described above.

\section{Sample preparation for 3D block face scanning electron microscopy (BF-SEM)}

Virally injected vGluT2-Cre mice, 4-6 weeks after the injection, were sacrificed for BF-SEM experiments. Mice were anesthetized and perfused according to "protocol C" as described above. $100 \mu \mathrm{m}$ thick sections were cut using a vibrating microtome from the blocks containing the lateral habenula and 50 $\mu \mathrm{m}$-thick sections were cut from the blocks containing the MRR. Sections were washed in PB for 1 hour, then cryoprotected by incubation in 30\% sucrose overnight and freeze-thawed three times over liquid nitrogen. Then, sections were blocked in $1 \%$ HSA in TBS, followed by incubation in a mixture of primary antibodies. After repeated washes in TBS, sections were incubated in blocking solution (Gel-BS) containing $0.2 \%$ cold water fish skin gelatin (Aurion) and 0.5\% HSA in TBS for $2 \mathrm{~h}$. Sections were then incubated in mixtures of secondary antibody solutions for 2 days. After intensive washes in TBS, the sections were treated with $2 \%$ glutaraldehyde in $0.1 \mathrm{M}$ PB for $30 \mathrm{~min}$ to fix the gold particles in the tissue. Then gold conjugated secondary was intensified with GOLDENHANCE ${ }^{\mathrm{TM}}$ EM Plus Kit (Nanoprobes). To get high contrast for BF-SEM equipped with field emission gun, we used a modified protocol of Deerinck et al. (70). Briefly, sections were postfixed in $1 \%$ osmiumtetroxide reduced with $0,75 \%$ potassium ferrocyanide, on ice for 1 hour, followed by thiocarbohydrazide (TCH) incubation for 30 minutes. Then sections were treated with $1 \%$ osmium-tetroxide solution for 30 minutes, and then for another 30 minutes with $1 \%$ aqueous uranyl-acetate in dark. Then, en bloc Walton's lead aspartate staining was performed at $60^{\circ} \mathrm{C}$ for 30 minutes. After each step, sections were washed $5 \times 3$ minutes in distilled water. Finally, the sections were dehydrated through ascending ethanol series on ice (from $30 \%$ to absolute ethanol for $2 \times 5$ minutes) and then infiltrated with acetonitrile for $2 \times 10$ minutes (first on ice, second at room temperature). The sections were transferred into aluminum boats and infiltrated with embedding resin (Epoxy Embedding Medium Kit, Sigma-Aldrich, hard mixture) overnight. The next day, sections were mounted on glass slides, covered and baked at $60^{\circ} \mathrm{C}$ for 48 hours. After baking, a small region of interest was cut out with razor blade and mounted on an aluminum specimen pin with Silver Conductive Epoxy, H2OE EPO-TEK ${ }^{\circledR}$ (Ted Pella) and baked at $60^{\circ} \mathrm{C}$ for 48 hours. After the conductive epoxy was polymerized, samples were trimmed with an ultracut (EM UC6, Leica, Wetzlar, Germany) to create a cube with a glass knife. The cube shaped block ( 400 $\mu \mathrm{m} \times 400 \mu \mathrm{m} \times 75 \mu \mathrm{m}$ ) was sputter coated with gold using a Rotary-Pumped Sputter Coater (Quorum 
Technologies, Q150R ES). The samples were stored in dust free holders and they were transferred into the vacuum chamber for at least one night before using them for BF-SEM imaging.

\section{BF-SEM imaging and image analysis}

We used a FEl Apreo field emission gun (FEG) SEM equipped with an in situ ultramicrotome (VolumeScope, FEl, Eindhoven, The Netherlands) and a T1 "in column" detector to record the backscattered electrons (BSE) from each voxel. For all image stacks, we collected BSE images with MAPs software from 6,5 $\mathrm{mm}$ working distance at high vacuum with fixed 0,1 nA beam current, $2.27 \mathrm{kV}$ high voltage, 1,25 $\mu$ s pixel dwell time, with a voxel size of $4 \mathrm{~nm} \times 4 \mathrm{~nm} \times 70 \mathrm{~nm}$. The images in the z-stacks measured $16384 \times 16383$ pixels with $70 \mathrm{~nm}$ thickness, and the final z-stacks contained 300 such slices, so the overall volume for each animal was cca. $90200 \mu \mathrm{m}^{3}$. All image post-processing was done in Fiji. The BF-SEM stacks were imported into FIJ ImageJ TrakEM2 and fine aligned. For segmentation, we used area lists for axonal profiles, mitochondria, and profile lists for synapses. Manual segmentation was performed on a Wacom Cintiq 27QHD Creative Pen and display tablet. After, synaptic surface measurements were finished using the built-in plugin of TrakEM2, data were retrieved by custom made excel datasheet and analyzed with Tibco Statistica 13.4. After segmentation, the models were exported in .obj format and imported into Blender (Blender Foundation, Amsterdam, The Netherlands) for further investigation and visualization.

\section{Stereology measurements}

Unbiased design-based stereological measurements were carried out using the optical fractionator method (71-73), which is based on the principle that one can accurately define the number of cells in the volume of interest by counting them in a predetermined fraction of the given volume (74). To get the total cell numbers, the number of counted cells is multiplied by the reciprocal of three different fractions: section, area, and thickness sampling fractions (75). Using systematic random sampling in each experiment, every second section of the MRR was used; therefore, section sampling fraction was 0.5 . In mounted sections, cells were counted only within a fraction of a predefined grid area. In the MRR, this fraction was $15^{2} / 80^{2} \mu \mathrm{m}$, in the paramedian raphe, this fraction was $10^{2} / 80^{2} \mu \mathrm{m}$. Finally, thickness sampling fraction was $15 / 28 \mu \mathrm{m}$, because the average mounted section thickness was $28 \mu \mathrm{m}$ and counting was performed only in a 15- $\mu \mathrm{m}$-high counting cube. We used a guard zone of minimum $5 \mu \mathrm{m}$ of tissue above and below the counting cube; however, for maximum accuracy, thickness sampling fractions were determined at every sampling site. Cells were counted inside the counting cubes or if they touched one of the 3 inclusion planes of the counting cubes. Cell counting was carried out in Stereo Investigator 10.0 stereology software (MBF Bioscience), while cells were identified parallel using NIS Elements AR 4.3 software.

\section{In vitro slice preparation}

In all slice studies, mice were decapitated under deep isoflurane anesthesia. The brain was removed and placed into an ice-cold cutting solution, which had been bubbled with $95 \% \mathrm{O}_{2} / 5 \% \mathrm{CO}_{2}$ (carbogen gas) for at least $30 \mathrm{~min}$ before use. The cutting solution contained the following (in $\mathrm{mM}$ ): 205 sucrose, $2.5 \mathrm{KCl}, 26$ $\mathrm{NaHCO}, 0.5 \mathrm{CaCl}_{2}, 5 \mathrm{MgCl}_{2}, 1.25 \mathrm{NaH}_{2} \mathrm{PO}_{4}, 10$ glucose. Then, coronal slices of $300 \mu \mathrm{m}$ thickness were cut using a Vibratome (Leica VT1000S). After acute slice preparation, slices were placed into an interface-type holding chamber for recovery. This chamber contained standard ACSF at $35^{\circ} \mathrm{C}$ that gradually cooled down to room temperature. The ACSF solution contained the following (in $\mathrm{mM}$ ): $126 \mathrm{NaCl}, 2.5 \mathrm{KCl}, 26 \mathrm{NaHCO}_{3}, 2 \mathrm{CaCl}_{2}, 2$ $\mathrm{MgCl}_{2}, 1.25 \mathrm{NaH}_{2} \mathrm{PO}_{4}, 10$ glucose saturated with carbogen gas. NBQX was ordered from Hello Bio Inc., and AP5 was from Tocris Bioscience. Drugs were administered from stock solutions via pipettes into the ACSF containing superfusion system. All other salts were obtained from Sigma-Aldrich or Molar Chemicals KFT. 


\section{Intracellular recordings}

The composition of the intracellular pipette solution was the following (in $\mathrm{mM}$ ): $110 \mathrm{~K}$-gluconate, 4 $\mathrm{NaCl}, 20$ HEPES, $0.1 \mathrm{EGTA}, 10$ phosphocreatine, 2 ATP, $0.3 \mathrm{GTP}, 3 \mathrm{mg} / \mathrm{ml}$ biocytin adjusted to $\mathrm{pH} 7.3-7.35$ using $\mathrm{KOH}$ (285-295 mOsm/L). Whole-cell series resistance was in the range of 5-15 M $\Omega$. Series resistance was not compensated, but was frequently monitored, and cells, where the values changed more than $25 \%$ during recording were discarded from further analysis. Voltage measurements were not corrected for the liquid junction potential. To record glutamatergic currents, membrane potential was clamped far ( $65 \mathrm{mV})$ from $\alpha$ amino-3-hydroxy-5-methyl-4-isoxazolepropionic acid (AMPA)/NMDA-R reversal potential. To block AMPA and NMDA currents, NBQX $(20 \mu \mathrm{M})$ and AP-5 $(50 \mu \mathrm{M})$ were added to the recording solution. For illumination, we used a blue laser diode ( $447 \mathrm{~nm}$, Roithner LaserTechnik $\mathrm{GmbH}$ ) attached to a single optic fiber (Thorlabs) positioned above the lateral habenula.

\section{Digital signal processing, analysis and statistics for in vitro experiments}

All data were processed and analyzed off-line using standard built-in functions of Python 2.7.0. Latency was defined as a time between light stimulus onset and time of reaching $10 \%$ of maximal EPSC amplitude. Throughout this manuscript, for in vitro electrophysiology data, we used median, first, and third quartiles for the description of data groups because they did not show Gaussian distribution.

\section{Stereotaxic surgeries for electrophysiological recordings in head-fixed mice}

Animals were anesthetized with isoflurane and mounted in a stereotaxic frame (David Kopf Instruments, Tujunga, CA). The cranium was exposed, the bone was dried. For the future hippocampal and median raphe recording sites, 2 cranial windows ( $1.5 \mathrm{~mm}$ width), and for the optical fiber, a hole $(0.5 \mathrm{~mm}$ diameter) were drilled into the cranium (from Bregma: $2.5 \mathrm{~mm}$ caudal and $2.5 \mathrm{~mm}$ lateral for the hippocampal window; $6.2 \mathrm{~mm}$ caudal and $0 \mathrm{~mm}$ lateral for median raphe window and $4.5 \mathrm{~mm}$ caudal and $0 \mathrm{~mm}$ lateral for the optical fiber). A hole was drilled above the cerebellum for the insertion of the ground electrode. A headplate was fixed to the skull surface using dental acrylate (Paladur). Finally, the skull surface and the holes were covered with a silicone sealant. After surgery, the mouse was continuously monitored until recovered, as demonstrated by their ability to maintain sternal recumbence and to exhibit purposeful movement.

\section{In vivo electrophysiological recording}

After a recovery period of 3-7 days, the mice were water restricted and habituated for 10 to 14 days to the spherical treadmill setup with their head fixed. The animal weights were monitored and when a mouse reached $85 \%$ of the initially measured baseline weight, the daily volume of water supplement was individually adjusted in order to maintain this $85 \%$ target weight. During the habituation period the animals learned to took water drops from a lick port positioned in front of the animals' mouth.

On the day of the experiment the animal was head-fixed above the air supported spherical treadmill. Hippocampal silicone probe (Buzsaki32 or Buzsaki64 type silicon probe, NeuroNexus, Ann-Arbor, MI) was lowered through the cranial window into the hippocampal CA1 pyramidal layer. The pyramidal layer was identified physiologically by increased unit activity and the occurrence of ripple events. The optical fiber was lowered to a $4.2 \mathrm{~mm}$ depth from the skull surface. The median raphe probe (Buzsaki32 or Poly5 type silicon probe, NeuroNexus, Ann-Arbor, MI) was inserted and lowered to a depth of $4.4 \mathrm{~mm}$ in an angle of 20 degree from caudal. Before the insertion of the probe and the optical fiber, they were coated with the lipophilic fluorescent dye, Dil (Thermo Fischer Scientific) for later histological verification of their location. Ground electrode was placed above the cerebellum.

The median raphe probe was advanced by a micromanipulator until multiple median raphe unit activity was detected in a depth of 4-8-5.2 $\mathrm{mm}$. Once the probes were positioned at their final position, recording was 
started. Following a 10-15 minutes baseline recording period LED flash ( $200 \mathrm{~ms}$, yellow), air puff ( $200 \mathrm{~ms}$ ) and rewarding water drops were applied at random intervals. Electrophysiological recordings were performed by a signal multiplexing head-stage. Signals were acquired at 20k sample/s (KJE-1001, Amplipex Ltd, Hungary). Mouse locomotor activity was recorded with an optical computer mouse positioned close to the spherical treadmill at the equator.

To represent the spectral components of hippocampal LFP activity on Fig. 4 we obtained the Morlet wavelet decomposition of the hippocampal recording. For calculating the theta to delta ratio, hippocampal LFP oscillations (delta: 1-4 Hz, theta: $5-12 \mathrm{~Hz}$ ) were separated on the basis of the Hilbert magnitude of the bandpass-filtered signal. The average Hilbert magnitudes were calculated before and during the laser stimulation (in $10 \mathrm{~s}$ long windows) and ratios (average theta / average delta magnitudes) were calculated in each period. All in vivo data were analyzed in Igor Pro 8 (Wavemetrics).

\section{Optogenetical tagging}

At the end of each recording session brief laser pulses were applied ( $n=30,1 \mathrm{~ms}$ at $4 \mathrm{~Hz}, 473 \mathrm{~nm}$ ) for offline identification of responsive units. Units were categorized as "tagged" if followed the laser pulse with short latency (within $4 \mathrm{~ms}$ ) and more than $50 \%$ success rate.

Neuronal spikes were detected and automatically sorted from the high-pass filtered local field potential recordings $(0.5-5 \mathrm{kHz})$ by a template matching algorithm Spyking-Circus (76), followed by manual adjustment of the clusters using the Phy software (77) to obtain well-isolated single units. Cluster isolation quality was estimated by calculating the interspike interval index for each cluster (78); poor quality clusters were discarded.

\section{Quantification and statistical analysis of in vivo physiological experiments}

The mean baseline firing rate values and standard deviations were calculated from a 4 second time window preceding stimulus onset. Changes in firing rate was declared significant if it deviated more than 2 standard deviations from the mean baseline value (z-score larger than 2 or smaller than -2 ) in a $200 \mathrm{~ms}$ time window after stimulus onset. Both responsive and non-responsive neurons distributed across animals.

All statistical analyses were performed with standard Igor Pro 8 functions. For paired comparisons the Wilcoxon signed rank test was used. All graphs indicate mean +/- SEM. For significance, $p=0.05$ was used.

\section{Real time place aversion (RTPA) and conditioned place aversion (CPA) tests}

After optic fiber implantations, mice were transferred to the animal room of the behavioral unit of the institute to rest, then they received 5 days of handling. On the 6th day (habituation day), mice were placed into a chamber $(40 \mathrm{~cm} \times 20 \mathrm{~cm} \times 20 \mathrm{~cm}$, divided into two areas with striped walls and floor on the one side and dotty walls and floor on the other side) for habituation for $10 \mathrm{~min}$. After each experiment, the chamber was washed with "macadamia-scented" soap. On the 7th day (real-time place aversion), mice were placed in into the non-stimulated side of the chamber and left moving freely for $15 \mathrm{~min}$. Blue laser stimulation ( $5 \mathrm{~ms}$ pulses at $25 \mathrm{~Hz}$ with $10-15 \mathrm{~mW}$ intensity, $473 \mathrm{~nm}$ ) started when the animal entered the stimulation side. On the 8th day (conditioned place aversion) mice were tested without laser stimulation for $5 \mathrm{~min}$ in the same chamber. The experiments were performed in a counter-balanced way, some mice received stimulation in the striped side, while others in the dotty side, to exclude the possibility of innate aversion for any context. The behavior of the mice was recorded with a Basler acA1300-60gc camcorder. Experimental data were collected and analyzed using the Noldus EthoVision 13.0 and Tibco Statistica 13.4 software. 


\section{Statistical analysis and evaluation of RTPA and CPA data}

To precisely examine whether mice distinguished the stimulated and non-stimulated sides in the RTPA and CPA paradigms, the chamber was divided into three virtual areas: a stimulation area, a non-stimulated area and a so-called decision zone. The decision zone was a rectangle with an area of $14 \mathrm{~cm} \times 8 \mathrm{~cm}$ ( $14 \%$ of the total chamber area of $800 \mathrm{~cm}^{2}$ ) placed in the middle of the chamber. We excluded the time spent in the decision zone to exclude any possible uncertainty of the detection of the position of the mice in the middle of the chamber. To define the percentage of time spent by the mice in the different contexts, we divided the time spent in the stimulation area with the sum of the time spent in the stimulation area plus the non-stimulated area.

\section{Operant conditioning}

On the 9th day (after RTPA and CPA tests), mice were started to be kept on a diet to keep their body weight between $80 \%-90 \%$ of the original. They were also habituated to the reward pellets (Bio-Serv, NJ, USA) used in the operant conditioning paradigm for 3 days. The diet was held for the whole duration of the operant conditioning tests to support the motivational drive to poke for pellet rewards.

On the 12th day (Fig. 5C), mice were put in an automatized operant conditioning chamber system (Med Associates Inc., VT, USA), and they were conditioned to nose-poke for pellet rewards (45mg) for 30 minutes/day for 10 days. The chamber was put in a dark box, but it was lit by a house light. Every correct nosepoke was followed by a 15 seconds-long interval, when the house light turned off and mice did not receive pellet rewards even if they performed nose-pokes. This interval was inserted into the experiment to help the mice learn the conditioning rule, and to allow them time to consume the pellets. After this interval, mice could perform a correct nose-poke again to receive pellets. The number of total nose-pokes was defined as the sum of the correct nose-pokes and the interval nose-pokes.

The operant conditioning chambers were washed after every individual mouse with distilled water. From the 20th day, mice were connected to a dummy fiber patch for habituation. On the 22th day (poke stimulation), mice received 5 seconds blue laser stimulation ( $5 \mathrm{~ms}$ pulses at $25 \mathrm{~Hz}$ with $10-15 \mathrm{~mW}$ intensity, 473 $\mathrm{nm}$ ), after every correct nose-poke. After the $30 \mathrm{~min}$ stimulation period, mice were placed back into their home cages and received food ad libitum again for 3 days to regain their original weight.

\section{Statistical analysis and evaluation of operant conditioning tests}

We compared the number of total-nose pokes performed by the individual mice in a pairwise manner between the 21th (poke baseline) and 22th (poke stimulation) days of the experiment. Then, we normalized the number of the total nose-pokes performed by a mouse on the 22th day to the number of the total nosepokes performed by the same mouse on the 21th day, respectively (Poke ratio, stimulation/base). These ratios were compared between the groups of ChR2-expressing and CTRL virus expressing mice.

\section{Optogenetic contextual fear conditioning (Opto-CFC)}

After operant conditioning, mice rested for 3 days to regain their original weight. On the 25th day, mice were placed into a plexiglass foot-shocking chamber (Suppl. Fig. 6C, $25 \mathrm{~cm} \times 25 \mathrm{~cm} \times 31 \mathrm{~cm}$ ) that was enriched with a specific combination of olfactory (baby soap scent), visual (grey wall), spatial (rectangular chamber walls) and tactile (metal bars on the floor) cues. Mice were allowed to freely move in the environment for 3 minutes to record baseline freezing levels. After this, mice received 15 seconds of blue laser stimulation ( 5 ms pulses at $25 \mathrm{~Hz}$ with $10-15 \mathrm{~mW}$ intensity, $473 \mathrm{~nm}$ ) that was repeated 10 times with 15 seconds interstimulation interval. After receiving the last stimulation, mice were kept in the context for another 3 minutes. 24 hours later, on the 26th day, mice were placed back to the same context to read out freezing levels. The behavior of mice was recorded with a Basler acA1300-60gc camcorder, and freezing behavior was analyzed 
manually using the Solomon Coder (https://solomoncoder.com) software. The experimenter evaluating freezing levels was blind to the conditions and treatment of the mice. Mice displaying higher than $5 \%$ baseline freezing levels were excluded from further analysis.

\section{Delayed cued fear conditioning (CuedFC)}

After optic fiber implantations, mice were transferred to the animal room of the behavioral unit, where they received 5 days of handling. On the 6 th day, mice were placed into the first environmental context (environment "A") in a plexiglass shocking chamber $(25 \mathrm{~cm} \times 25 \mathrm{~cm} \times 31 \mathrm{~cm})$ that was enriched with a specific combination of olfactory (macadamia nut scent), visual (black dotted wall with white background), spatial (bended chamber walls), auditory (white noise) and tactile (metal bars on the floor) cues. Mice were allowed to freely move in the first environment for 3 minutes to record baseline freezing levels. After this, mice received 3 shocks ( 2 seconds, $2 \mathrm{~mA}$ intensity, 60 seconds inter-shock interval) that were paired with an auditory cue (30s long sound at $7500 \mathrm{~Hz}$ ). The footshocks and the auditory cues were co-terminated each time. Footshocks were paired with 6 seconds-long yellow laser light illumination (10-15 mW intensity at the tip of the optic fiber at $593 \mathrm{~nm}$ wavelength), which was precisely aligned with the shocks, starting 2 seconds before the shock onset and finishing 2 seconds after shock offset. After receiving the last shock, mice were kept in the context for another 30 seconds. After 3 successfully delivered shocks, mice were placed back into their home cages for 24 h. On the 7th day, mice were placed back into the environment " $A$ " for 3 minutes to record freezing behavior related to the contextual fear memories. 24 hours later, on the 8th day, mice were placed into a second environmental context (environment "B") with distinct olfactory (citrus scent), visual (black and white striped wall), spatial (square shaped chamber), auditory (no noise) and tactile (plastic floor) cues. For 3 minutes, generalized fear levels were recorded in environment " $B$ ". After this, mice were presented with the auditory cue for 1 minute to record freezing behavior related to the cued fear memories. After the termination of the auditory cue, mice were kept in the environment " $B$ " for 1 minute to read out post-cue freezing levels. The behavior of mice was recorded with a Basler acA1300-60gc camcorder and freezing behavior was analyzed manually using the Solomon Coder software. The experimenter evaluating freezing levels was blind to the conditions and treatment of the mice. Mice displaying higher than $5 \%$ baseline freezing levels in environment " $A$ " were excluded from the further analysis.

\section{Behavioral test battery for chemogenetic experiments}

We carried out a series of behavioral tests with mice that were injected either with the hM3Dqcontaining virus (that expressed a clozapine-N-oxide (CNO)-sensitive, excitatory G-protein-coupled receptor plus a fluorescent protein) or with a control virus (that expressed only a fluorescent protein). All behavioral tests were done between 9:00 am - 1:00 pm, at the early phase of the active period under reversed $12 \mathrm{~h}$ lightdark cycle. $48-72 \mathrm{~h}$ rest was left for the mice between each tests. The test cages were cleaned with $20 \%$ ethanol between animals in each test. In order to activate the hM3Dq-virus CNO (1 $\mathrm{mg} / \mathrm{kg}$ in $10 \mathrm{ml}$ saline, Tocris) was injected intraperitoneally 30 minutes before each behavioral test. Not all tests were conclusive either because of technical difficulties and/or because of insufficient number of animals for the given test. We briefly describe all tests, but give all details only about those that were fully evaluated and reported in this study. On day 1 , mice were tested in a sociability test, in which two small cylinders were placed in the cage and after habituation, an unfamiliar mouse was placed in one of the cylinders. Then a familiar mouse was placed into one cylinder and an unfamiliar new mouse was put in the other cylinder. These tests were inconclusive. On day 3, we carried out a social interaction test, as described below. On day 5, we tested mice in an elevated plus maze test apparatus that had two open and two closed arms, crossed in the middle, perpendicularly with each other. Mice were put into the center and could freely explore the apparatus for 5 minutes. These tests were inconclusive. On day 8 , we carried out a resident intruder test, as described below. On day 10, we tested 
locomotor activity in a Y-maze test, as described below. On day 12, we explored behavioral changes to cat odor. A perforated plastic bottle $(50 \mathrm{ml})$ filled with used cat litter was put into one of the corners of the test arena and mice could freely explore. These tests were inconclusive. On day 15, we carried out a self-care test, in which a few drops of $10 \%$ sucrose solution was splashed onto the back of the mice. These tests were inconclusive. On day 17, mice were forced to swim for 6 minutes individually in an open glass cylinder with 20 $\mathrm{cm}$ of fresh water at $23-25^{\circ} \mathrm{C}$. They could not reach the bottom of the tank and were unable to escape. These tests were inconclusive. On day 19, we carried out an anhedonia test, as described below. Tests were video recorded and analyzed later by an observer blind to the treatment protocols using Ethovision 10.0 (Noldus Information Technology, The Netherlands), Solomon Coder (https://solomoncoder.com) or H77 (Mihály Dobos-Kovács, 2017) software. After this battery of behavioral tests, mice were sacrificed, and their adrenal glands were removed and their weight measured.

\section{Social interaction test}

Social interaction test measures social and anxiety-like and aggressive behavior, and it was performed on the day 3 of the battery. Mice were confronted with an unknown conspecific with the same size and treatment, in a new environment, with bright illumination, which increases the anxiety-like behavior of mice. The day before the test, habituation was carried out for $2 \times 15$ min consisting of single housing in the test cage $(41.3 \times 26 \times 29.8 \mathrm{~cm}$, GeoMaxi, Ferplast, Italy). This reduced the novelty of the environment, with the aim to enhance social behavior during the test. During the test phase, two mice with the same treatment were taken together into the test cage for 10 minutes. Duration, frequency and percentage of the following behaviors were recorded: social (direct sniffing of the conspecific), aggressive, (biting, chasing, boxing, aggressive grooming, offensive upright posture and mounting), defensive (escape from conspecific) and other (exploring, grooming).

\section{Resident intruder test}

Resident intruder test was conducted to measure territorial aggression and it was performed on the day 8 of the battery (79). A 20\% smaller intruder mouse was placed into the subject's home cage for 10 minutes. The same parameters were measured as in the social interaction test. These tests were performed under red light illumination.

\section{Locomotor activity in Y-maze}

In a Y-maze, we observed the locomotor activity of mice (Suppl. Fig. 4I), and it was performed on the day 10 of the battery. The apparatus had three arms $(25 \mathrm{~cm} \times 5 \mathrm{~cm} \times 21 \mathrm{~cm})$ at 120 degrees. Mice could freely explore the maze for $5 \mathrm{~min}$.

\section{Sucrose preference test}

Anhedonia, a typical symptom of depression, is reflected by neglect of the rewarding sucrose. This test was performed on the day 19 of the battery. The experiment started with a habituation phase. On the first day, two identical bottles of water were available. One day later, both of the bottles were filled with $1 \%$ sucrose solution. Then, after 15-hour liquid deprivation, we tested mice for 5 hours in a cage with one bottle of water and another one with $1 \%$ sucrose solution. Pre-weighted bottles were used. The sucrose preference was the percentage of sucrose solution consumed, relative to the total liquid consumption. The formula was as follows: $\mathrm{SP}=($ sucrose intake $/[$ sucrose consumption + water consumption $]) \times 100 \%$ 


\section{Statistics for behavioral and in vivo experiments}

In case of data groups that did not display a Gaussian distribution, we used median and $25 \%-75 \%$ interquartile range to describe data. We used means and standard deviations to describe data groups that displayed Gaussian distribution. To test for statistical differences, we used the non-parametric Mann-Whitney U-test or parametric Student's t-test in independent data populations, and we used the Wilcoxon's signedrank test in non-parametric dependent data populations. Statistical difference have always been tested using two-sided tests. Homogeneity of variance was tested using F-test and if it was significant then populations were compared using nonparametric tests. For indicating significance levels on figures, we used the following rules, $*$ : $p<0.05,{ }^{* *}: p<0.01, * * *: p<0.001$.

\section{Supplementary Text for Main Figures 1 to 8}

\section{Supplementary Data for Figure 1:}

Fig. 1G: Our measurements in 2 mice showed that at least 47\% (369/780) of eYFP-positive MRR terminals established synaptic contacts with TH-positive profiles, while at least $61 \%(97 / 160)$ of TH-positive cells received at least one synaptic contact from eYFP-positive MRR terminals.

Fig. 1L: Our measurements in 2 mice showed that at least 39\% (201/518) of vGluT2-positive LHb fibers established synaptic contacts with vGluT2-positive MRR profiles, and at least 55\% (48/88) of MRR vGluT2positive cells received at least one synaptic contact from mCherry-labelled LHb terminals.

Fig. 1P-T: Abbreviations: DR: dorsal raphe; LH: lateral hypothalamus; LDTg: laterodorsal tegmental nucleus; LHb: lateral habenula; LPO: lateral preoptic area; MHb: medial habenula; NI: nucleus incertus; PDTg: posterodorsal tegmental nucleus; VP: ventral pallidum.

\section{Supplementary Data for Figure 2:}

Fig. 2C: At least $81 \%$ (22/27, $n=2$ mice) of vGluT2-positive MRR synapses established in the LHb contain the GluN2A subunit, and $81 \%(9 / 11, n=1$ mouse) contain the GluN1 subunit of the NMDA-receptors, postsynaptically.

\section{Supplementary Data for Figure 3:}

Fig. 3C: Population data showing relative second and third EPSC amplitude distributions compared to the first EPSC for 10 cells are as follows (median [25\%-75\% quartiles]): $2 \mathrm{~Hz}: 0.80$ [0.79-0.94]; 0.78 [0.73-0.90]; $5 \mathrm{~Hz}$ : 0.73 [0.67-0.88]; 0.73 [0.64-0.91]; $10 \mathrm{~Hz}: 0.79$ [0.64-0.90]; 0.69 [0.65-0.82]; $20 \mathrm{~Hz}: 0.71$ [0.62-0.84]; 0.78 [0.58$0.86]$.

Fig. 3D: Population data showing EPSC amplitude distributions in pA are as follows (median [25\%-75\% quartiles]): control conditions: 65.78 [46.29-139.79]; NBQX/AP5: 0 [0-0.15], washout: 33.89 [30.24-60.54]. Population data showing latency distributions of the recorded cells in msec are as follows (median [25\%-75\% quartiles]): 2.05 [1.87, 3.05].

\section{Supplementary Data for Figure 4:}

Fig. 4F: Population data for the activity of tagged MRR vGluT2-neurons in baseline ( $4 \mathrm{~s}$ window before stimulus onset) and stimulated conditions ( $0.5 \mathrm{~s}$ window after stimulus onset), respectively are as follows (mean $+/$ SEM). Air puff: $0.41+/-0.04$ vs $0.99+/-0.13, n=41$ neurons, $p=1.1 * 10^{-4}$. LED flash: CTRL: $0.43+/-0.04$; STIM: $0.53+/-0.04, n=41$ neurons, $p=6.9 * 10^{-5}$. Reward: CTRL: $0.38+/-0.07$; STIM: $0.41+/-0.08, n=16$ neurons, $\mathrm{p}=0.98$; Wilcoxon signed-rank test. Air puff evoked significantly larger response than LED flash (comparing percentage elevation of baseline activity, LED: $57.9+/-20.0 \%$ vs air puff: $340.9+/-133.3 \%, n=41, p=4.3^{*} 10^{-4}$, Wilcoxon signed-rank test). By analyzing them separately, we found that no neuron decreased its firing. Firing 
frequency increased in 18 out of 41 neurons for air puffs, in 3 out of 41 for LED and with a longer latency in 1 out of 16 neurons for reward.

\section{Supplementary Data for Figure 5:}

Fig. 5B: Population data for the time spent in the stimulated area (\% of the sum of the time spent in the stimulated area). Results for RTPA test and CPA test for 21 CTRL- and 19 ChR2-mice that received light above the MRR (median [25\%-75\% quartiles]). During habituation (see Fig. S5B) CTRL: 44.10 [32.60-56.19]; ChR2: 52.84 [43.76-59.03]. During RTPA test, CTRL: 52.52 [44.27-68.72]; ChR2: 18.86 [12.70-36.64]. During CPA test, CTRL: 55.98 [37.37-80.27]; ChR2: 28.50 [13.95-54.11]. *: $p=0.045,{ }^{* * *}: p=3.4 \times 10^{-4}$, Mann-Whitney U-test.

Fig. 5D: Population data for the total number of nose-pokes for rewards at the base and stimulation performance for 11 CTRL- and 7 ChR2-mice in the operant conditioning task are as follows (median [25\%-75\% quartiles]). During base performance, CTRL: 39 [23-46]; ChR2: 57 [40-67]. During stimulation performance, CTRL: 35 [26-47]; ChR2: 35 [11-46]. *: $p=0.018$, Wilcoxon signed-rank test.

Fig. 5E: Population data for the ratios of stimulation/base performance of $11 \mathrm{CTRL}$ - and 7 ChR2-mice are as follows: (mean, +/-SD): CTRL: $1.06,+/-0.47$; ChR2: 0.56, +/- 0.31. *: $p=0.025$, Student's t-test.

\section{Supplementary Data for Figure 6:}

Fig. 6B: Population data for the percentage of time spent with aggressive behavior in the social interaction test for CTRL- and h3MDq-mice, respectively are as follows (median [25\%-75\% quartiles]): CTRL: 0.00 [0.00-0.00]; h3MDq: 6.89 [0.53-11.77]; **: p=0.002, Mann-Whitney U-test.

Population data for the aggressivity index in the social interaction test for CTRL- and h3MDq-mice, respectively are as follows (median [25\%-75\% quartiles]): CTRL: 0.00 [0.00-0.00]; h3MDq: 37.28 [3.68-52.56]; **: p=0.002, Mann-Whitney U-test.

Fig. 6C: Population data for the percentage of time spent with aggressive behavior in the resident-intruder test for CTRL- and h3MDq-mice, respectively are as follows (median [25\%-75\% quartiles]): CTRL: 0.42 [0.00-0.89]; h3MDq: 13.10 [1.17-22.37]. *: p=0.013, Mann-Whitney U-test.

Population data for the aggressivity index in the resident-intruder test for CTRL- and h3MDq-mice, respectively are as follows (median [25\%-75\% quartiles]): CTRL: 2.14 [0.00-5.37]; h3MDq: 36.05 [3.79-43.89]. *: p=0.032, Mann-Whitney U-test.

Fig. 6D: Population data in the sucrose preference test for CTRL- and h3MDq-mice, respectively are as follows (median [25\%-75\% quartiles]): CTRL: 55.11 [52.21-59.42]; h3MDq: 40.93 [38.60-48.80]. *: p=0.010, MannWhitney U-test.

\section{Supplementary Data for Figure 7:}

Fig. 7C: Our measurements in 2 mice showed that at least 79\% (497/626) of vGluT2-positive MRR terminals targeted PV-positive profiles, while at least 53\% (35/66) of PV-positive cells received at least one contact from these vGluT2-positive MRR terminals.

Fig. 7E: Our measurements in 2 mice showed that at least 67\% (14/21) of the synapses of MRR vGluT2-neurons contain the GluN2A subunit of the NMDA-receptors, postsynaptically in the MS/VDB.

Fig. 7K: Our measurements in 2 mice showed that at least $61 \%(138 / 225)$ of the cells projecting to the MS/VDB projected to the LHb as well.

\section{Supplementary Data for Figure 8:}

Fig. 8D: Population data in 7 mice for the movement speed of the mice and theta/delta ratios of the hippocampal network activity during baseline (10 s long window before laser onset) and stimulation (10 s long window after laser onset) periods in arbitrary units are as follows (mean +/-SEM): speed: base: 445.0 +/- 128.9; 
stim: $2235.3+/-646.2, p=0.016$, Wilcoxon signed-rank test; theta/delta ratios: base: $1.7+/-0.1$; stim: $2.6+/-$ $0.2, p=0.016$, Wilcoxon signed-rank test.

Fig. 8E: Population data for the contextual freezing levels (\% of total time) in the " $\mathrm{A}$ " environment for $13 \mathrm{CTRL}$ and 9 ArchT-mice are as follows (median [25\%-75\% quartiles]), CTRL: 13.68 [5.67-17.57]; ArchT: 3.00 [0.006.11]. *: $p=0.025$, Mann-Whitney U-test.

Population data for the generalized freezing levels (\% of total time) in the "B" environment for 13 CTRL- and 9 ArchT-mice are as follows (median [25\%-75\% quartiles]), CTRL: 7.77 [1.11-14.33]; ArchT: 0.00 [0.00-2.44]. *: $\mathrm{p}=0.026$, Mann-Whitney U-test.

Population data for the cued freezing levels (\% of total time) in the "B" environment for 13 CTRL- and 9 ArchTmice are as follows (median [25\%-75\% quartiles]), CTRL: 52.67 [43.33-59.67]; ArchT: 22.00 [21.33-29.00]. $*_{p}=0.011$, Mann-Whitney U-test. 


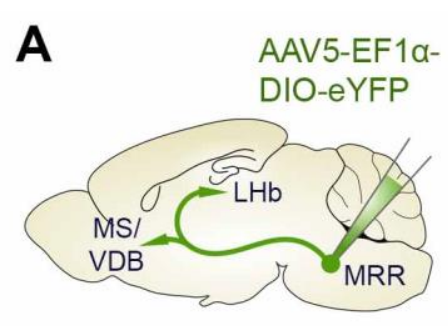

vGluT2-Cre mouse
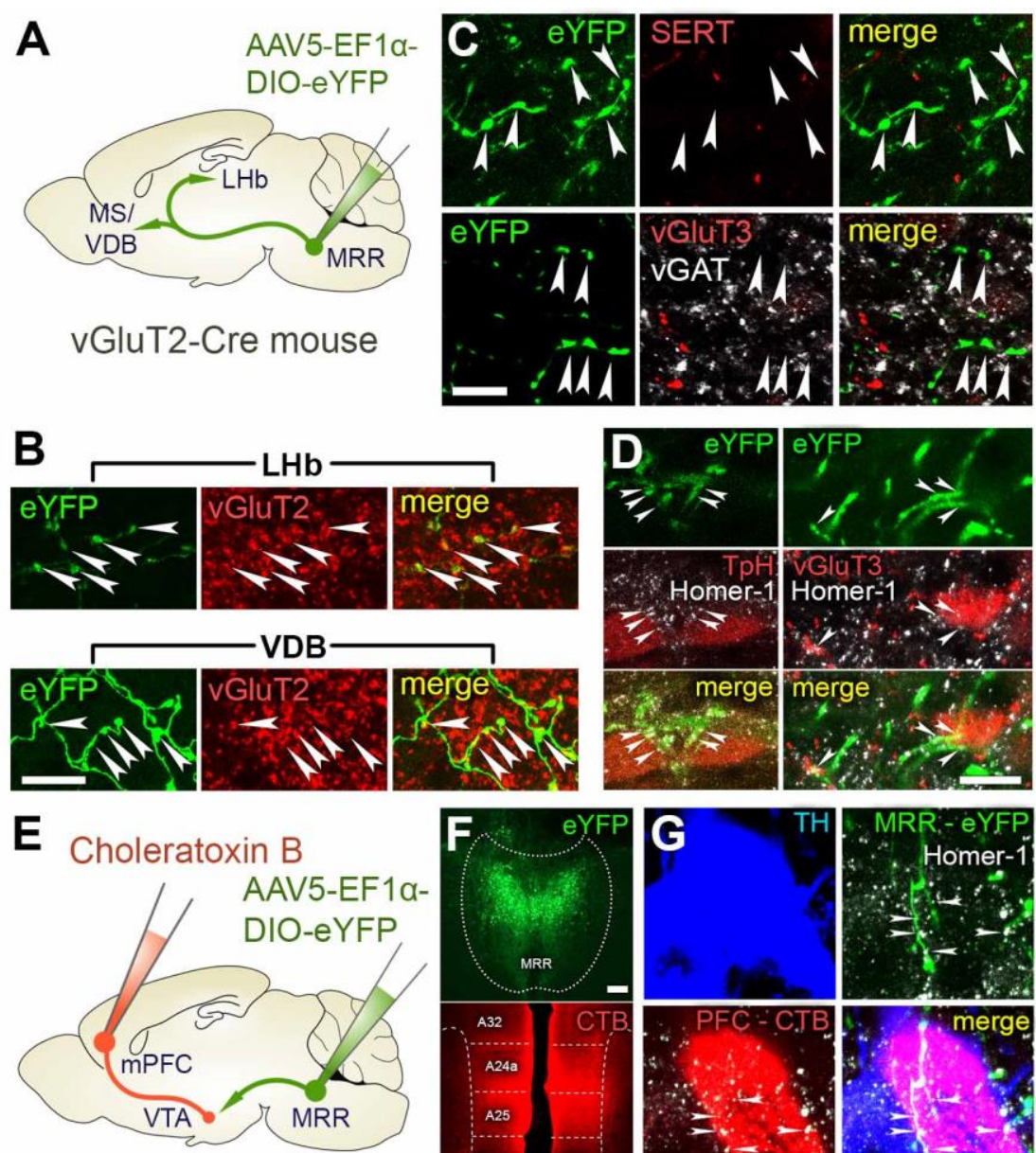

vGluT2-Cre mouse
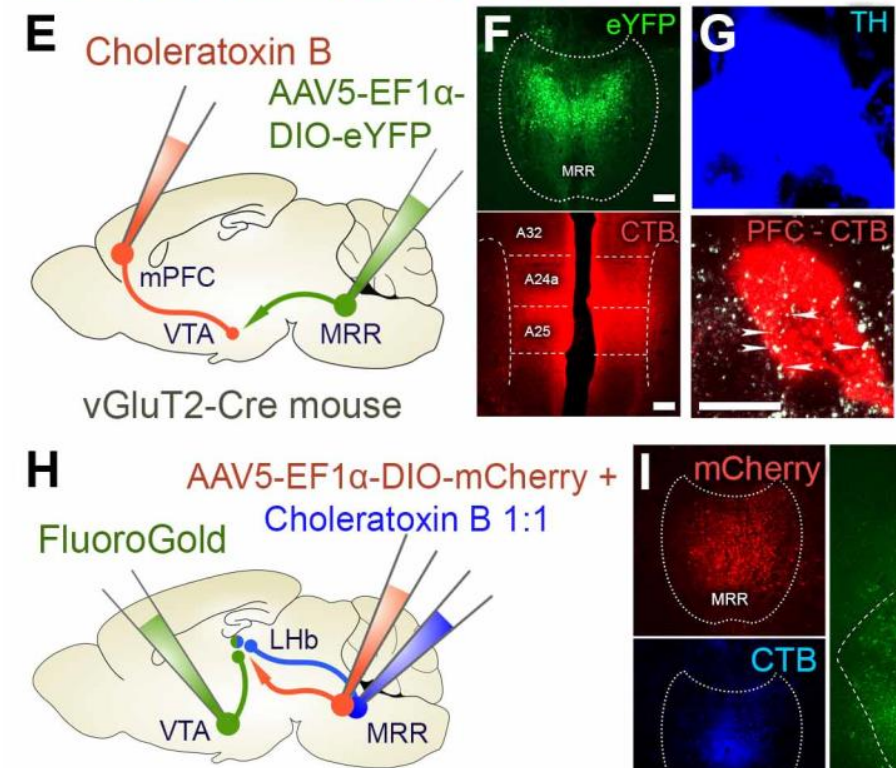

vGluT2-Cre mouse
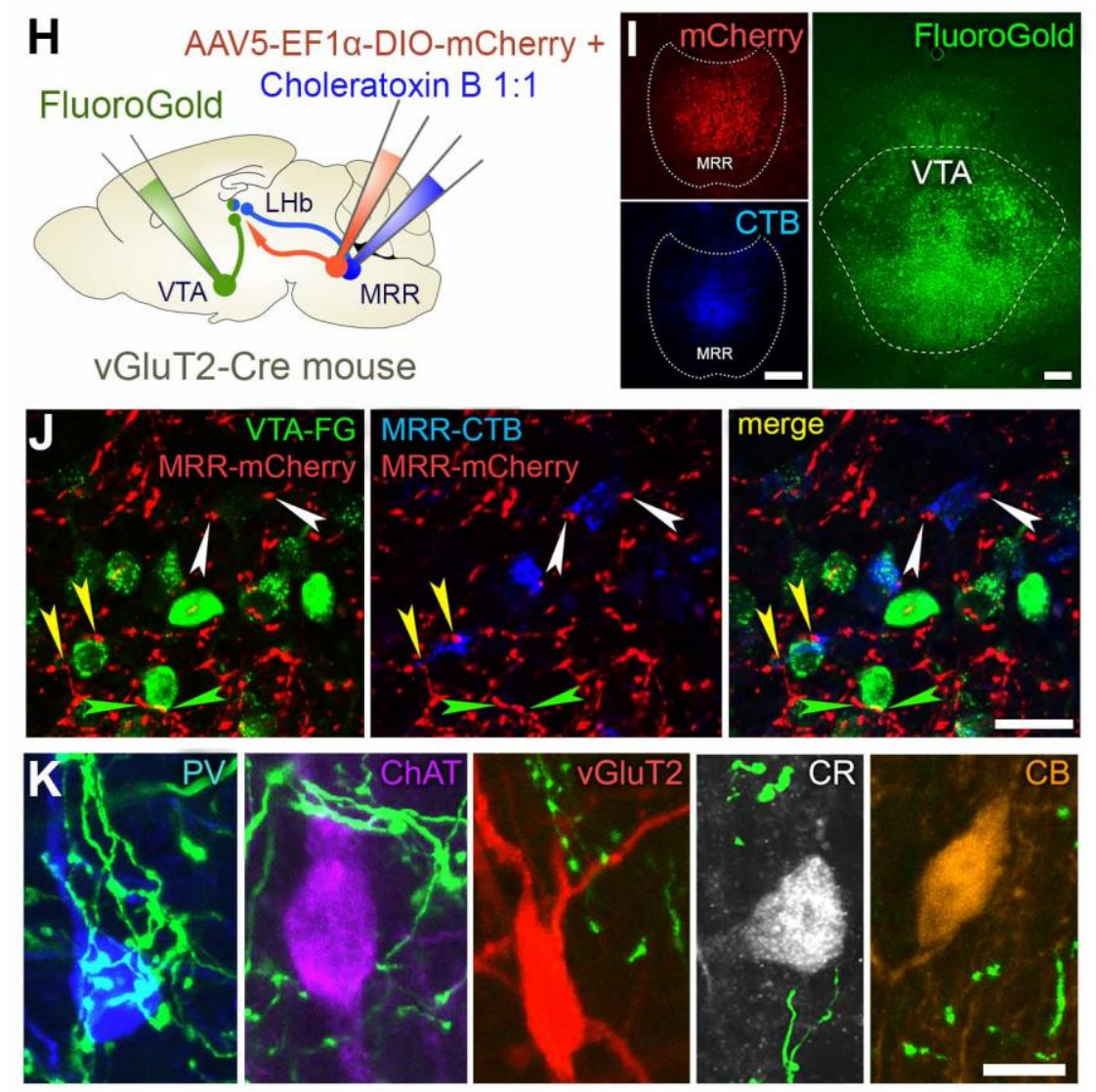
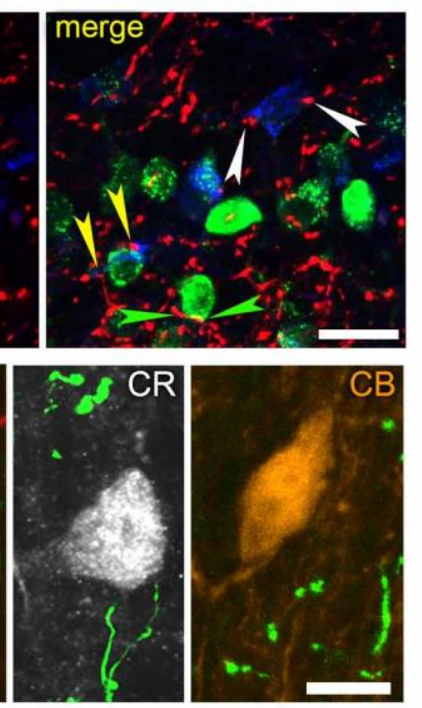

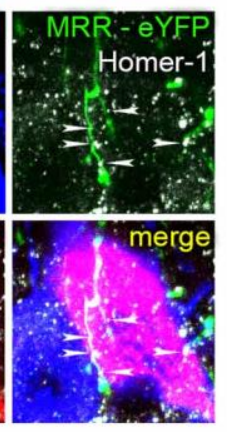

FluoroGold
A: AAV2/5-EF1 $\alpha$-DIO-eYFP was injected into the MRR of vGluT2-Cre mice $(n=2)$.

B: Representative images from $\mathrm{LHb}$ (upper panel) and VDB (lower panel) show that eYFP-labelled MRR fibers (green) are indeed immunopositive for vGluT2 (red). Double immunopositive terminals are labelled with white arrowheads. At least 93\% (339/367) of $\mathrm{LHb}$ and at least $97 \%$ (284/293) of VDB eYFPlabelled MRR terminals were clearly immunopositive for vGluT2. Scale bar for both panels: $10 \mu \mathrm{m}$.

C: Upper panel: representative images show that eYFP-labelled MRR terminals (green, white arrowheads) in the LHb are negative for SERT (red).

Lower panel: representative images show that eYFP-labelled MRR terminals in the LHb (green, white arrowheads) are negative for vGluT3 (red) or vGAT (white). In the LHb, only $4 \%(8 / 200)$ of eYFP-labelled terminals seemed positive for either vGluT3 or vGAT. In the VDB, only $8 \%$ $(17 / 200)$ of eYFP-labelled MRR terminals seemed positive for either vGluT3 or vGAT. These few positive looking terminals were probably false positive due to detection issues. Scale bar for both panels: 10 $\mu \mathrm{m}$.

D: Left panel: confocal fluorescent images show that eYFP-labelled MRR fibers (green) establish synaptic contacts (white arrowheads), marked by Homer-1 (white), with $\mathrm{TpH}$ positive (serotonergic) cells (red) in the MRR. Our measurements showed that at least $17 \%(113 / 680)$ of eYFP-labeled terminals established synaptic contacts on 
$\mathrm{TpH}$-positive profiles, and at least 68\% (90/132) of $\mathrm{TpH}$-positive cells received at least one synaptic contact from eYFP-labelled terminals (white arrowheads).

Right panel: confocal fluorescent images show that eYFP-labelled MRR fibers (green) establish synaptic contacts (white arrowheads), marked by Homer-1 (white), with vGluT3-positive cells (red) in the MRR. Our measurements showed that at least $17 \%(132 / 797)$ of eYFP-labeled terminals established synaptic contacts on vGluT3-positive profiles, and at least 36\% (48/135) of vGluT3-positive cells received at least one synaptic contact from eYFP-labelled terminals (white arrowheads). Scale bar for both panels: $10 \mu \mathrm{m}$.

E: Anterograde tracer AAV2/5-EF1 $\alpha$-DIO-eYFP was injected into the MRR, and retrograde tracer CTB into the medial prefrontal cortex (PFC) of vGluT2-Cre mice $(n=2)$.

F: Fluorescent images show representative injection sites in the MRR and MPFC, respectively. Scale bars: 200 $\mu \mathrm{m}$.

G: Confocal laser-scanning microscopy images show a medial VTA dopaminergic neuron (blue), retrogradely labeled with CTB (red) from the MPFC, receiving several Homer-1 (white) positive synaptic contacts from eYFPcontaining vGluT2-positive MRR fibers (green). Scale bar: $10 \mu \mathrm{m}$.

H: Anterograde tracer AAV2/5-EF1 $\alpha$-DIO-mCherry and retrograde tracer CTB (diluted 1:1) was injected into the MRR and retrograde tracer FluoroGold (FG) was injected into the VTA of vGluT2-Cre mice $(n=2)$.

I: Fluorescent images show representative injection sites in the MRR and VTA, respectively.

Scale bars: $200 \mu \mathrm{m}$.

J: mCherry-containing vGluT2-positive MRR fibers (red) establish putative contacts with FG-positive (green) VTA projecting neurons (green arrows), with CTB-positive (blue) MRR projecting neurons (white arrows) and with FG-CTB-positive double projecting neurons (yellow arrows) in the LHb, respectively. Altogether, we counted 466 cells in the LHb that projected to the VTA and/or to the MRR, 70\% (325/466) of which projected only to the VTA, $17 \%$ (78/466) only to the MRR and $13 \%$ (63/466) was double-projecting cells. $45 \%$ (63/141) of the cells that projected to the MRR, also projected to the VTA. Furthermore, 78\% (254/325) of the cells projecting only to the VTA, $69 \%$ (54/78) of the cells projecting only to MRR and 78\% (49/63) of the doubleprojecting cells received at least 5 appositions from mCherry-containing MRR terminals. These data show that MRR vGluT2-neurons target LHb neurons, irrespectively from their preferences of targeting MRR or VTA. Scale bar: $20 \mu \mathrm{m}$.

K: Representative confocal fluorescent microscopic images show that only PV-positive, but not ChAT, vGluT2, calretinin (CR) or calbindin (CB)-positive MS/VDB cells received dense basket-like innervation from vGluT2positive MRR cells. Scale bar: $10 \mu \mathrm{m}$. 


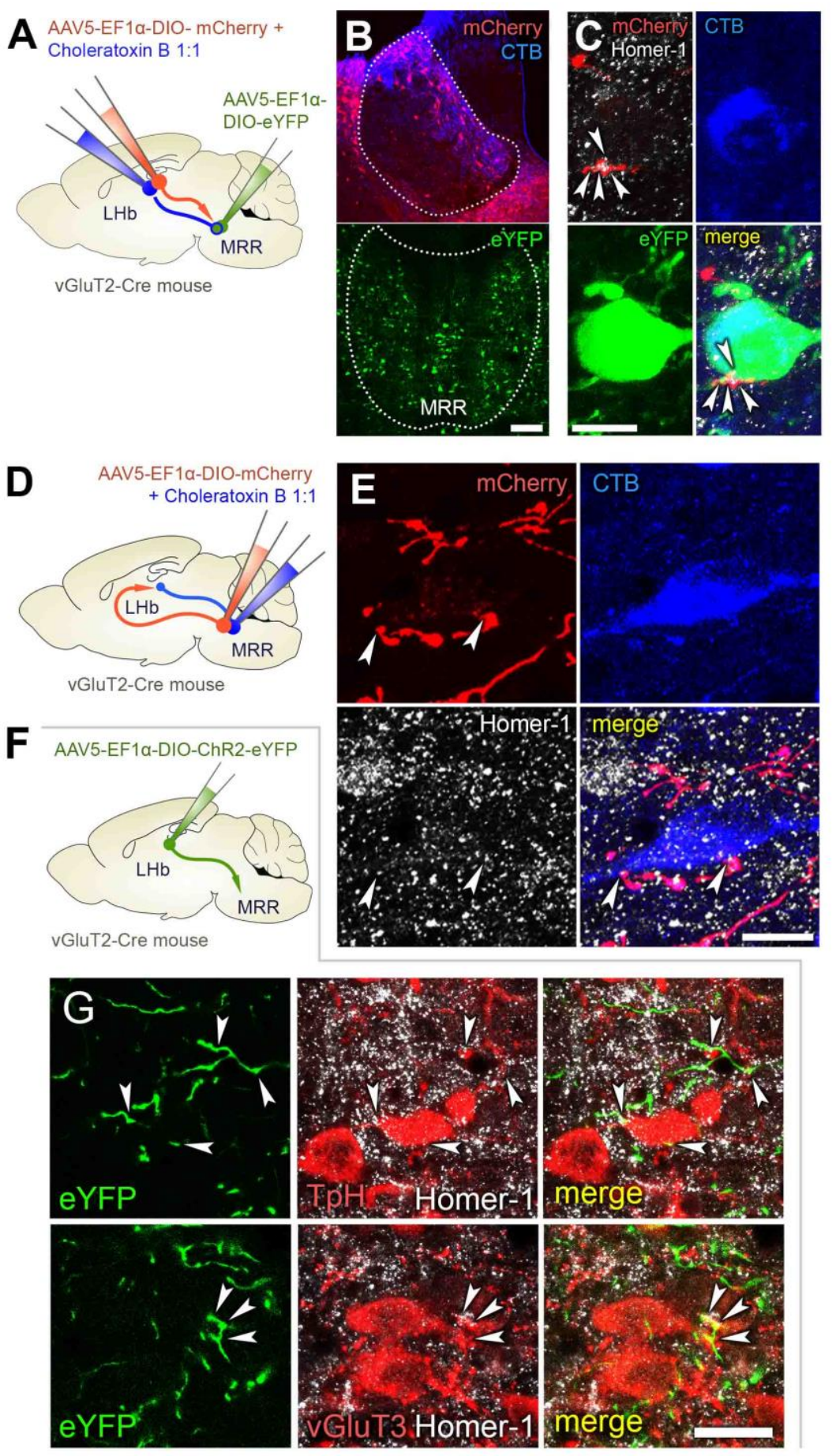

A: The anterograde tracer AAV2/5-EF1 $\alpha$ DIO-mCherry and the retrograde tracer СTB was injected into the bilateral $\mathrm{LHb}$ and anterograde tracer AAV2/5-EF1 $\alpha$ DIO-eYFP was injected into the MRR of vGluT2-Cre mice $(n=2)$. B: Fluorescent images showing representative injection sites in the LHb and MRR, respectively. Scale bar: $100 \mu \mathrm{m}$. C: Confocal laser scanning microscopic images show that LHb vGluT2-positive fibers (red) establish synaptic contacts, marked by Homer-1 (white), on a CTB-positive (blue), LHbprojecting vGluT2-positive MRR neuron (green). At least 53\% (32/60) of LHbprojecting vGluT2-positive MRR cells received altogether 122 Homer-1 positive synaptic contacts from vGluT2positive LHb neurons. Scale bar: $10 \mu \mathrm{m}$. D: Anterograde tracer AAV2/5-EF1 $\alpha$-DIOmCherry and retrograde tracer CTB was injected into the MRR of vGluT2-Cre mice $(n=2)$. E: Confocal laser scanning microscopic images show that MRR vGluT2-positive fibers (red) establish synaptic contacts, marked by the scaffolding protein Homer-1 (white), with CTB-positive MRR-projecting LHb neurons (blue). At least $58 \%$ (71/122) of MRR-projecting $\mathrm{LHb}$ cells received altogether 268 Homer-1 positive synaptic contacts from vGluT2-positive MRR cells. Scale bar: $10 \mu \mathrm{m}$.

F: AAV2/5-EF1 $\alpha$-DIO-ChR2-eYFP was injected into the bilateral LHb of vGluT2-

Cre mice ( $n=2)$. G: Upper panel: vGluT2-positive LHb fibers (green) establish Homer-1 (white) positive synaptic contacts with TpH-positive neurons (red) in the MRR. Our measurements showed that at least $12 \%(35 / 306)$ of eYFP labeled LHb terminals established synapses on TpH-positive profiles, while at least $57 \%(29 / 51)$ of TpHpositive cells received at least one synaptic contact from eYFP-labelled terminals (white arrowheads). Lower panel: vGluT2-positive LHb fibers (green) establish Homer-1 (white) positive synaptic contacts with vGluT3positive neurons (red) in the MRR. Our measurements showed that at least $5 \%(11 / 223)$ of eYFP labeled LHb terminals established synapses on vGluT3-positive profiles, while at least $28 \%$ (10/36) of vGluT3-positive cells received at least one synaptic contact from eYFP-labelled terminals (white arrowheads). Scale bar for both panels: $20 \mu \mathrm{m}$. 
A

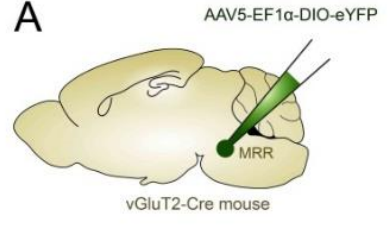

B

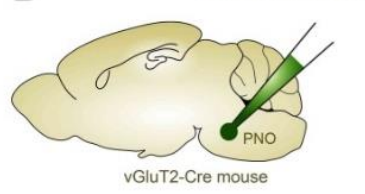

C

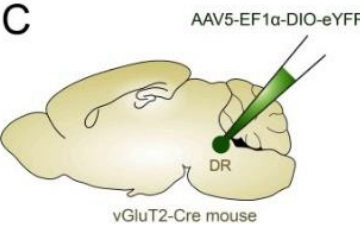

D

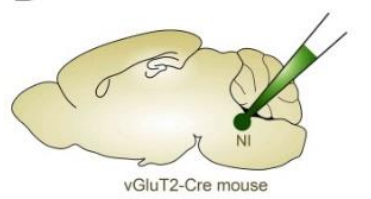

E

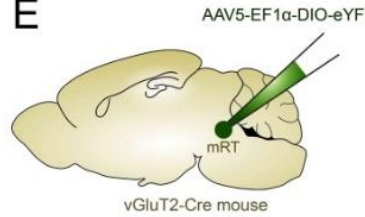

$\mathrm{F}$

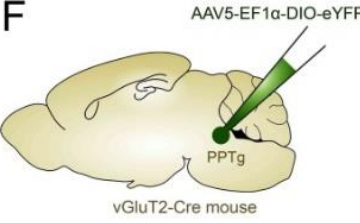

G

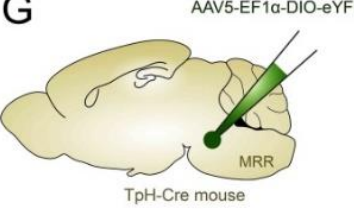

$\mathrm{H}$ AAVS-EF1G-DIO-YYFP
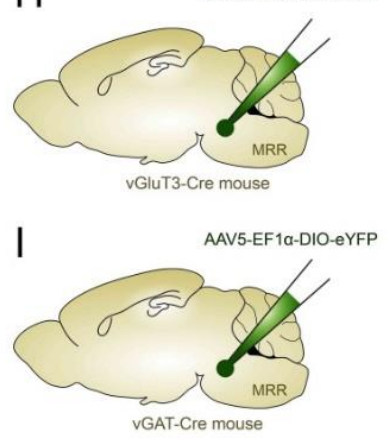
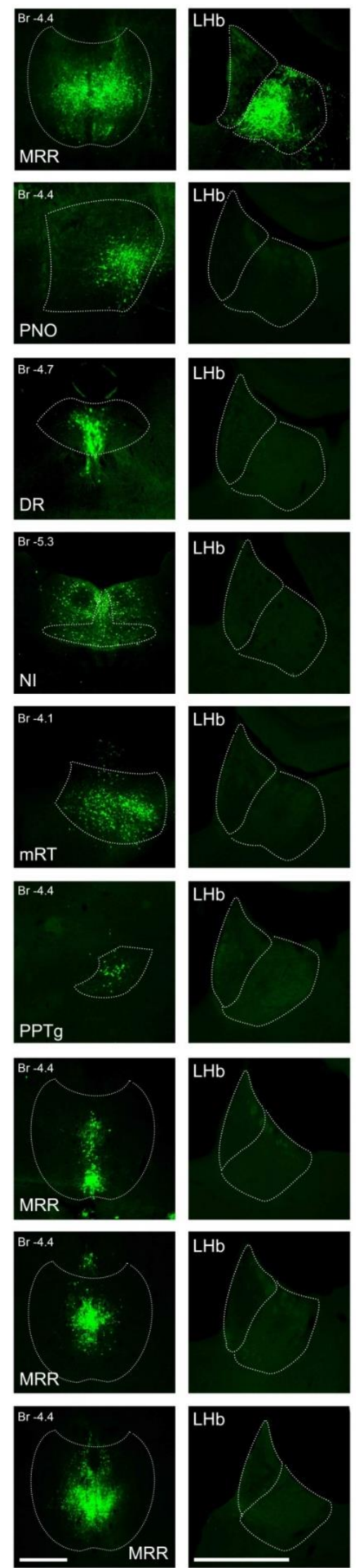
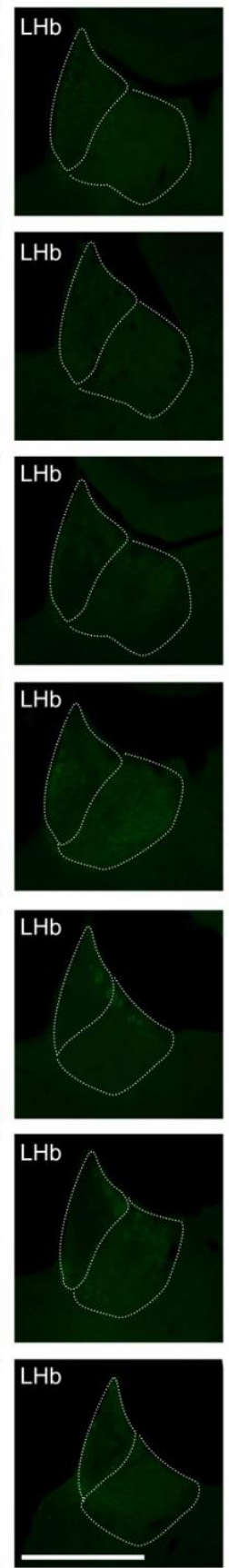
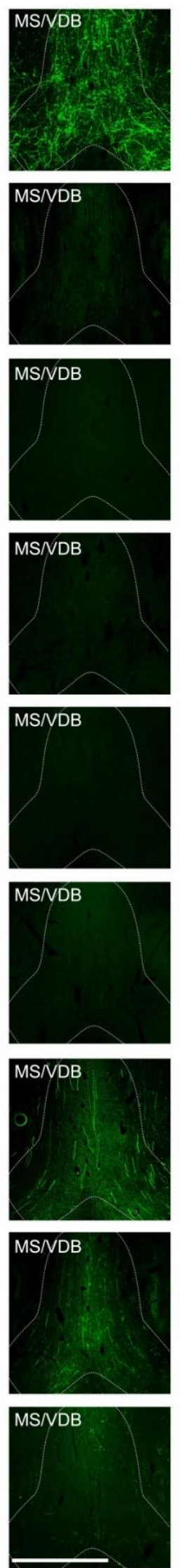

A-I: $\quad$ AAV2/5-EF1 $\alpha$-DIO-eYFP

was injected into various adjacent areas in the brainstem in vGluT2-Cre mice to confirm that the pathway described here originates selectively from the MRR (A-F). Furthermore, AAV2/5-EF1 $\alpha$-DIO-eYFP was injected into the MRR of $\mathrm{TpH}-$ Cre (labeling serotonergic cells), vGluT3-Cre (labeling vesicular glutamate transporter type 3 positive glutamatergic cells) and vGAT-Cre mice (labeling GABAergic cells) to illustrate that the pathway described here originates selectively from vGluT2-positive neurons in MRR (G-I). The images illustrate representative coronal sections from the regions of different injection sites and from the $\mathrm{LHb}$ and MS-VDB. The centers of the injection sites were also identified and defined by their anteroposterior coordinates from Bregma, as seen in the images. In LHb and MS/VDB, vGluT2-positive fibers can only be observed if viruses were injected into MRR (A), and they are absent in experiments, where the AAV-eYFP was injected into the neighboring brain areas (B-F) or into the MRR of TpH-Cre or vGluT3-Cre or GAT-Cre mice (G-I). All combinations of tracings were confirmed in at least 2 mice. Scale bars in panel I are $500 \mu \mathrm{m}$ for all image columns. [Median raphe region (MRR), nucleus pontis oralis (PNO), dorsal raphe (DR), nucleus incertus (NI), mesencephalic reticular formation (mRT), pontine peduncular tegmentum (PPTg)] 


\section{Supplementary Figure 4}
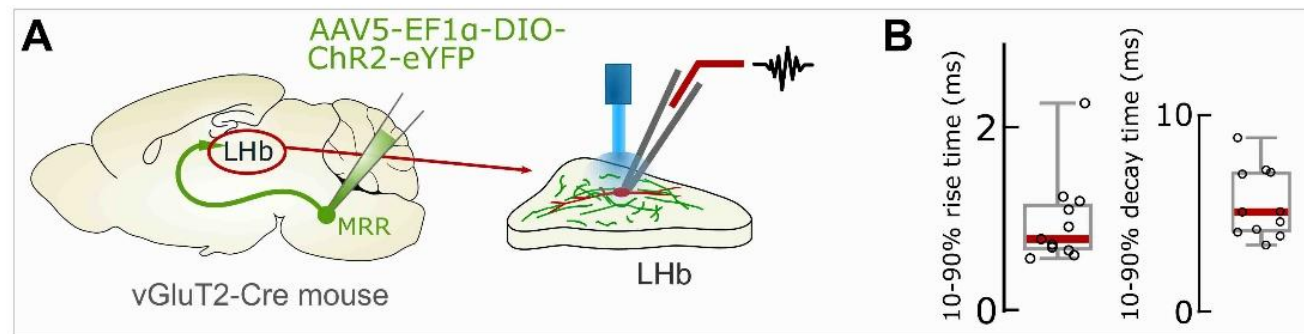

EPSC traces

(originals and average)

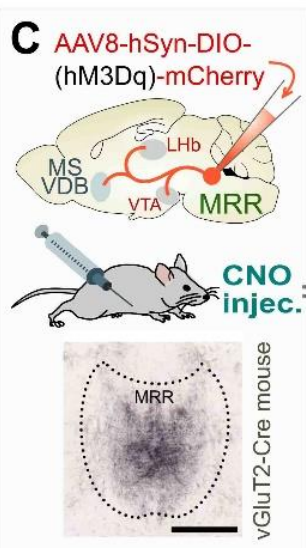

D

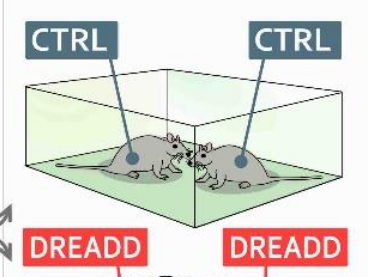

E
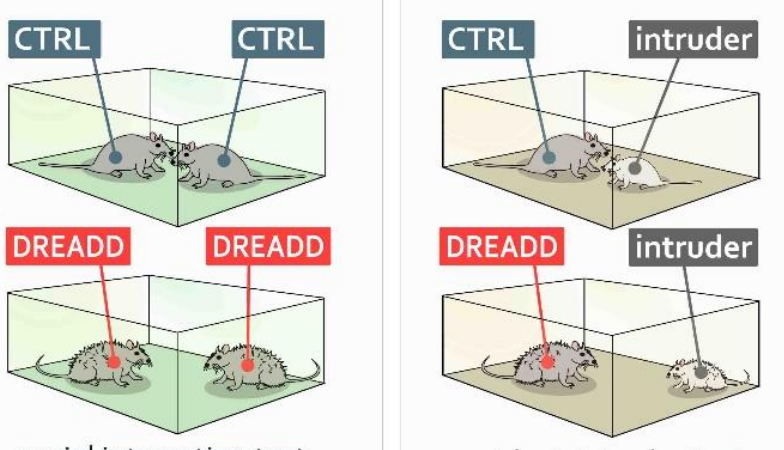

social interaction test
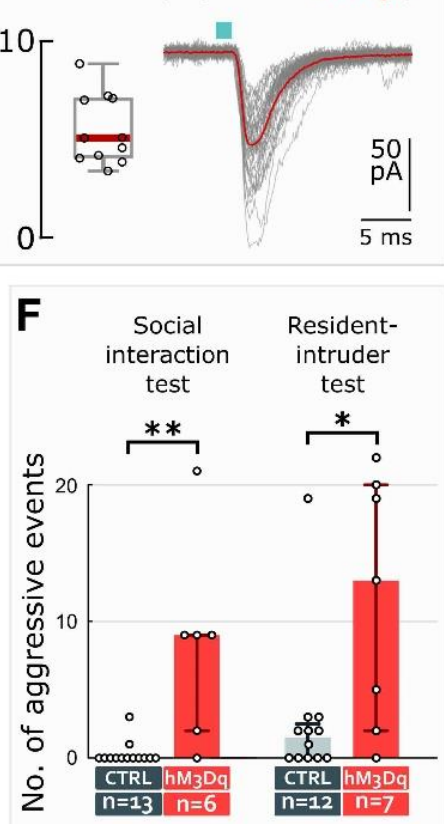
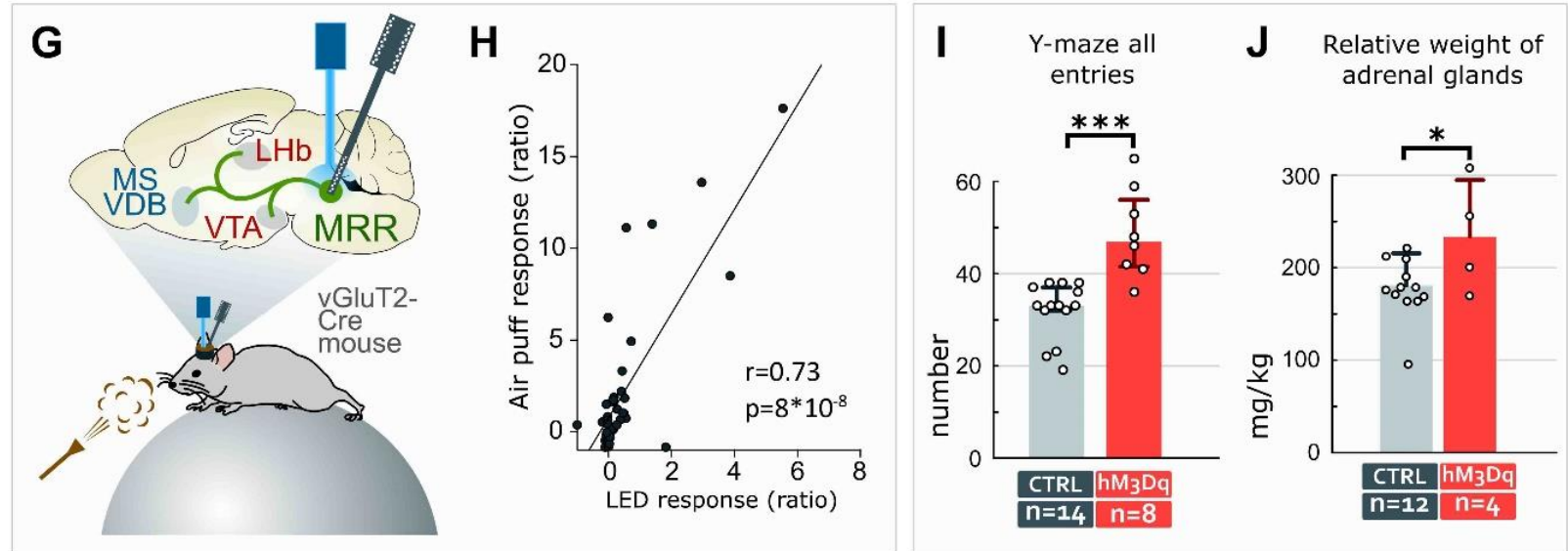

A-B: Additional data for Fig. 3A. Population data for $10-90 \%$ rise and decay time distributions respectively in ms are as follows (median [25\%-75\% quartiles]), 10-90\% rise time: 0.77 [0.66-1.14]; 10-90\% decay time 5.06 [4.10-7.03]. Original and averaged individual traces are also shown.

C-F: Additional data for Fig. 6A-C. The number of aggressive events in the social interaction and residentintruder tests for CTRL- and h3MDq-mice, respectively are as follows (median [25\%-75\% quartiles]), social interaction test: CTRL: 0.00 [0.00-0.00]; h3MDq: 9.00 [2.00-9.00]; resident intruder test: CTRL: 0.00 [0.00-0.00]; h3MDq: 13.00 [2.00-20.00]. *: p=0.031, **: p=0.002, Mann-Whitney U-test.

G-H: Additional data for Fig. 4A. Air puff-triggered change of firing was significantly correlated with the effect of LED flashes on the activity of the vGLuT2-positive MRR neurons $\left(r=0.73, p=8 * 10^{-8}\right)$.

I: Population data for the number of total entries in the exploration of a Y-maze for CTRL- and h3MDq-mice are as follows (median [25\%-75\% quartiles]), CTRL: 33 [32-37]; h3MDq: 47 [41-56].

***: $p=4.71 \times 10^{-4}$, Mann-Whitney U-test.

$\mathrm{J}$ : Population data for the relative weight of adrenal glands to the body weight for CTRL- and h3MDq-mice, respectively are as follows, in $\mathrm{mg} / \mathrm{kg}$ (mean +/- SD), CTRL: 180.661 +/- 34.88; h3MDq: 233.41 +/- 61.37. *: $\mathrm{p}=0.047$, Student's t-test. 


\section{Supplementary Figure 5}

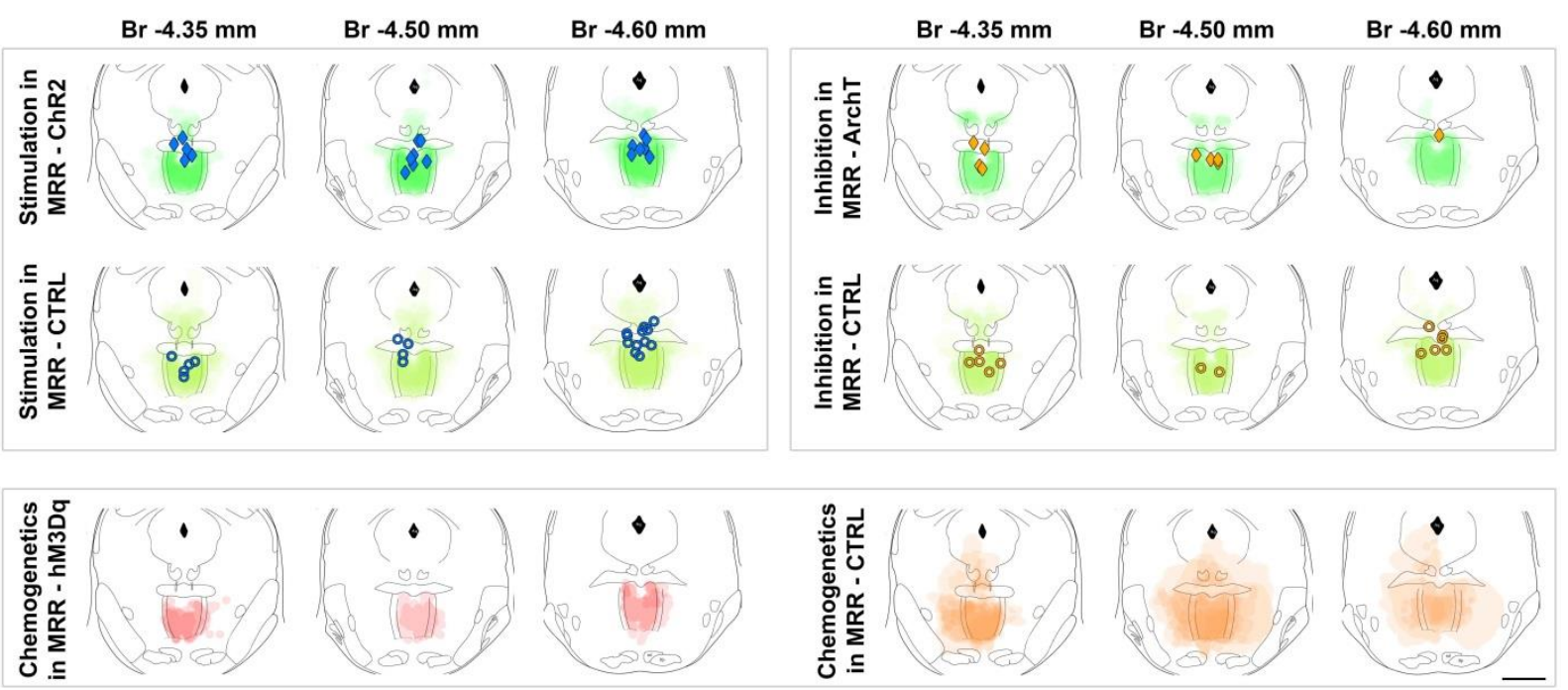

Summary of virus injection sites in every mouse used in the behavioral opto- and chemogenetic experiments. The virus injection sites in the different mice participating in the different experiments were checked one-byone and overlaid onto each other in these images. AAV2/5-EF1a-DIO-ChR2-eYFP (ChR2) or AAV2/5-CAG-FLEXArchT-GFP (ArchT) expression is labeled with green, AAV2/5-EF1a-DIO-eYFP (CTRL) expression is labeled with yellow, AAV2/8-hSyn-DIO-hM3Dq-mCherry is labeled with red and AAV2/8-hSyn-DIO-mCherry is labeled with orange in the area of MRR and adjacent structures at 3 different coronal levels (Bregma $-4.35,-4.50$ and -4.60 $\mathrm{mm}$, respectively). The tips of the optic fibers positioned over the MRR are also labeled as follows: In experiments comparing ChR2 stimulation vs. CTRL in the MRR (described in Fig. 5A-D), blue rhombs show the tip of optic fibers in ChR2-expressing mice, whereas blue circles show the tip of optic fibers in CTRL-mice. In experiments comparing ArchT inhibition vs. CTRL (described in Fig. 8E), orange rhombs show the tip of optic fibers in ArchT-expressing mice, whereas orange circles show the tip of optic fibers in CTRL-mice. 
A
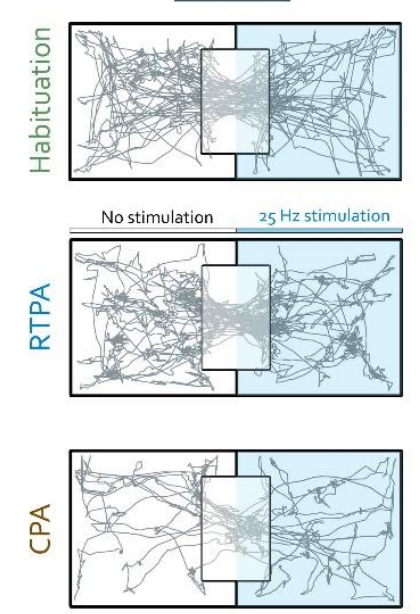

C

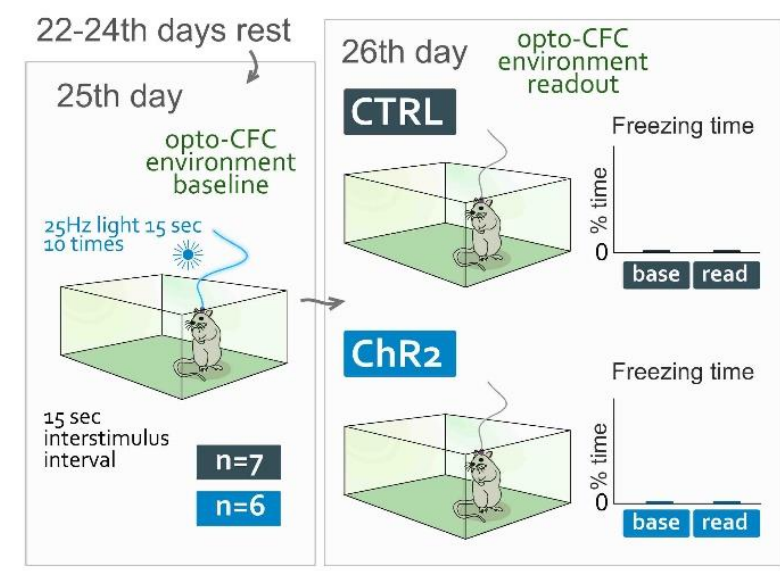

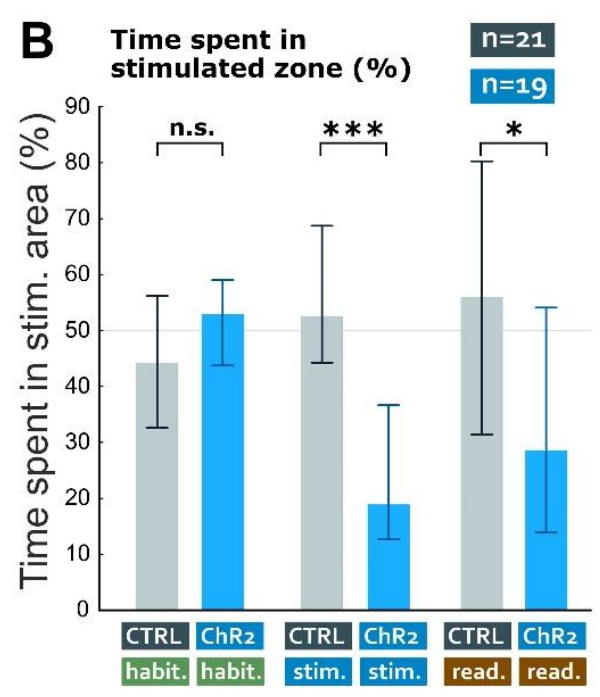

D

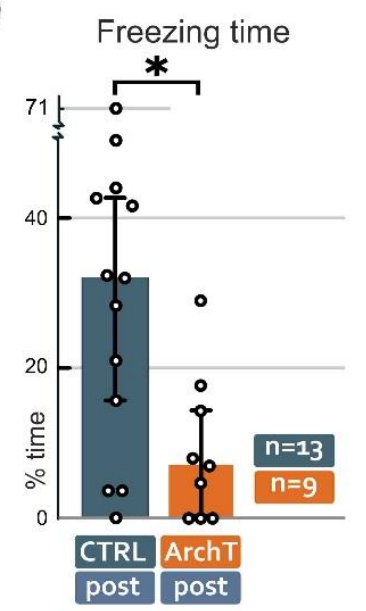

A: Animal movement traces of a representative CTRL- and ChR2-mouse during the habituation, real time place aversion (RTPA) and conditioned place aversion (CPA) experiments. Mice were light stimulated in the blue shaded area of the test chamber. The CTRL-mouse spent equal time in the two sides of the chamber, whereas the ChR2-mouse avoided the stimulation area during and 24 hours after the $25 \mathrm{~Hz}$ blue laser light stimulation of the vGluT2-positive MRR cells. We found no statistical difference either in the velocity of locomotion (MannWhitney U-test, $\mathrm{p}=0.1293$ ) or in distance travelled (Mann-Whitney $\mathrm{U}$-test, $\mathrm{p}=0.1363$ ) during RTPA experiments. B: Population data for the time spent in the two areas during habituation, RTPA and CPA tests (the latter two graphs are the same as in Fig. 5B). Medians and interquartile range shown on the graphs. (For statistical details see Suppl. Data for Fig. 5).

C: Additional data for Fig. 5. Experimental design of optogenetic stimulation of vGluT2-positive MRR cells. During the 3 days following operant conditioning, animals gained back their original body weight. Mice were then placed into a new "opto-CFC" environment, and after $3 \mathrm{~min}$ of baseline freezing recording, they were light-stimulated for 10 times 15 seconds, with 15 seconds interstimulus interval. 24 hours later mice were placed back into the same environment to detect freezing levels. Freezing behavior was absent in both groups ( $n=7$ CTRL and $n=6$ ChR2-mice) during both conditions.

D: Additional data for Fig. 8E. Population data for the post-cue freezing levels (\% of total time) in environment "B" for 13 CTRL- and 9 ArchT-mice are as follows: (median [25\%-75\% quartiles]), CTRL: 32.00 [15.67-42.67]; ArchT: 0.00 [0.00-14.33]. ${ }^{*} p=0.021$, Mann-Whitney U-test. 


\section{Supplementary Figure 7}

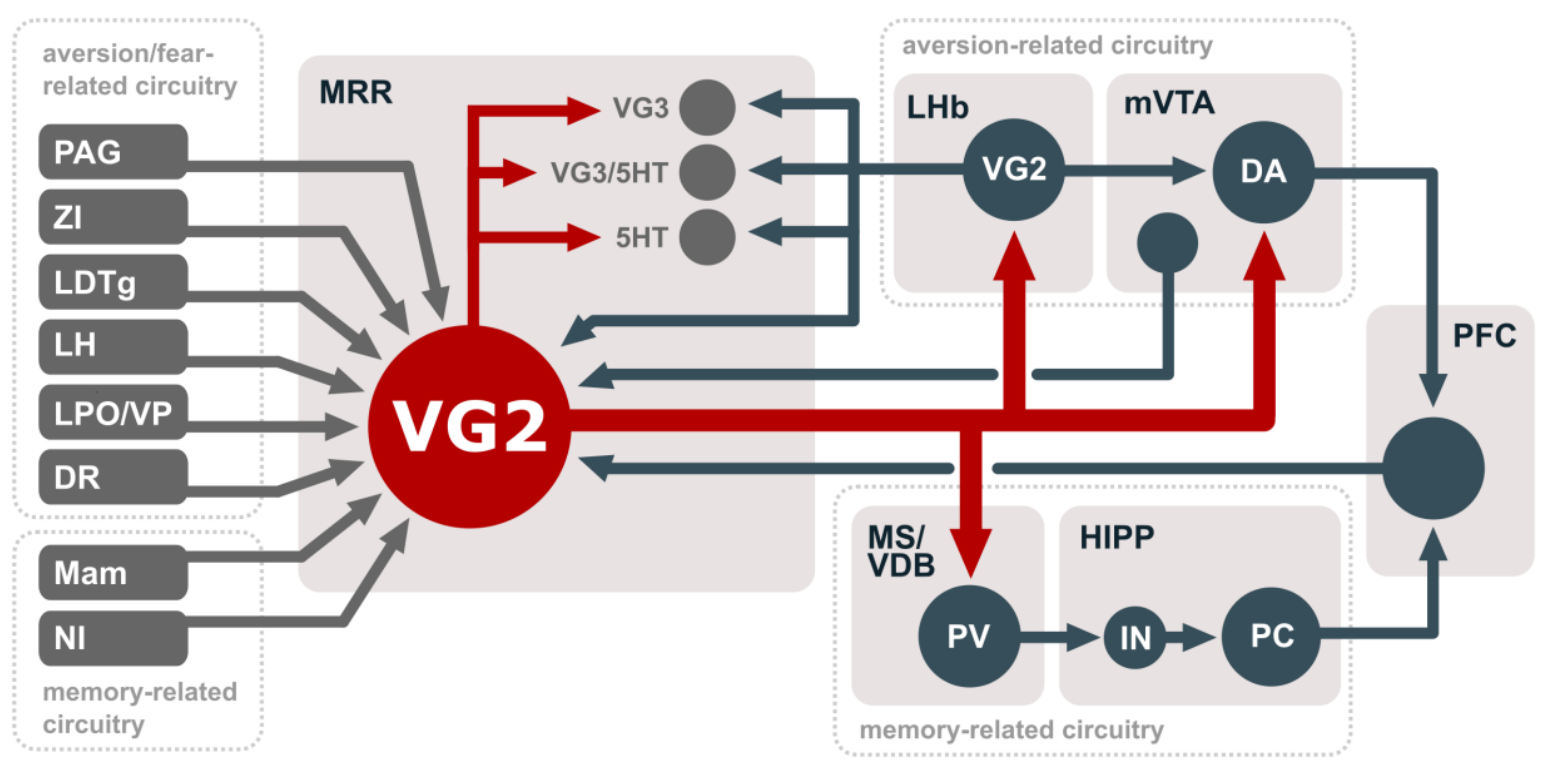

MRR vGluT2-neurons provide a neural hub for processing negative experiences.

Illustration of the input and output connections of the MRR vGluT2-neurons (VG2). MRR vGluT2-neurons receive extensive inputs both from aversion-, freezing-, fear-related brain areas (see on the left) and from areas related to the memorization of negative experience (see on the left). In addition, MRR vGluT2-neurons project to $\mathrm{LHb}$ and $\mathrm{mVTA}$, which are centers for aversion and for the prediction of negative experience, whereas they also project to the MS/VDB that induces hippocampal theta-rhythm activity, which is essential for contextual memory formation of negative experience. PAG: periaqueductal gray, ZI: zona incerta, LDTg: laterodorsal tegmental nucleus, LH: lateral hypothalamus, LPO/VP: lateral preoptic area \& ventral pallidum, DR: dorsal raphe, Mam: mammillary complex, NI: nucleus incertus, MRR: median raphe region, VG2: vesicular glutamate transporter 2-positive neurons, VG3: vesicular glutamate transporter 3-positive neurons, 5TH: serotonergic neurons, LHb: lateral habenula, mVTA: medial ventral tegmental nucleus, DA: dopaminergic neurons, PFC: prefrontal cortex, MS/VDB: medial septum \& vertical limb of the diagonal band of Broca, PV: parvalbumin-positive neurons, HIPP: hippocampus, IN: interneurons, PC: pyramidal cells. 
Table S1: Characterization of used primary antibodies and retrograde tracers

\begin{tabular}{|c|c|c|c|c|c|c|}
\hline $\begin{array}{l}\text { Antigen or } \\
\text { reagent }\end{array}$ & $\begin{array}{l}\text { 艹ั̆ } \\
\text { ำ }\end{array}$ & $\frac{\text { 은 }}{\frac{2}{2}}$ & Source & 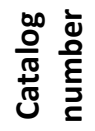 & $\begin{array}{l}\text { Charac- } \\
\text { terization }\end{array}$ & Specificity \\
\hline Calbindin & $\frac{: \frac{1}{0}}{\frac{0}{0}}$ & $\begin{array}{l}\stackrel{8}{8} \\
\stackrel{\text { }}{+}\end{array}$ & $\begin{array}{l}\text { Kind gift } \\
\text { from K. } \\
\text { Baimbridg } \\
\text { e }\end{array}$ & & 1 & $\begin{array}{c}\text { The antibody recognizes one major } \\
\text { broad band of the expected } \\
\text { molecular weight ( } 28 \mathrm{kDa}) \text { on } \\
\text { western blots from rat cerebellum } \\
\text { samples and immunostaining was } \\
\text { abolished by preadsorption with } \\
\text { the immunogen }\end{array}$ \\
\hline Calretinin & 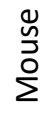 & 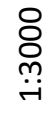 & Swant & ஜ̂ & 17 & KO verified \\
\hline $\begin{array}{c}\text { Choline } \\
\text { Acetyltransferas } \\
\text { e (ChAT) }\end{array}$ & 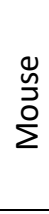 & 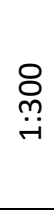 & $\begin{array}{l}\text { Kind gift } \\
\text { from C. } \\
\text { Cozzari }\end{array}$ & ' & 2,3 & $\begin{array}{l}\text { Staining is typical for cholinergic } \\
\text { cells; complete overlap of staining } \\
\text { with eYFP-positive cells in ChAT- } \\
\text { iRES-Cre mice injected with AAV- } \\
\text { EF1a-DIO-eYFP }\end{array}$ \\
\hline $\begin{array}{l}\text { Choleratoxin B } \\
\text { subunit }\end{array}$ & $\begin{array}{l}\stackrel{\pi}{\pi} \\
0 \\
0\end{array}$ & 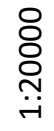 & $\begin{array}{l}\text { List } \\
\text { Biologicals }\end{array}$ & $\stackrel{m}{\text { m }}$ & 4 & No staining in non-injected animals \\
\hline $\begin{array}{l}\text { Choleratoxin B } \\
\text { subunit }\end{array}$ & 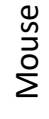 & $\begin{array}{l}\stackrel{8}{8} \\
\stackrel{+}{r} \\
\end{array}$ & Abcam & $\begin{array}{l}m \\
\varnothing \\
\frac{1}{0} \\
\frac{0}{0}\end{array}$ & 5 & No staining in non-injected animals \\
\hline $\begin{array}{l}\text { Choleratoxin B } \\
\text { subunit }\end{array}$ & 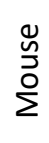 & 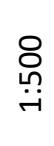 & Abcam & $\begin{array}{l}\infty \\
\infty \\
\stackrel{0}{1} \\
\\
\stackrel{0}{\sigma}\end{array}$ & 6 & No staining in non-injected animals \\
\hline eGFP & $\frac{c}{d}$ & $\begin{array}{l}\stackrel{8}{\circ} \\
\stackrel{+}{r}\end{array}$ & $\begin{array}{l}\text { Thermo } \\
\text { Fisher } \\
\text { Scientific }\end{array}$ & 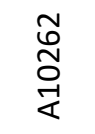 & 17 & $\begin{array}{c}\text { No staining in animals not injected } \\
\text { with eGFP-expressing virus }\end{array}$ \\
\hline eGFP & $\frac{: \frac{\pi}{0}}{\frac{\pi}{0}}$ & 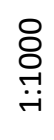 & $\begin{array}{l}\text { Thermo } \\
\text { Fisher } \\
\text { Scientific }\end{array}$ & 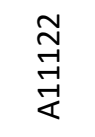 & 17 & $\begin{array}{c}\text { No staining in animals not injected } \\
\text { with eGFP-expressing virus }\end{array}$ \\
\hline $\begin{array}{l}\text { Fluoro } \\
\text { Gold }\end{array}$ & $\frac{: \frac{\pi}{0}}{\frac{\pi}{\pi}}$ & 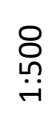 & Chemicon & $\begin{array}{l}\bar{n} \\
\stackrel{1}{n} \\
\stackrel{\infty}{\alpha}\end{array}$ & 7 & No staining in non-injected animals \\
\hline $\begin{array}{l}\text { Fluoro } \\
\text { Gold }\end{array}$ & 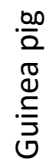 & 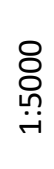 & $\begin{array}{l}\text { Protos } \\
\text { Biotech } \\
\text { Corp }\end{array}$ & $\underset{\substack{-1 \\
\stackrel{1}{1}}}{\sum_{z}}$ & 17 & No staining in non-injected animals \\
\hline
\end{tabular}




\begin{tabular}{|c|c|c|c|c|c|c|}
\hline Homer-1 & $\begin{array}{l}\frac{5}{0} \\
\frac{\pi}{\pi} \\
\simeq\end{array}$ & 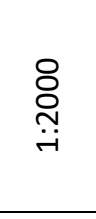 & $\begin{array}{l}\text { Synaptic } \\
\text { Systems }\end{array}$ & $\begin{array}{l}\text { n̊ } \\
8 \\
\stackrel{8}{0}\end{array}$ & 17 & $\begin{array}{l}\text { Specific for Homer } 1 \text {. Cross- } \\
\text { reactivity of the serum to Homer } 2 \\
\text { and } 3 \text { was removed by pre- } \\
\text { adsorption with Homer } 2 \text { (aa } \\
1 \text { - 176) and Homer } 3 \text { (aa } 1 \text { - 177). }\end{array}$ \\
\hline mCherry & $\frac{: \frac{\pi}{0}}{\frac{\pi}{\pi}}$ & 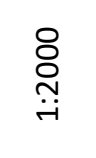 & BioVision & $\begin{array}{l}\text { ○ } \\
\text { ஸे } \\
\text { ஸे } \\
\text { مे }\end{array}$ & 17 & $\begin{array}{l}\text { No staining in animals not injected } \\
\text { with mCherry-expressing virus }\end{array}$ \\
\hline $\begin{array}{l}\text { NMDA receptor } \\
\text { GluN1 subunit }\end{array}$ & $\frac{: \frac{:}{0}}{\frac{0}{\pi}}$ & 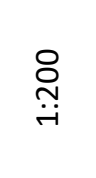 & $\begin{array}{l}\text { Kind gift } \\
\text { from } \\
\text { Watanabe } \\
\text { M. }\end{array}$ & ' & 8 & KO verified \\
\hline $\begin{array}{l}\text { NMDA receptor } \\
\text { GluN2A subunit }\end{array}$ & $\begin{array}{l}\frac{:}{0} \\
\frac{\pi}{\pi} \\
\sim \frac{1}{\pi}\end{array}$ & 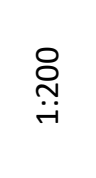 & $\begin{array}{l}\text { Kind gift } \\
\text { from } \\
\text { Watanabe } \\
\text { M. }\end{array}$ & & 8 & KO verified \\
\hline Parvalbumin & 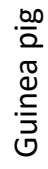 & $\begin{array}{l}8 \\
\stackrel{8}{8} \\
\stackrel{-}{\rightarrow}\end{array}$ & $\begin{array}{l}\text { Synaptic } \\
\text { Systems }\end{array}$ & $\begin{array}{l}\text { ठ } \\
\text { மூ } \\
\text { ๙ }\end{array}$ & 17,9 & $\begin{array}{l}\text { Labels the same cell populations ir } \\
\text { the brain as other antibodies to } \\
\text { parvalbumin }\end{array}$ \\
\hline Parvalbumin & $\frac{: \frac{\pi}{0}}{\frac{\pi}{\pi}}$ & 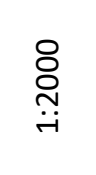 & $\begin{array}{l}\text { Kind gift } \\
\text { from K. } \\
\text { Baimbridg } \\
\text { e }\end{array}$ & ' & 10,11 & $\begin{array}{l}\text { Labels the same cell populations in } \\
\text { the brain as other antibodies to } \\
\text { parvalbumin }\end{array}$ \\
\hline Parvalbumin & 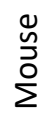 & 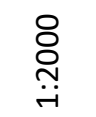 & Swant & $\stackrel{\stackrel{n}{n}}{\sim}$ & 17 & KO verified \\
\hline RFP & $\frac{: \frac{1}{0}}{\frac{0}{0}}$ & 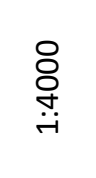 & $\begin{array}{l}\text { Rockland } \\
\text { Immuno- } \\
\text { chemicals } \\
\text { Inc. }\end{array}$ & 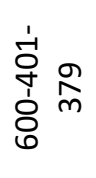 & 17 & $\begin{array}{l}\text { No staining in animals not injected } \\
\text { with mCherry-expressing virus }\end{array}$ \\
\hline RFP & $\begin{array}{l}+\pi \\
\stackrel{\pi}{x}\end{array}$ & 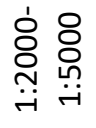 & Chromotek & $\underset{w}{\infty}$ & 17 & $\begin{array}{l}\text { No staining in animals not injected } \\
\text { with mCherry-expressing virus }\end{array}$ \\
\hline SERT & $\begin{array}{l}\frac{000}{2} \\
\stackrel{0}{0} \\
\stackrel{\frac{1}{5}}{0} \\
0\end{array}$ & $\begin{array}{l}\stackrel{8}{\circ} \\
\stackrel{\leftrightarrow}{-} \\
\stackrel{-}{-1}\end{array}$ & $\begin{array}{l}\text { Frontier } \\
\text { Institute }\end{array}$ & $\frac{\hat{N}}{\stackrel{N}{N}}$ & 12 & $\begin{array}{c}\text { Immunoblot detects a single } \\
\text { protein band at } 67-69 \mathrm{kDa} \text {. This } \\
\text { selectively stains serotonergic } \\
\text { neurons and fibers. }\end{array}$ \\
\hline $\mathrm{TH}$ & 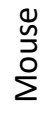 & 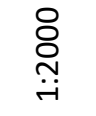 & $\begin{array}{l}\text { Immuno } \\
\text { Star }\end{array}$ & 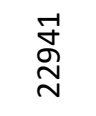 & 13 & $\begin{array}{c}\text { Staining is typical for TH-positive } \\
\text { cells }\end{array}$ \\
\hline $\mathrm{TpH}$ & 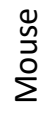 & $\underset{\substack{8 \\
m}}{\stackrel{m}{-}}$ & $\begin{array}{l}\text { Sigma- } \\
\text { Aldrich }\end{array}$ & $\stackrel{\infty}{\varrho}$ & 17,14 & $\begin{array}{l}\text { Staining is typical for TpH-positive } \\
\text { cells }\end{array}$ \\
\hline
\end{tabular}




\begin{tabular}{|c|c|c|c|c|c|c|}
\hline $\begin{array}{l}\text { vesicular GABA } \\
\text { transporter } \\
\text { (vGAT) }\end{array}$ & 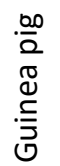 & 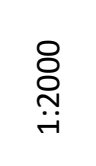 & $\begin{array}{l}\text { Synaptic } \\
\text { Systems }\end{array}$ & $\begin{array}{l}\text { ठ } \\
\varnothing \\
\vec{m} \\
\rightarrow\end{array}$ & 17 & KO verified \\
\hline $\begin{array}{c}\text { vesicular } \\
\text { glutamate } \\
\text { transporter, type } \\
2 \text { (vGluT2) }\end{array}$ & 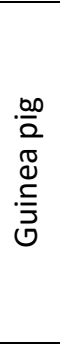 & $\begin{array}{l}\stackrel{8}{\circ} \\
\stackrel{N}{-}\end{array}$ & $\begin{array}{l}\text { Synaptic } \\
\text { Systems }\end{array}$ & 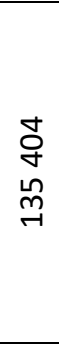 & 17,15 & $\begin{array}{l}\text { The antibody recognizes one major } \\
\text { broad band of the expected } \\
\text { molecular weight ( } 65 \mathrm{kDa} \text { ) on } \\
\text { western blots of a synaptic vesicle } \\
\text { fraction of rat brain and } \\
\text { immunostaining was abolished by } \\
\text { preadsorption with the } \\
\text { immunogen }\end{array}$ \\
\hline $\begin{array}{c}\text { vesicular } \\
\text { glutamate } \\
\text { transporter, type } \\
3 \text { (vGluT3) }\end{array}$ & $\begin{array}{l}\frac{1}{0} \\
\frac{0}{0} \\
\frac{0}{\pi}\end{array}$ & 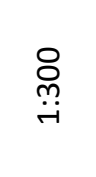 & $\begin{array}{l}\text { Synaptic } \\
\text { Systems }\end{array}$ & $\begin{array}{l}\stackrel{m}{N} \\
\stackrel{n}{m} \\
\rightarrow-1\end{array}$ & 17 & KO verified \\
\hline $\begin{array}{c}\text { vesicular } \\
\text { glutamate } \\
\text { transporter, type } \\
3(\text { vGluT3) }\end{array}$ & 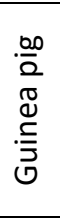 & 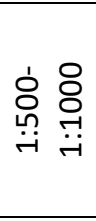 & $\begin{array}{l}\text { Frontier } \\
\text { Institute }\end{array}$ & $\begin{array}{l}\infty \\
\infty \\
\stackrel{\sim}{N} \\
\stackrel{N}{n}\end{array}$ & 17 & $\begin{array}{l}\text { Immunoblot detects a single } \\
\text { protein band at } 60-62 \mathrm{kDa} \text {. This } \\
\text { stains distinct neuronal } \\
\text { populations, which have not been } \\
\text { classified as glutamatergic neurons. }\end{array}$ \\
\hline DAPI & & $\begin{array}{l}\stackrel{8}{\circ} \\
\circ \\
\stackrel{-}{-}\end{array}$ & $\begin{array}{l}\text { Sigma- } \\
\text { Aldrich }\end{array}$ & & - & nuclear marker \\
\hline $\begin{array}{l}\text { Choleratoxin B } \\
\text { subunit }\end{array}$ & & ㅇํํ & $\begin{array}{c}\text { List } \\
\text { Biologicals }\end{array}$ & $\underset{+}{ \pm}$ & 16 & retrograde tracer \\
\hline FluoroGold & & ৯े & $\begin{array}{l}\text { Fluoro } \\
\text { Chrome } \\
\text { Inc. }\end{array}$ & ' & 16 & retrograde tracer \\
\hline \multicolumn{7}{|c|}{$\begin{array}{l}\text { References: 1. Buchan, A. M. et al., Peptides 9, 333-8; 2. Chédotal, A. et al., Brain Res. (1994); 3. Takács, V. } \\
\text { T. et al., Nat. Commun. 9, } 2848 \text { (2018); 4. Dederen, P. J. et al., Histochem. J. 26, 856-62 (1994); 5. } \\
\text { Hamorsky, K. T. et al., PLoS Negl. Trop. Dis. (2013); 6. Dautan, D. et al., Nat. Neurosci. (2016). 7. Varga, C. et } \\
\text { al., J. Neurosci. 22, 6186-94 (2002). 8. Watanabe, M. et al. Eur. J. Neurosci. 10, 478-87 (1998), 9. Hartwich, } \\
\text { K. et al., J. Neurosci. (2012). 10. Mascagni, F. et al., Neuroscience 158, 1541-50 (2009), 11. Condé, F. et al., } \\
\text { J. Comp. Neurol. 341, 95-116 (1994), 12. Somogyi, J. et al., Eur. J. Neurosci. 19, 552-69 (2004), 13. } \\
\text { Chermenina, M. et al., Parkinsons. Dis. (2015), 14. Kodani, S. et al., J. Neurosci. 37, 7164-7176 (2017). } 15 . \\
\text { Broms, J. et al., J. Comp. Neurol. (2015), 16. Lanciego, J. L. et al., Journal of Chemical Neuroanatomy } \\
\text { (2011). 17. Information is provided by the distributor. }\end{array}$} \\
\hline
\end{tabular}


Table S2: Secondary antibodies

\begin{tabular}{|c|c|c|c|c|c|}
\hline Raised in & $\begin{array}{l}\text { Raised } \\
\text { against }\end{array}$ & Conjugated with & Dilution & Source & $\begin{array}{l}\text { Catalog } \\
\text { number }\end{array}$ \\
\hline Donkey & Rabbit & Alexa 647 & $1: 500$ & Jackson Immunoresearch & 711-605-152 \\
\hline Donkey & Mouse & Alexa 647 & $1: 500$ & Jackson Immunoresearch & $715-605-151$ \\
\hline Donkey & Guinea pig & Alexa 647 & $1: 500$ & Jackson Immunoresearch & $706-605-148$ \\
\hline Goat & Chicken & Alexa 488 & $1: 1000$ & ThermoFisher Scientific & A11039 \\
\hline Donkey & Rabbit & Alexa 488 & $1: 1000$ & ThermoFisher Scientific & A21206 \\
\hline Donkey & Mouse & Alexa 488 & $1: 500$ & ThermoFisher Scientific & A21202 \\
\hline Goat & Guinea pig & Alexa 488 & $1: 500$ & ThermoFisher Scientific & A11073 \\
\hline Donkey & Rabbit & Alexa 594 & $1: 500$ & ThermoFisher Scientific & A21207 \\
\hline Donkey & Rat & Alexa 594 & $1: 500$ & ThermoFisher Scientific & A21209 \\
\hline Donkey & Guinea pig & Alexa 594 & $1: 500$ & Jackson Immunoresearch & $706-585-148$ \\
\hline Donkey & Mouse & Alexa 594 & $1: 500$ & ThermoFisher Scientific & A21203 \\
\hline- & - & DyLight405 & $1: 500$ & Jackson Immunoresearch & 016-470-084 \\
\hline Goat & Rabbit & $1.4 \mathrm{~nm}$ gold & $1: 100$ & Nanoprobes & $\# 2004$ \\
\hline Goat & Chicken & biotinylated & $1: 200$ & Vector Laboratories & BA-9010 \\
\hline Donkey & Mouse & biotinylated & 1:1000 & Jackson Immunoresearch & 715-066-151 \\
\hline Goat & Rabbit & biotinylated & $1: 1000$ & Rocklan Immunochemicals Inc. & 611-106-B76 \\
\hline Horse & Mouse & $\begin{array}{l}\text { Horseradish } \\
\text { peroxidase } \\
\text { (ImmPress) }\end{array}$ & $1: 3$ & Vector Laboratories & MP-7402 \\
\hline
\end{tabular}


Table S3: Primary and secondary antibody combinations used in immunofluorescent experiments

\begin{tabular}{|c|c|c|c|c|}
\hline $\begin{array}{l}\text { mouse } \\
\text { strain }\end{array}$ & $\begin{array}{l}\text { experiment } \\
\text { types }\end{array}$ & $\begin{array}{l}\text { used primary } \\
\text { antibodies or } \\
\text { reagents }\end{array}$ & used secondary antibodies & note \\
\hline \multirow{4}{*}{$\begin{array}{l}\text { vGluT2- } \\
\text { Cre }\end{array}$} & \multirow{4}{*}{ Stereology } & DAPI & - & \multirow{4}{*}{ Stereological measurement } \\
\hline & & $\begin{array}{l}\text { chicken-anti- } \\
\text { eGFP }\end{array}$ & $\begin{array}{c}\text { Alexa 488-conjugated goat- } \\
\text { anti-chicken }\end{array}$ & \\
\hline & & $\begin{array}{l}\text { rabbit-anti- } \\
\text { vGluT3 }\end{array}$ & $\begin{array}{c}\text { Alexa 594-conjugated } \\
\text { donkey-anti-rabbit }\end{array}$ & \\
\hline & & mouse-anti-TpH & $\begin{array}{c}\text { Alexa } 647 \text { conjugated } \\
\text { donkey-anti-mouse }\end{array}$ & \\
\hline $\begin{array}{l}\text { vGluT2- } \\
\text { Cre }\end{array}$ & $\begin{array}{l}\text { viral } \\
\text { anterograde } \\
\text { tracing }\end{array}$ & $\begin{array}{l}\text { chicken-anti- } \\
\text { eGFP }\end{array}$ & $\begin{array}{c}\text { Alexa 488-conjugated goat- } \\
\text { anti-chicken }\end{array}$ & $\begin{array}{l}\text { Labeling the injection sites } \\
\text { and ascending fibers from } \\
\text { MRR in vGluT2-Cre mice }\end{array}$ \\
\hline \multirow[t]{2}{*}{$\begin{array}{l}\text { vGluT2- } \\
\text { Cre }\end{array}$} & \multirow[t]{2}{*}{$\begin{array}{c}\text { viral } \\
\text { anterograde } \\
\text { tracing, } \\
\text { monosynaptic } \\
\text { rabies tracing }\end{array}$} & $\begin{array}{l}\text { chicken-anti- } \\
\text { eGFP }\end{array}$ & $\begin{array}{c}\text { Alexa 488-conjugated goat- } \\
\text { anti-chicken }\end{array}$ & \multirow{2}{*}{$\begin{array}{l}\text { Labeling the injection sites } \\
\text { and ascending fibers from } \\
\text { DR, NI, mRT, PnO, PPTg in } \\
\text { vGluT2-Cre mice. } \\
\text { Injection site analysis and } \\
\text { identification of } \\
\text { monosynaptically labeled } \\
\text { cells in the forebrain and in } \\
\text { the brainstem }\end{array}$} \\
\hline & & rat-anti-RFP & $\begin{array}{c}\text { Alexa 594-conjugated } \\
\text { donkey-anti-rat }\end{array}$ & \\
\hline $\begin{array}{l}\text { vGAT-Cre, } \\
\text { vGluT3- } \\
\text { Cre, TpH- } \\
\text { Cre }\end{array}$ & $\begin{array}{l}\text { viral } \\
\text { anterograde } \\
\text { tract-tracing }\end{array}$ & $\begin{array}{l}\text { chicken-anti- } \\
\text { eGFP }\end{array}$ & $\begin{array}{c}\text { Alexa 488-conjugated goat- } \\
\text { anti-chicken }\end{array}$ & $\begin{array}{l}\text { Labeling the injection sites } \\
\text { and ascending fibers from } \\
\text { MRR in vGAT-Cre, vGluT3- } \\
\text { Cre, TpH-Cre mouse }\end{array}$ \\
\hline \multirow{2}{*}{$\begin{array}{l}\text { vGluT2- } \\
\text { Cre }\end{array}$} & \multirow{2}{*}{$\begin{array}{l}\text { Analysis of the } \\
\text { neurochemical } \\
\text { identity of } \\
\text { MRR fibers }\end{array}$} & $\begin{array}{l}\text { chicken-anti- } \\
\text { eGFP }\end{array}$ & $\begin{array}{c}\text { Alexa 488-conjugated goat- } \\
\text { anti-chicken }\end{array}$ & \multirow{2}{*}{$\begin{array}{l}\text { vGluT2-labeling and MRR } \\
\text { fibers identification in the } \\
\text { forebrain }\end{array}$} \\
\hline & & $\begin{array}{c}\text { guinea pig anti- } \\
\text { vGluT2 }\end{array}$ & $\begin{array}{l}\text { Alexa 594-conjugated } \\
\text { donkey-anti-guinea pig }\end{array}$ & \\
\hline \multirow{3}{*}{$\begin{array}{l}\text { vGluT2- } \\
\text { Cre }\end{array}$} & \multirow{3}{*}{$\begin{array}{l}\text { Analysis of the } \\
\text { neurochemical } \\
\text { identity of } \\
\text { MRR fibers }\end{array}$} & $\begin{array}{l}\text { chicken-anti- } \\
\text { eGFP }\end{array}$ & $\begin{array}{c}\text { Alexa 488-conjugated goat- } \\
\text { anti-chicken }\end{array}$ & \multirow{3}{*}{$\begin{array}{c}\text { vGluT3 and vGAT-labeling } \\
\text { and MRR fibers identification } \\
\text { in the forebrain }\end{array}$} \\
\hline & & $\begin{array}{l}\text { rabbit anti- } \\
\text { vGluT3 }\end{array}$ & $\begin{array}{c}\text { Alexa 594-conjugated } \\
\text { donkey-anti-rabbit }\end{array}$ & \\
\hline & & $\begin{array}{c}\text { guinea pig anti- } \\
\text { VGAT }\end{array}$ & $\begin{array}{c}\text { Alexa } 647 \text { conjugated } \\
\text { donkey-anti-guinea pig }\end{array}$ & \\
\hline
\end{tabular}




\begin{tabular}{|c|c|c|c|c|}
\hline \multirow{2}{*}{$\begin{array}{l}\text { vGluT2- } \\
\text { Cre }\end{array}$} & \multirow{2}{*}{$\begin{array}{c}\text { Analysis of the } \\
\text { neurochemical } \\
\text { identity of } \\
\text { MRR fibers }\end{array}$} & $\begin{array}{l}\text { chicken-anti- } \\
\text { eGFP }\end{array}$ & $\begin{array}{c}\text { Alexa 488-conjugated goat- } \\
\text { anti-chicken }\end{array}$ & \multirow{2}{*}{$\begin{array}{l}\text { SERT-labeling and MRR fibers } \\
\text { identification in the forebrain }\end{array}$} \\
\hline & & $\begin{array}{l}\text { guinea pig anti- } \\
\text { SERT }\end{array}$ & $\begin{array}{l}\text { Alexa 594-conjugated } \\
\text { donkey-anti-guinea pig }\end{array}$ & \\
\hline \multirow{3}{*}{$\begin{array}{l}\text { vGluT2- } \\
\text { Cre }\end{array}$} & \multirow{3}{*}{$\begin{array}{c}\text { Target cell } \\
\text { selectivity of } \\
\text { LHb fibers in } \\
\text { the MRR; Local } \\
\text { connections of } \\
\text { MRR vGluT2 } \\
\text { fibers to } \\
\text { vGluT3+ cells }\end{array}$} & $\begin{array}{l}\text { chicken-anti- } \\
\text { eGFP }\end{array}$ & $\begin{array}{c}\text { Alexa 488-conjugated goat- } \\
\text { anti-chicken }\end{array}$ & \multirow{3}{*}{$\begin{array}{l}\text { Labeling vGluT3 cells in the } \\
\text { MRR }\end{array}$} \\
\hline & & $\begin{array}{l}\text { guinea pig-anti- } \\
\text { vGluT3 }\end{array}$ & $\begin{array}{c}\text { Alexa 594-conjugated } \\
\text { donkey-anti-guinea pig }\end{array}$ & \\
\hline & & $\begin{array}{l}\text { rabbit-anti- } \\
\text { Homer }\end{array}$ & $\begin{array}{l}\text { Alexa 647-conjugated } \\
\text { donkey-anti-rabbit }\end{array}$ & \\
\hline \multirow{3}{*}{$\begin{array}{l}\text { vGluT2- } \\
\text { Cre }\end{array}$} & \multirow{3}{*}{$\begin{array}{c}\text { Target cell } \\
\text { selectivity of } \\
\text { LHb fibers in } \\
\text { the MRR; Local } \\
\text { connections of } \\
\text { MRR vGluT2 } \\
\text { fibers to } \\
\text { serotonergic } \\
\text { cells }\end{array}$} & $\begin{array}{l}\text { chicken-anti- } \\
\text { eGFP }\end{array}$ & $\begin{array}{l}\text { Alexa 488-conjugated goat- } \\
\text { anti-chicken }\end{array}$ & \multirow{3}{*}{$\begin{array}{c}\text { Labeling serotonergic cells in } \\
\text { the MRR }\end{array}$} \\
\hline & & mouse-anti-TpH & $\begin{array}{c}\text { Alexa } 594 \text { conjugated } \\
\text { donkey-anti-mouse }\end{array}$ & \\
\hline & & $\begin{array}{l}\text { rabbit-anti- } \\
\text { Homer }\end{array}$ & $\begin{array}{l}\text { Alexa 647-conjugated } \\
\text { donkey-anti-rabbit }\end{array}$ & \\
\hline \multirow{3}{*}{$\begin{array}{l}\text { vGluT2- } \\
\text { Cre }\end{array}$} & \multirow{3}{*}{$\begin{array}{l}\text { Target cell } \\
\text { selectivity of } \\
\text { MRR fibers in } \\
\text { the LHb and } \\
\text { LHb fibers in } \\
\text { the MRR }\end{array}$} & $\begin{array}{l}\text { chicken-anti- } \\
\text { eGFP }\end{array}$ & $\begin{array}{c}\text { Alexa 488-conjugated goat- } \\
\text { anti-chicken }\end{array}$ & \multirow{3}{*}{$\begin{array}{l}\text { Viraly labeling vGluT2 cells in } \\
\text { LHb and MRR }\end{array}$} \\
\hline & & rat-anti-RFP & $\begin{array}{l}\text { Alexa 594-conjugated } \\
\text { donkey-anti-rat }\end{array}$ & \\
\hline & & $\begin{array}{l}\text { rabbit-anti- } \\
\text { Homer }\end{array}$ & $\begin{array}{c}\text { Alexa 647-conjugated } \\
\text { donkey-anti-rabbit }\end{array}$ & \\
\hline \multirow{4}{*}{$\begin{array}{l}\text { vGluT2- } \\
\text { Cre }\end{array}$} & \multirow{4}{*}{$\begin{array}{l}\text { Target cell } \\
\text { selectivity of } \\
\text { LHb fibers in } \\
\text { MRR }\end{array}$} & $\begin{array}{l}\text { chicken-anti- } \\
\text { eGFP }\end{array}$ & $\begin{array}{l}\text { Alexa 488-conjugated goat- } \\
\text { anti-chicken }\end{array}$ & \multirow{4}{*}{$\begin{array}{l}\text { Measurement from } \\
\text { retrogradely traced vGluT2- } \\
\text { positive cells from LHb in the } \\
\text { MRR }\end{array}$} \\
\hline & & rat-anti-RFP & $\begin{array}{l}\text { Alexa 594-conjugated } \\
\text { donkey-anti-rat }\end{array}$ & \\
\hline & & $\begin{array}{l}\text { rabbit-anti- } \\
\text { Homer }\end{array}$ & $\begin{array}{l}\text { Alexa 647-conjugated } \\
\text { donkey-anti-rabbit }\end{array}$ & \\
\hline & & $\begin{array}{l}\text { mouse-anti- } \\
\text { Choleratoxin B }\end{array}$ & $\begin{array}{l}\text { biotinylated donkey-anti- } \\
\text { mouse + DyLight } 405 \\
\text { conjugated streptavidin }\end{array}$ & \\
\hline \multirow{3}{*}{$\begin{array}{l}\text { vGluT2- } \\
\text { Cre }\end{array}$} & \multirow{3}{*}{$\begin{array}{l}\text { Target cell } \\
\text { selectivity of } \\
\text { MRR fibers in } \\
\text { the LHb }\end{array}$} & $\begin{array}{l}\text { guinea pig-anti- } \\
\text { FluoroGold }\end{array}$ & $\begin{array}{c}\text { Alexa 488-conjugated goat- } \\
\text { anti-guinea pig }\end{array}$ & \multirow{3}{*}{$\begin{array}{l}\text { Retrograde tracing from VTA } \\
\text { and MRR in the LHb }\end{array}$} \\
\hline & & $\begin{array}{l}\text { rabbit-anti- } \\
\text { mCherry }\end{array}$ & $\begin{array}{c}\text { Alexa 594-conjugated } \\
\text { donkey-anti-rabbit }\end{array}$ & \\
\hline & & $\begin{array}{l}\text { mouse-anti- } \\
\text { Choleratoxin B }\end{array}$ & $\begin{array}{l}\text { Alexa 647-conjugated } \\
\text { donkey-anti-mouse }\end{array}$ & \\
\hline
\end{tabular}




\begin{tabular}{|c|c|c|c|c|}
\hline \multirow{3}{*}{$\begin{array}{l}\text { vGluT2- } \\
\text { Cre }\end{array}$} & \multirow{3}{*}{$\begin{array}{l}\text { Target cell } \\
\text { selectivity of } \\
\text { MRR fibers in } \\
\text { the LHb }\end{array}$} & $\begin{array}{l}\text { mouse-anti- } \\
\text { Choleratoxin B }\end{array}$ & $\begin{array}{l}\text { Alexa 488-conjugated } \\
\text { donkey-anti-mouse }\end{array}$ & \multirow{3}{*}{$\begin{array}{l}\text { Measurement from } \\
\text { retrograde tracing from MRR } \\
\text { in the LHb }\end{array}$} \\
\hline & & rat-anti-RFP & $\begin{array}{c}\text { Alexa 594-conjugated } \\
\text { donkey-anti-rat }\end{array}$ & \\
\hline & & $\begin{array}{c}\text { rabbit-anti- } \\
\text { Homer }\end{array}$ & $\begin{array}{c}\text { Alexa 647-conjugated } \\
\text { donkey-anti-rabbit }\end{array}$ & \\
\hline \multirow{4}{*}{$\begin{array}{l}\text { vGluT2- } \\
\text { Cre }\end{array}$} & \multirow{4}{*}{$\begin{array}{l}\text { Target cell } \\
\text { selectivity of } \\
\text { MRR fibers in } \\
\text { the mVTA }\end{array}$} & $\begin{array}{l}\text { chicken-anti- } \\
\text { eGFP }\end{array}$ & $\begin{array}{c}\text { Alexa 488-conjugated goat- } \\
\text { anti-chicken }\end{array}$ & \multirow{4}{*}{$\begin{array}{c}\text { LHb and MRR vGluT2- } \\
\text { neurons target medial VTA } \\
\text { DA neurons }\end{array}$} \\
\hline & & rat-anti-RFP & $\begin{array}{c}\text { Alexa 594-conjugated } \\
\text { donkey-anti-rat }\end{array}$ & \\
\hline & & $\begin{array}{l}\text { rabbit-anti- } \\
\text { Homer }\end{array}$ & $\begin{array}{c}\text { Alexa 647-conjugated } \\
\text { donkey-anti-rabbit }\end{array}$ & \\
\hline & & mouse-anti-TH & $\begin{array}{l}\text { biotinylated donkey-anti- } \\
\text { mouse + DyLight } 405 \\
\text { conjugated streptavidin }\end{array}$ & \\
\hline \multirow{4}{*}{$\begin{array}{l}\text { vGluT2- } \\
\text { Cre }\end{array}$} & \multirow{4}{*}{$\begin{array}{l}\text { Target cell } \\
\text { selectivity of } \\
\text { MRR fibers in } \\
\text { the mVTA }\end{array}$} & $\begin{array}{l}\text { chicken-anti- } \\
\text { eGFP }\end{array}$ & $\begin{array}{c}\text { Alexa 488-conjugated } \\
\text { donkey-anti-chicken }\end{array}$ & \multirow{4}{*}{$\begin{array}{l}\text { MRR vGluT2-neurons target } \\
\text { medial VTA DA neurons that } \\
\text { project to PFC }\end{array}$} \\
\hline & & goat-anti-CTB & $\begin{array}{c}\text { Alexa 594-conjugated } \\
\text { donkey-anti-goat }\end{array}$ & \\
\hline & & $\begin{array}{c}\text { rabbit-anti- } \\
\text { Homer }\end{array}$ & $\begin{array}{c}\text { Alexa 647-conjugated } \\
\text { donkey-anti-rabbit }\end{array}$ & \\
\hline & & mouse-anti-TH & $\begin{array}{l}\text { biotinylated donkey-anti- } \\
\text { mouse + DyLight405 } \\
\text { conjugated streptavidin }\end{array}$ & \\
\hline \multirow{3}{*}{$\begin{array}{l}\text { vGluT2- } \\
\text { Cre }\end{array}$} & \multirow{3}{*}{$\begin{array}{l}\text { Target cell } \\
\text { selectivity of } \\
\text { MRR fibers in } \\
\text { the VDB }\end{array}$} & $\begin{array}{l}\text { chicken-anti- } \\
\text { eGFP }\end{array}$ & $\begin{array}{c}\text { Alexa 488-conjugated goat- } \\
\text { anti-chicken }\end{array}$ & \multirow{3}{*}{$\begin{array}{c}\text { Labeling PV positive cells in } \\
\text { the VDB }\end{array}$} \\
\hline & & $\begin{array}{l}\text { mouse-anti- } \\
\text { Parvalbumin }\end{array}$ & $\begin{array}{c}\text { Alexa } 594 \text { conjugated } \\
\text { donkey-anti-mouse }\end{array}$ & \\
\hline & & $\begin{array}{l}\text { rabbit-anti- } \\
\text { Homer }\end{array}$ & $\begin{array}{c}\text { Alexa 647-conjugated } \\
\text { donkey-anti-rabbit }\end{array}$ & \\
\hline \multirow{3}{*}{$\begin{array}{l}\text { vGluT2- } \\
\text { Cre }\end{array}$} & \multirow{3}{*}{$\begin{array}{l}\text { Target cell } \\
\text { selectivity of } \\
\text { MRR fibers in } \\
\text { the VDB }\end{array}$} & $\begin{array}{l}\text { chicken-anti- } \\
\text { eGFP }\end{array}$ & $\begin{array}{c}\text { Alexa 488-conjugated goat- } \\
\text { anti-chicken }\end{array}$ & \multirow{3}{*}{$\begin{array}{l}\text { Labeling PV and ChAT } \\
\text { positive cells in the VDB }\end{array}$} \\
\hline & & $\begin{array}{l}\text { rabbit-anti- } \\
\text { Parvalbumin }\end{array}$ & $\begin{array}{l}\text { Alexa } 594 \text { conjugated } \\
\text { donkey-anti-rabbit }\end{array}$ & \\
\hline & & $\begin{array}{l}\text { mouse-anti- } \\
\text { ChAT }\end{array}$ & $\begin{array}{c}\text { Alexa } 647 \text { conjugated } \\
\text { donkey-anti-mouse }\end{array}$ & \\
\hline \multirow{2}{*}{$\begin{array}{l}\text { vGluT2- } \\
\text { Cre }\end{array}$} & \multirow{2}{*}{$\begin{array}{l}\text { Target cell } \\
\text { selectivity of } \\
\text { MRR fibers in } \\
\text { the VDB }\end{array}$} & $\begin{array}{l}\text { chicken-anti- } \\
\text { eGFP }\end{array}$ & $\begin{array}{c}\text { Alexa 488-conjugated goat- } \\
\text { anti-chicken }\end{array}$ & \multirow{2}{*}{$\begin{array}{c}\text { Labeling CR positive cells in } \\
\text { the VDB }\end{array}$} \\
\hline & & $\begin{array}{l}\text { mouse-anti- } \\
\text { Calretinin }\end{array}$ & $\begin{array}{l}\text { Alexa } 647 \text { conjugated } \\
\text { donkey-anti-mouse }\end{array}$ & \\
\hline \multirow{3}{*}{$\begin{array}{l}\text { vGluT2- } \\
\text { Cre }\end{array}$} & \multirow{3}{*}{$\begin{array}{l}\text { Target cell } \\
\text { selectivity of } \\
\text { MRR fibers in } \\
\text { the VDB }\end{array}$} & $\begin{array}{l}\text { chicken-anti- } \\
\text { eGFP }\end{array}$ & $\begin{array}{c}\text { Alexa 488-conjugated goat- } \\
\text { anti-chicken }\end{array}$ & \multirow{3}{*}{$\begin{array}{l}\text { Labeling vGluT2+ and CB } \\
\text { positive cells in the VDB }\end{array}$} \\
\hline & & rat-anti-RFP & $\begin{array}{l}\text { Alexa 594-conjugated } \\
\text { donkey-anti-rat }\end{array}$ & \\
\hline & & $\begin{array}{l}\text { rabbit-anti- } \\
\text { calbindin }\end{array}$ & $\begin{array}{l}\text { Alexa 647-conjugated } \\
\text { donkey-anti-rabbit }\end{array}$ & \\
\hline
\end{tabular}




\begin{tabular}{|c|c|c|c|c|}
\hline \multirow{3}{*}{$\begin{array}{l}\text { vGluT2- } \\
\text { Cre }\end{array}$} & \multirow{3}{*}{$\begin{array}{l}\text { Target cell } \\
\text { selectivity of } \\
\text { MRR fibers in } \\
\text { the LHb }\end{array}$} & $\begin{array}{l}\text { guinea pig-anti- } \\
\text { FluoroGold }\end{array}$ & $\begin{array}{c}\text { Alexa 488-conjugated goat- } \\
\text { anti-guinea pig }\end{array}$ & \multirow{3}{*}{$\begin{array}{l}\text { Measurement from } \\
\text { retrograde tracing from HIPP } \\
\text { in the VDB }\end{array}$} \\
\hline & & $\begin{array}{l}\text { rabbit-anti- } \\
\text { mCherry }\end{array}$ & $\begin{array}{c}\text { Alexa 594-conjugated } \\
\text { donkey-anti-rabbit }\end{array}$ & \\
\hline & & $\begin{array}{l}\text { mouse-anti- } \\
\text { Parvalbumin }\end{array}$ & $\begin{array}{c}\text { Alexa 647-conjugated } \\
\text { donkey-anti-mouse }\end{array}$ & \\
\hline \multirow{3}{*}{$\begin{array}{l}\text { vGluT2- } \\
\text { Cre }\end{array}$} & \multirow{3}{*}{$\begin{array}{c}\text { Post-hoc } \\
\text { anatomical } \\
\text { identification } \\
\text { of in vitro } \\
\text { labeled cells in } \\
\text { the LHb }\end{array}$} & $\begin{array}{l}\text { chicken-anti- } \\
\text { eGFP }\end{array}$ & $\begin{array}{c}\text { Alexa 488-conjugated } \\
\text { donkey-anti-rabbit }\end{array}$ & \multirow{3}{*}{$\begin{array}{l}\text { Labeling of MRR fibers and in } \\
\text { vitro labeled cells in LHb }\end{array}$} \\
\hline & & $\begin{array}{l}\text { Alexa 594- } \\
\text { conjugated } \\
\text { Streptavidin }\end{array}$ & $\begin{array}{l}\text { Alexa 594-conjugated } \\
\text { Streptavidin }\end{array}$ & \\
\hline & & $\begin{array}{c}\text { rabbit-anti- } \\
\text { Homer }\end{array}$ & $\begin{array}{l}\text { Alexa 647-conjugated } \\
\text { donkey-anti-rabbit }\end{array}$ & \\
\hline \multirow{3}{*}{$\begin{array}{l}\text { vGluT2- } \\
\text { Cre }\end{array}$} & \multirow{3}{*}{$\begin{array}{l}\text { VDB-LHb } \\
\text { double } \\
\text { retrograde } \\
\text { tracing }\end{array}$} & $\begin{array}{l}\text { rabbit-anti- } \\
\text { FluoroGold }\end{array}$ & $\begin{array}{c}\text { Alexa 488-conjugated } \\
\text { donkey-anti-rabbit }\end{array}$ & \multirow{3}{*}{$\begin{array}{l}\text { Identification of the } \\
\text { retrogradely labeled cells in } \\
\text { the MRR }\end{array}$} \\
\hline & & rat-anti-RFP & $\begin{array}{c}\text { Alexa 594-conjugated } \\
\text { donkey-anti-rat }\end{array}$ & \\
\hline & & $\begin{array}{c}\text { mouse-anti- } \\
\text { Choleratoxin B }\end{array}$ & $\begin{array}{c}\text { Alexa 647-conjugated } \\
\text { donkey-anti-mouse }\end{array}$ & \\
\hline
\end{tabular}


Table S4: Primary and secondary antibody combinations used in immunoperoxidase and electron microscopic experiments

\begin{tabular}{|c|c|c|c|c|}
\hline \multirow{2}{*}{ vGluT2-Cre } & \multirow{2}{*}{$\begin{array}{c}\text { Analysis of NMDA } \\
\text { receptor GluN2A subunit } \\
\text { positivity of MRR fibers in } \\
\text { the LHb and MS }\end{array}$} & chicken-anti-eGFP & $\begin{array}{l}\text { biotinylated } \\
\text { goat-anti- } \\
\text { chicken } \\
\end{array}$ & \multirow{4}{*}{$\begin{array}{l}\text { Correlated } \\
\text { double } \\
\text { immunogold- } \\
\text { immuno- } \\
\text { peroxidase } \\
\text { electron } \\
\text { microscopy for } \\
\text { glutamatergic } \\
\text { molecular } \\
\text { machinery } \\
\text { analysis in MRR } \\
\text { vGluT2 fibers }\end{array}$} \\
\hline & & $\begin{array}{c}\text { rabbit-anti-NMDA } \\
\text { receptor NR2A } \\
\text { subunit }\end{array}$ & $\begin{array}{c}1.4 \mathrm{~nm} \text { gold } \\
\text { conjugated } \\
\text { goat-anti-rabbit }\end{array}$ & \\
\hline \multirow{2}{*}{ vGluT2-Cre } & \multirow{2}{*}{$\begin{array}{l}\text { Analysis of NMDA } \\
\text { receptor GluN1 subunit } \\
\text { positivity of MRR fibers in } \\
\text { the LHb }\end{array}$} & chicken-anti-eGFP & $\begin{array}{l}\text { biotinylated } \\
\text { goat-anti- } \\
\text { chicken } \\
\end{array}$ & \\
\hline & & $\begin{array}{l}\text { rabbit-anti-NMDA } \\
\text { receptor NR1 subunit }\end{array}$ & \begin{tabular}{|c|}
$1.4 \mathrm{~nm}$ gold \\
conjugated \\
goat-anti-rabbit
\end{tabular} & \\
\hline \multirow[b]{2}{*}{ vGluT2-Cre } & \multirow[b]{2}{*}{$\begin{array}{l}\text { Parvalbumin-specificity } \\
\text { of MRR fibers in the VDB }\end{array}$} & chicken-anti-eGFP & $\begin{array}{l}\text { biotinylated } \\
\text { goat-anti- } \\
\text { chicken }\end{array}$ & \multirow{2}{*}{$\begin{array}{c}\text { Correlated } \\
\text { double SI- } \\
\text { DAB/DAB-Ni } \\
\text { electron } \\
\text { microscopy for } \\
\text { target specificity } \\
\text { of MRR fibers in } \\
\text { the MS/VDB }\end{array}$} \\
\hline & & $\begin{array}{l}\text { mouse-anti- } \\
\text { Parvalbumin }\end{array}$ & $\begin{array}{l}\text { ImmPress } \\
\text { horse-anti- } \\
\text { mouse }\end{array}$ & \\
\hline vGluT2-Cre & Experiment for BFSEM & rabbit-anti-eGFP & $\begin{array}{c}1.4 \mathrm{~nm} \text { gold } \\
\text { conjugated } \\
\text { goat-anti-rabbit }\end{array}$ & $\begin{array}{l}\text { MRR terminal } \\
\text { reconstruction in } \\
\text { LHb }\end{array}$ \\
\hline vGluT2-Cre & $\begin{array}{l}\text { Chemogenetic virus } \\
\text { injection site } \\
\text { identification }\end{array}$ & rabbit-anti-RFP & $\begin{array}{c}\text { biotinylated } \\
\text { goat-anti-rabbit }\end{array}$ & $\begin{array}{l}\text { Chemogenetic } \\
\text { virus injection } \\
\text { site identification }\end{array}$ \\
\hline
\end{tabular}


Table S5: Stereological estimation of MRR neurons

\begin{tabular}{|l|r|r|r|r|}
\hline & Mouse1 & Mouse2 & Mouse3 & Average \\
\hline Total counted vGluT2 positive neurons & 8524 & 7014 & 4826 & $\mathbf{6 7 8 8}$ \\
\hline Total counted TpH or/and vGluT3 positive neurons & 5886 & 3362 & 3995 & $\mathbf{4 4 1 4}$ \\
\hline $\begin{array}{l}\text { vGluT2 positive neurons / TpH and/or vGluT3 } \\
\text { positive neurons }\end{array}$ & 1,45 & 2,09 & 1,21 & $\mathbf{1 , 5 8}$ \\
\hline \multicolumn{3}{|l|}{} \\
\hline All TpH and/or vGluT3 positive neurons (22) & & $\mathbf{6 0 6 7}$ \\
\hline Total neurons (22) & & $\mathbf{4 7 4 5 8}$ \\
\hline vGluT2 positive neurons in MRR & & $\mathbf{1 , 5 8 * 6 0 6 7 = 9 5 8 6}$ \\
\hline vGluT2 positive neurons ratios in MRR & $\mathbf{2 0 , 2 0 \%}$ \\
\hline
\end{tabular}


Table S6: Quantification of monosynaptically-labeled neurons with rabies virus in the different brain areas projecting to MRR vGluT2 neurons.

\begin{tabular}{|c|c|c|c|c|c|c|}
\hline \multirow[t]{2}{*}{ Brain area /Nucleus } & \multirow[t]{2}{*}{$\begin{array}{l}\text { Median } \\
\%\end{array}$} & \multicolumn{3}{|c|}{$\begin{array}{l}\text { Estimation of cell numbers } \\
\text { per brain area }\end{array}$} & \multirow[t]{2}{*}{ Behavioral relevance } & \multirow[t]{2}{*}{ Ref. } \\
\hline & & Mouse1 & Mouse2 & Mouse3 & & \\
\hline $\begin{array}{l}\text { Lateral habenular } \\
\text { nucleus }\end{array}$ & $10,0 \%$ & 588 & 456 & 756 & aversion center, depression & $1-4$ \\
\hline Mammillary region & $8,5 \%$ & 504 & 396 & 252 & memory formation & 5,6 \\
\hline Dorsal raphe nucleus & $7,8 \%$ & 468 & 354 & 678 & $\begin{array}{l}\text { Anti-aversion, } \\
\text { antidepressant }\end{array}$ & 7,8 \\
\hline VTA together & $7,4 \%$ & 438 & 384 & 384 & aversion, reward & 9 \\
\hline $\begin{array}{l}\text { Lateral hypothalamic } \\
\text { area }\end{array}$ & $6,6 \%$ & 408 & 300 & 510 & cued-dependent aversion & 10,11 \\
\hline PAG together & $6,0 \%$ & 354 & 342 & 324 & freezing behavior & 12 \\
\hline $\begin{array}{l}\text { Laterodorsal tegmental } \\
\text { nucleus }\end{array}$ & $5,9 \%$ & 348 & 174 & 721 & $\begin{array}{l}\text { innate fear, reward } \\
\text { processing }\end{array}$ & 13,14 \\
\hline Nucleus pontis oralis & $5,2 \%$ & 198 & 234 & 846 & REM sleep, theta generation & 15 \\
\hline Zona incerta & $4,0 \%$ & 258 & 24 & 360 & fear, freezing, attention & $16-18$ \\
\hline PFC together & $2,3 \%$ & 138 & 108 & 78 & fear, reward, aversion & 14,19 \\
\hline Nucleus incertus & $1,7 \%$ & 300 & 78 & 126 & memory formation & 20 \\
\hline Raphe magnus nucleus & $1,6 \%$ & 108 & 42 & 144 & pain inhibition & 21 \\
\hline Lateral preoptic area & $1,5 \%$ & 90 & 144 & 78 & aversion, reward & 22 \\
\hline Ventral pallidum & $1,3 \%$ & 102 & 60 & 84 & reward seeking & 23 \\
\hline $\begin{array}{l}\text { Posterior hypothalamic } \\
\text { nucleus }\end{array}$ & $1,2 \%$ & 72 & 42 & 192 & $\begin{array}{l}\text { theta rhythm, spatial } \\
\text { memory }\end{array}$ & 24,25 \\
\hline $\begin{array}{l}\text { Dorsomedial } \\
\text { hypothalamic nucleus }\end{array}$ & $1,1 \%$ & 6 & 66 & 96 & circadian rhythms & 26 \\
\hline $\begin{array}{l}\text { Substantia nigra, } \\
\text { reticular part }\end{array}$ & $1,1 \%$ & 66 & 12 & 156 & motor control & 27,28 \\
\hline Rostral linear nucleus & $1,0 \%$ & 60 & 78 & 0 & olfactory-guided behavior & 29 \\
\hline TOTAL & $74,43 \%$ & 4506 & 3294 & 5785 & & \\
\hline
\end{tabular}

References: 1. Stephenson-Jones et al., Proc. Natl. Acad. Sci. 109, E164-E173 (2012), 2. Stopper et al., Nat. Neurosci. 17, 33-35 (2014), 3. Li et al., Elife 8, 1-17 (2019). 4. Yang, Y. et al., Nature 554, 317-322 (2018), 5. Dillingham et al., Neurosci. Biobehav. Rev. 54, 108-119 (2015), 6. Vann, S. D. et al., Nat. Rev. Neurosci. 5, 3544 (2004). 7. Luo, M. et al., Learn. Mem. 22, 452-460 (2015), 8. Zhang, H. et al., Brain Struct. Funct. 223, 2243-2258 (2018), 9. Lammel, S. et al., Neuropharmacology 76 Pt B, 351-9 (2014), 10. de Jong, J. W. et al., Neuron (2019), 11. Lazaridis, I. et al., Mol. Psychiatry (2019), 12. Tovote, P. et al. Nature 534, 206-212 (2016), 13. Yang, H. et al., Nat. Neurosci. 19, 283-9 (2016), 14. Lammel, S. et al., Nature 491, 212-217 (2012), 15. Sanford, L. D. et al., J. Neurophysiol. 90, 938-945 (2006). 16. Chou, X. L. et al. Nat. Commun. 9, 1-12 (2018), 17. Watson et al., J. Neurosci. 35, 9463-9476 (2015), 18. Chometton, S. et al., Brain Struct. Funct. (2017), 19. Rozeske et al., Genes, Brain Behav. 14, 22-36 (2015), 20. Szőnyi, A. et al., Science 364, (2019), 21. Brodie et al., Brain Res. (1986), 22. Barker, D. J. et al., Cell Rep. 21, 1757-1769 (2017), 23. Tooley, J. et al., Biol. Psychiatry (2018), 24. Bocian, R. et al., Hippocampus 26, 1354-1369 (2016), 25. Gutiérrez-Guzmán, B. E. et al., Eur. J. Pharmacol. 682, 99-109 (2012), 26. Chou, T. C. et al., J. Neurosci. (2003), 27. Hikosaka, O. et al., J. Neurophysiol. (1983), 28. Sato, M. et al., J. Neurosci. (2002), 29. Del-Fava, F. et al., Neuroscience (2007). 


\section{References}

1. E. S. Bromberg-Martin, M. Matsumoto, H. Nakahara, O. Hikosaka, Multiple Timescales of Memory in Lateral Habenula and Dopamine Neurons. Neuron. 67, 499-510 (2010).

2. E. S. Bromberg-Martin, O. Hikosaka, Lateral habenula neurons signal errors in the prediction of reward information. Nat. Neurosci. 14, 1209-1218 (2011).

3. E. S. Bromberg-Martin, M. Matsumoto, O. Hikosaka, Distinct tonic and phasic anticipatory activity in lateral habenula and dopamine neurons. Neuron. 67, 144-155 (2010).

4. C. A. Orsini, D. E. Moorman, J. W. Young, B. Setlow, S. B. Floresco, Neural mechanisms regulating different forms of riskrelated decision-making: Insights from animal models. Neurosci. Biobehav. Rev. 58, 147-167 (2015).

5. C. M. Stopper, S. B. Floresco, What's better for me? Fundamental role for lateral habenula in promoting subjective decision biases. Nat. Neurosci. 17, 33-35 (2014).

6. C. M. Stopper, M. T. L. Tse, D. R. Montes, C. R. Wiedman, S. B. Floresco, Overriding phasic dopamine signals redirects action selection during risk/reward decision making. Neuron. 84, 177-189 (2014).

7. P. M. Baker, S. E. Oh, K. S. Kidder, S. J. Y. Mizumori, Ongoing behavioral state information signaled in the lateral habenula guides choice flexibility in freely moving rats. Front. Behav. Neurosci. 9, 295 (2015).

8. R. Goutagny, M. Loureiro, J. Jackson, J. Chaumont, S. Williams, P. Isope, C. Kelche, J. C. Cassel, L. Lecourtier, Interactions between the lateral habenula and the Hippocampus: Implication for spatial memory processes. Neuropsychopharmacology. 38, 2418-2426 (2013).

9. R. Crooks, J. Jackson, B. H. Bland, Dissociable pathways facilitate theta and non-theta states in the median rapheSeptohippocampal circuit. Hippocampus. 22, 1567-1576 (2012).

10. A. Domonkos, L. Nikitidou Ledri, T. Laszlovszky, C. Cserép, Z. Borhegyi, E. Papp, G. Nyiri, T. F. Freund, V. Varga, Divergent in vivo activity of non-serotonergic and serotonergic VGluT3-neurones in the median raphe region. J. Physiol. 594, 3775-3790 (2016).

11. J. Jackson, C. T. Dickson, B. H. Bland, Median Raphe Stimulation Disrupts Hippocampal Theta Via Rapid Inhibition and StateDependent Phase Reset of Theta-Related Neural Circuitry. J. Neurophysiol. 99, 3009-3026 (2008).

12. G. V. Di Prisco, Z. Albo, R. P. Vertes, B. Kocsis, Discharge properties of neurons of the median raphe nucleus during hippocampal theta rhythm in the rat. Exp. Brain Res. 145, 383-394 (2002).

13. D. V. Wang, H. J. Yau, C. J. Broker, J. H. Tsou, A. Bonci, S. Ikemoto, Mesopontine median raphe regulates hippocampal ripple oscillation and memory consolidation. Nat. Neurosci. 18, 728-735 (2015).

14. H. Aizawa, S. Yanagihara, M. Kobayashi, K. Niisato, T. Takekawa, R. Harukuni, T. J. McHugh, T. Fukai, Y. Isomura, H. Okamoto, The Synchronous Activity of Lateral Habenular Neurons Is Essential for Regulating Hippocampal Theta Oscillation. J. Neurosci. 33, 8909-8921 (2013).

15. T. G. C. S. Andrade, H. Zangrossi, F. G. Graeff, The median raphe nucleus in anxiety revisited. J. Psychopharmacol. 27, 11071115 (2013).

16. D. G. Balázsfi, D. Zelena, L. Farkas, K. Demeter, I. Barna, C. Cserép, V. T. Takács, G. Nyíri, F. Gölöncsér, B. Sperlágh, T. F. Freund, J. Haller, Median raphe region stimulation alone generates remote, but not recent fear memory traces. PLoS One. 12, e0181264 (2017).

17. T. F. Freund, a I. Gulyás, L. Acsády, T. Görcs, K. Tóth, A. I. Gulyas, L. Acsady, T. Gorcs, K. Toth, Serotonergic control of the hippocampus via local inhibitory interneurons. Proc. Natl. Acad. Sci. 87, 8501-8505 (1990).

18. J. Jackson, B. H. Bland, M. C. Antle, Nonserotonergic projection neurons in the midbrain raphe nuclei contain the vesicular glutamate transporter VGLUT3. Synapse. 63, 31-41 (2009).

19. V. Varga, A. Losonczy, B. V. Zemelman, Z. Borhegyi, G. Nyiri, A. Domonkos, B. Hangya, N. Holderith, J. C. Magee, T. F. Freund, Fast synaptic subcortical control of hippocampal circuits. Science (80-. ). 326, 449-453 (2009).

20. S. J. Bang, P. Jensen, S. M. Dymecki, K. G. Commons, Projections and interconnections of genetically defined serotonin neurons in mice. Eur. J. Neurosci. 35, 85-96 (2012).

21. C. Leranth, R. P. Vertes, Median raphe serotonergic innervation of medial septum/diagonal band of broca (MSDB) parvalbumin-containing neurons: possible involvement of the MSDB in the desynchronization of the hippocampal EEG. J. Comp. Neurol. 410, 586-98 (1999).

22. K. E. Sos, M. I. Mayer, C. Cserép, F. S. Takács, A. Szőnyi, T. F. Freund, G. Nyiri, Cellular architecture and transmitter phenotypes of neurons of the mouse median raphe region. Brain Struct. Funct. 222, 287-299 (2017).

23. S. Lammel, B. K. Lim, C. Ran, K. W. Huang, M. J. Betley, K. M. Tye, K. Deisseroth, R. C. Malenka, Input-specific control of reward and aversion in the ventral tegmental area. Nature. 491, 212-217 (2012).

24. S. Lammel, B. K. Lim, R. C. Malenka, Reward and aversion in a heterogeneous midbrain dopamine system. Neuropharmacology. 76 Pt B, 351-9 (2014).

25. L. A. Quina, L. Tempest, L. Ng, J. A. Harris, S. Ferguson, T. C. Jhou, E. E. Turner, Efferent pathways of the mouse lateral habenula. J. Comp. Neurol. 523, 32-60 (2015).

26. I. R. Wickersham, D. C. Lyon, R. J. O. Barnard, T. Mori, S. Finke, K.-K. Conzelmann, J. A. T. Young, E. M. Callaway, Monosynaptic restriction of transsynaptic tracing from single, genetically targeted neurons. Neuron. 53, 639-47 (2007).

27. A. Szőnyi, K. E. Sos, R. Nyilas, D. Schlingloff, A. Domonkos, V. T. Takács, B. Pósfai, P. Hegedüs, J. B. Priestley, A. L. Gundlach, A. I. Gulyás, V. Varga, A. Losonczy, T. F. Freund, G. Nyiri, Brainstem nucleus incertus controls contextual memory formation. Science. 364 (2019), doi:10.1126/science.aaw0445.

28. Y. Cui, Y. Yang, Z. Ni, Y. Dong, G. Cai, A. Foncelle, S. Ma, K. Sang, S. Tang, Y. Li, Y. Shen, H. Berry, S. Wu, H. Hu, Astroglial Kir4.1 in the lateral habenula drives neuronal bursts in depression. Nature. 554, 323-327 (2018).

29. K. Li, T. Zhou, L. Liao, Z. Yang, C. Wong, F. Henn, R. Malinow, J. R. Yates, H. Hu, BCaMKII in lateral habenula mediates core 
symptoms of depression. Science (80-. ). 341, 1016-1020 (2013).

30. Y. Yang, Y. Cui, K. Sang, Y. Dong, Z. Ni, S. Ma, H. Hu, Ketamine blocks bursting in the lateral habenula to rapidly relieve depression. Nature. 554, 317-322 (2018).

31. S. A. Golden, M. Heshmati, M. Flanigan, D. J. Christoffel, K. Guise, M. L. Pfau, H. Aleyasin, C. Menard, H. Zhang, G. E. Hodes, D. Bregman, L. Khibnik, J. Tai, N. Rebusi, B. Krawitz, D. Chaudhury, J. J. Walsh, M. H. Han, M. L. Shapiro, S. J. Russo, Basal forebrain projections to the lateral habenula modulate aggression reward. Nature. 534, 688-692 (2016).

32. L. A. Martin, H. W. Neighbors, D. M. Griffith, The experience of symptoms of depression in men vs women: Analysis of the national comorbidity survey replication. JAMA Psychiatry. 70, 1100-1106 (2013).

33. N. Verdolini, G. Perugi, L. Samalin, A. Murru, J. Angst, J. M. Azorin, C. L. Bowden, S. Mosolov, A. H. Young, M. Barbuti, G. Guiso, D. Popovic, E. Vieta, I. Pacchiarotti, Aggressiveness in depression: a neglected symptom possibly associated with bipolarity and mixed features. Acta Psychiatr. Scand. 136, 362-372 (2017).

34. C. R. Yang, Y. Y. Bai, C. S. Ruan, H. F. Zhou, D. Liu, X. F. Wang, L. J. Shen, H. Y. Zheng, X. F. Zhou, Enhanced Aggressive Behaviour in a Mouse Model of Depression. Neurotox. Res. 27, 129-142 (2014).

35. B. Li, J. Piriz, M. Mirrione, C. Chung, C. D. Proulx, D. Schulz, F. Henn, R. Malinow, Synaptic potentiation onto habenula neurons in the learned helplessness model of depression. Nature. 470, 535-9 (2011).

36. S. J. Russo, E. J. Nestler, The brain reward circuitry in mood disorders. Nat. Rev. Neurosci. 14, 609-25 (2013).

37. G. Buzsáki, E. I. Moser, Memory, navigation and theta rhythm in the hippocampal-entorhinal system. Nat. Neurosci. 16, 130138 (2013).

38. B. Hangya, Z. Borhegyi, N. Szilagyi, T. F. Freund, V. Varga, GABAergic Neurons of the Medial Septum Lead the Hippocampal Network during Theta Activity. J. Neurosci. 29, 8094-8102 (2009).

39. Z. Borhegyi, V. Varga, N. Szilágyi, D. Fabo, T. F. Freund, Phase segregation of medial septal GABAergic neurons during hippocampal theta activity. J. Neurosci. 24, 8470-9 (2004).

40. D. J. Barker, J. Miranda-Barrientos, S. Zhang, D. H. Root, H. L. Wang, B. Liu, E. S. Calipari, M. Morales, Lateral Preoptic Control of the Lateral Habenula through Convergent Glutamate and GABA Transmission. Cell Rep. 21, 1757-1769 (2017).

41. M. Stephenson-Jones, K. Yu, S. Ahrens, J. M. Tucciarone, A. N. Van Huijstee, L. A. Mejia, M. A. Penzo, L. H. Tai, L. Wilbrecht, B. $\mathrm{Li}, \mathrm{A}$ basal ganglia circuit for evaluating action outcomes. Nature. 539, 289-293 (2016).

42. J. W. de Jong, S. A. Afjei, I. Pollak Dorocic, J. R. Peck, C. Liu, C. K. Kim, L. Tian, K. Deisseroth, S. Lammel, A Neural Circuit Mechanism for Encoding Aversive Stimuli in the Mesolimbic Dopamine System. Neuron. 101, 133-151.e7 (2019).

43. K. Brinschwitz, A. Dittgen, V. I. Madai, R. Lommel, S. Geisler, R. W. Veh, Glutamatergic axons from the lateral habenula mainly terminate on GABAergic neurons of the ventral midbrain. Neuroscience. 168, 463-476 (2010).

44. T. C. Jhou, S. Geisler, M. Marinelli, B. A. Degarmo, D. S. Zahm, The mesopontine rostromedial tegmental nucleus: A structure targeted by the lateral habenula that projects to the ventral tegmental area of Tsai and substantia nigra compacta. J. Comp. Neurol. 513, 566-596 (2009).

45. S. Hong, T. C. Jhou, M. Smith, K. S. Saleem, O. Hikosaka, Negative Reward Signals from the Lateral Habenula to Dopamine Neurons Are Mediated by Rostromedial Tegmental Nucleus in Primates. J. Neurosci. 31, 11457-11471 (2011).

46. A. M. Stamatakis, G. D. Stuber, Activation of lateral habenula inputs to the ventral midbrain promotes behavioral avoidance. Nat. Neurosci. 15, 1105-1107 (2012).

47. J. Tian, N. Uchida, Habenula Lesions Reveal that Multiple Mechanisms Underlie Dopamine Prediction Errors. Neuron. 87, 1304-1316 (2015).

48. M. Matsumoto, O. Hikosaka, Lateral habenula as a source of negative reward signals in dopamine neurons. Nature. 447, 1111-1115 (2007).

49. H. Li, D. Pullmann, T. C. Jhou, Valence-encoding in the lateral habenula arises from the entopeduncular region. Elife. 8, 1-17 (2019).

50. F. J. Meye, K. Valentinova, S. Lecca, L. Marion-Poll, M. J. Maroteaux, S. Musardo, I. Moutkine, F. Gardoni, R. L. Huganir, F. Georges, M. Mameli, Cocaine-evoked negative symptoms require AMPA receptor trafficking in the lateral habenula. Nat. Neurosci. 18, 376-380 (2015).

51. C. D. Proulx, O. Hikosaka, R. Malinow, Reward processing by the lateral habenula in normal and depressive behaviors. Nat Neurosci. 17, 1146-52 (2014).

52. M. Trusel, A. Nuno-Perez, S. Lecca, H. Harada, A. L. Lalive, M. Congiu, K. Takemoto, T. Takahashi, F. Ferraguti, M. Mameli, Punishment-Predictive Cues Guide Avoidance through Potentiation of Hypothalamus-to-Habenula Synapses. Neuron. 102, 120-127.e4 (2019).

53. D. Wang, Y. Li, Q. Feng, Q. Guo, J. Zhou, M. Luo, Learning shapes the aversion and reward responses of lateral habenula neurons. Elife. 6, 1-20 (2017).

54. D. V Wang, H.-J. Yau, C. J. Broker, J.-H. Tsou, A. Bonci, S. Ikemoto, I. S. Wang DV, Yau HJ, Broker CJ, Tsou JH, Bonci A, Mesopontine median raphe regulates hippocampal ripple oscillation and memory consolidation. Nat. Neurosci. 18, 728-35 (2015).

55. D. H. Root, C. A. Mejias-Aponte, J. Qi, M. Morales, Role of glutamatergic projections from ventral tegmental area to lateral habenula in aversive conditioning. J. Neurosci. 34, 13906-10 (2014).

56. D. S. Zahm, D. H. Root, Review of the cytology and connections of the lateral habenula, an avatar of adaptive behaving. Pharmacol. Biochem. Behav. 162, 3-21 (2017).

57. U. Kim, Topographic commissural and descending projections of the habenula in the rat. J. Comp. Neurol. 513, 173-187 (2009).

58. J. Tooley, L. Marconi, J. B. Alipio, B. Matikainen-Ankney, P. Georgiou, A. V. Kravitz, M. C. Creed, Glutamatergic Ventral Pallidal Neurons Modulate Activity of the Habenula-Tegmental Circuitry and Constrain Reward Seeking. Biol. Psychiatry (2018), doi:10.1016/j.biopsych.2018.01.003. 
59. A. M. Stamatakis, M. Van Swieten, M. L. Basiri, G. A. Blair, P. Kantak, G. D. Stuber, Lateral Hypothalamic Area Glutamatergic Neurons and Their Projections to the Lateral Habenula Regulate Feeding and Reward. J. Neurosci. (2016), doi:10.1523/jneurosci.1202-15.2016.

60. J. Kaufling, Alterations and adaptation of ventral tegmental area dopaminergic neurons in animal models of depression. Cell Tissue Res. (2019), , doi:10.1007/s00441-019-03007-9.

61. S. F. Maier, M. E. P. Seligman, Learned helplessness at fifty: Insights from neuroscience. Psychol. Rev. 123, 349-67 (2016).

62. I. Lazaridis, O. Tzortzi, M. Weglage, A. Märtin, Y. Xuan, M. Parent, Y. Johansson, J. Fuzik, D. Fürth, L. E. Fenno, C. Ramakrishnan, G. Silberberg, K. Deisseroth, M. Carlén, K. Meletis, A hypothalamus-habenula circuit controls aversion. Mol. Psychiatry (2019), doi:10.1038/s41380-019-0369-5.

63. D. Knowland, V. Lilascharoen, C. P. Pacia, S. Shin, E. H.-J. Wang, B. K. Lim, Distinct Ventral Pallidal Neural Populations Mediate Separate Symptoms of Depression. Cell (2017), doi:10.1016/j.cell.2017.06.015.

64. A. Friedman, E. Lax, Y. Dikshtein, L. Abraham, Y. Flaumenhaft, E. Sudai, M. Ben-Tzion, G. Yadid, Electrical stimulation of the lateral habenula produces an inhibitory effect on sucrose self-administration. Neuropharmacology (2011), doi:10.1016/j.neuropharm.2010.10.006.

65. G. Gangadharan, J. Shin, S.-W. Kim, A. Kim, A. Paydar, D. D.-S. Kim, T. Miyazaki, M. Watanabe, Y. Yanagawa, J. Kim, Y.-S. Kim, D. D.-S. Kim, H.-S. Shin, Medial septal GABAergic projection neurons promote object exploration behavior and type 2 theta rhythm. Proc. Natl. Acad. Sci. 113, 6550-6555 (2016).

66. S. Aznar, Z. X. Qian, G. M. Knudsen, Non-serotonergic dorsal and median raphe projection onto parvalbumin- and calbindincontaining neurons in hippocampus and septum. Neuroscience (2004), doi:10.1016/j.neuroscience.2003.12.020.

67. A. Szőnyi, M. I. Mayer, C. Cserép, V. T. Takács, M. Watanabe, T. F. Freund, G. Nyiri, The ascending median raphe projections are mainly glutamatergic in the mouse forebrain. Brain Struct. Funct. 221, 735-751 (2016).

68. E. J. Kim, M. W. Jacobs, T. Ito-Cole, E. M. Callaway, Improved Monosynaptic Neural Circuit Tracing Using Engineered Rabies Virus Glycoproteins. Cell Rep. 15, 692-699 (2016).

69. E. Dobó, V. T. Takács, A. I. Gulyás, G. Nyiri, A. Mihály, T. F. Freund, New silver-gold intensification method of diaminobenzidine for double-labeling immunoelectron microscopy. J. Histochem. Cytochem. 59, 258-269 (2011).

70. J. B. West, Z. Fu, T. J. Deerinck, M. R. Mackey, J. T. Obayashi, M. H. Ellisman, Structure-function studies of blood and air capillaries in chicken lung using 3D electron microscopy. Respir. Physiol. Neurobiol. (2010), doi:10.1016/j.resp.2009.12.010.

71. D. C. Sterio, The unbiased estimation of number and sizes of arbitrary particles using the disector. J. Microsc. 134, 127-36 (1984).

72. H. J. G. Gundersen, in Science on Form: Proceeding of the first International Symposium for Science on Form (1986), pp. 509516.

73. C. Schmitz, P. R. Hof, Design-based stereology in neuroscience. Neuroscience (2005), , doi:10.1016/j.neuroscience.2004.08.050.

74. K. A. Dorph-Petersen, J. R. Nyengaard, H. J. G. Gundersen, Tissue shrinkage and unbiased stereological estimation of particle number and size. J. Microsc. (2001), doi:10.1046/j.1365-2818.2001.00958.x.

75. H. J. G. G. West M.J., Slomianka L., Unbiased Stereological Estimation of the Total Number of Neurons in the Subdivisions of the Rat Hippocampus Using the Optical Fractionator. Anat. Rec., 482-497 (1991).

76. P. Yger, G. L. B. Spampinato, E. Esposito, Fast and accurate spike sorting in vitro and in vivo for up to thousands of electrodes. bioRxiv, 1-21 (2016).

77. C. Rossant, S. N. Kadir, D. F. M. Goodman, J. Schulman, M. L. D. Hunter, A. B. Saleem, A. Grosmark, M. Belluscio, G. H. Denfield, A. S. Ecker, A. S. Tolias, S. Solomon, G. Buzsáki, M. Carandini, K. D. Harris, Spike sorting for large, dense electrode arrays. Nat. Neurosci. 19, 634-641 (2016).

78. N. Schmitzer-Torbert, J. Jackson, D. Henze, K. Harris, A. D. Redish, Quantitative measures of cluster quality for use in extracellular recordings. Neuroscience. 131, 1-11 (2005).

79. M. Aliczki, Z. K. Varga, Z. Balogh, J. Haller, Involvement of 2-arachidonoylglycerol signaling in social challenge responding of male CD1 mice. Psychopharmacology (Berl). 232, 2157-2167 (2015). 